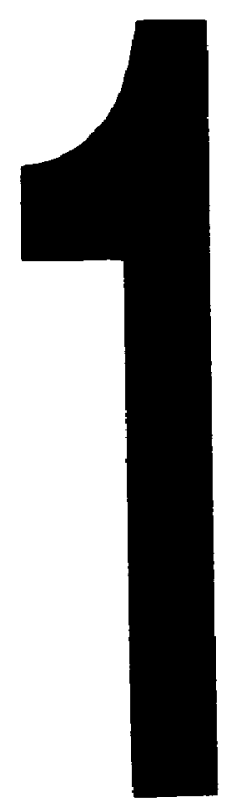

PM.1 31 $1 \frac{2}{2}$ "X4" PHOTOGAAPHIC MICROCOPY TARGET NES 1010a ANSI/ISO \#2 EQUIVALENT

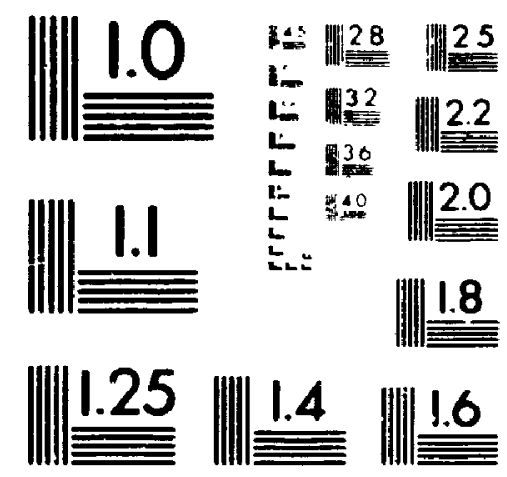

PRECISIONSM RESOLUTION TARGETS 


\title{
An Analysis of the ro-4 gene and its product in Neurospora crassa.
}

\section{by}

Margaret Ann Wilson, B.Sc(Hons), B.Ed.

\author{
A thesis submitted to \\ the Faculty of Graduate studies and Research \\ in partial fulfillment of \\ the requirements for the degree of \\ Master of Science \\ ottawa-Carleton Institute of Biology \\ Carleton University \\ ottawa, ontario.
}

\author{
April, 1996 \\ copyright \\ 1996, Margaret A. Wilson
}


National Library

of Canada

Acquisitions and

Bibliographic Services Branch

395 Weltungton Street

Ottawa. Ontario

K1A ON4
Biblıotheque nationale

du Cariada

Direction des acquisitions et des services bibliographiques

395. rue Wethington

Ottawa (Ontaro)

Vour fite vorre reterence

Our the Norre ieterence

The author has granted an irrevocable non-exclusive licence allowing the National Library of Canada to reproduce, loan, distribute or sell copies of his/her thesis by any means and in any form or format, making this thesis available to interested persons.
L'auteur a accordé une licence irrévocable et non exclusive permettant à la Bibliothèque nationale du Canada de reproduire, prêter, distribuer ou vendre des copies de sa thèse de quelque manière et sous quelque forme que ce soit pour mettre des exemplaires de cette thèse à la disposition des personnes intéressées.

L'auteur conserve la propriété: du droit d'auteur qui protège sa thèse. Ni la thèse ni des extraits substantiels de celle-ci ne doivent être imprimés ou autrement reproduits sans son autorisation.

ISBN $0-612-1387 \div-7$ 
Nome

Margaret Ann WILSON

Diventation Abatocts invmotiond is arronged by brood, generd subject categories. Please select the one subject which most neorly describes the cordent of your dissertotion. Enter the corresponding lour-digit code in the spoces provided.

$$
\text { MoLecce.7K BLCLCEK }
$$

\section{Subipat Congovies}

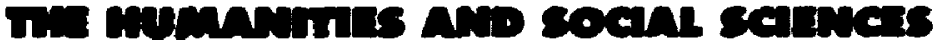

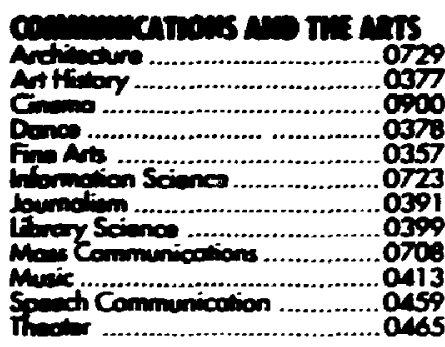

\section{:ancentin}

Gerwed

0515

Adrinitation

Adt and Continuing ...................0516

Agriaturad ...............................0517

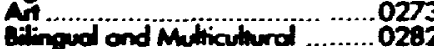

Orsiness .............................0688

Community Colvar ...................0275

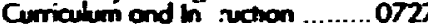

Eorty Chithood ............................0518

Enombry ..............................052

Finopce ...........................

Gere obe

Hicher ...................... 0745

Hition of ................................. 0520

Home Fonomin

Industrial .....................................

Moinemotics …..... - ...........0280

Music .......................... 0522

Pribsophy of ................... 099 longuoge and iberature .............0279

Prysicol .... .........................0523

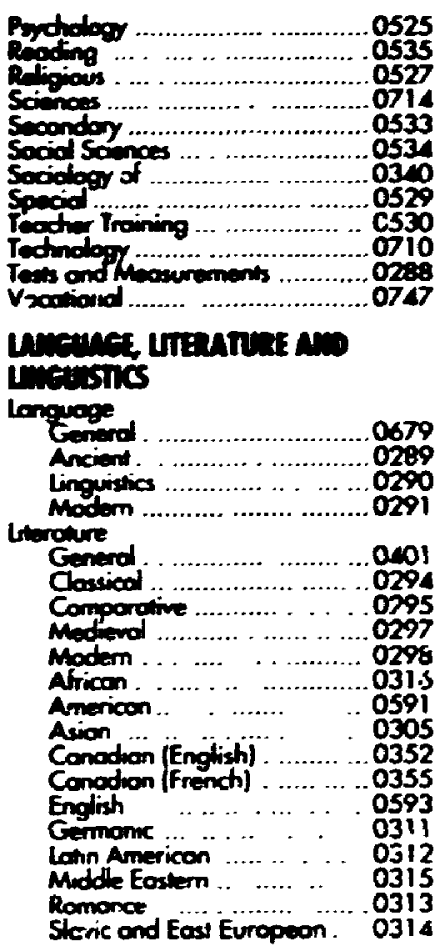

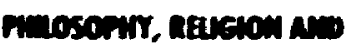

Ixever

Philowoply

Dipion

ontion sindies.

0321

Cogr ... ... 0319

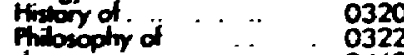

Theology

sean soangs

Ammicon Studies

Aminropology

Anchoology . ... .... 0324

Pedurd ........... $\quad$. 0326

Business Administrotion

Genend ...

Accounting

Bonting

Morketing

Conodion Studies

Economics

Generol ind

Commerce-Busuness

Fincince

History

lobor

folltore

Geogrophy

Gerondology

Gerory

General
0422

0322

0323

0310

0272

0770

0338

0385

0501

0503

0505

0508
0509

0509
0510

051

0358

0366

0351

0578

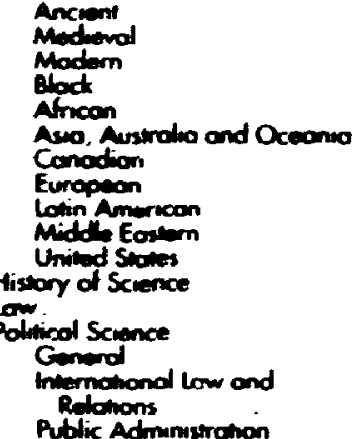

Recreotion

Sociol Wort

Gegred

Crumnology and Pendogy

Demogrophy

Exhnic and Raciol Sudies

Indinduet and fancly Srudies

Industerus and Labor

Retotions

Public and Sacral Wellore

Sociol Structure and

Denelopmerm

Theory and Methods Ironsportiction

Ution and Rogmonal Planning

women's Shudies
0579

05.

0328

0331

0332

0335

0336

0337

0398

0615

216

Q8i4

as52

0626

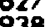

Q631

0828

0629

0700

034

0709

0453

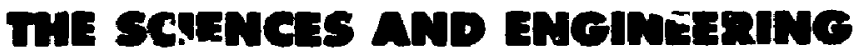

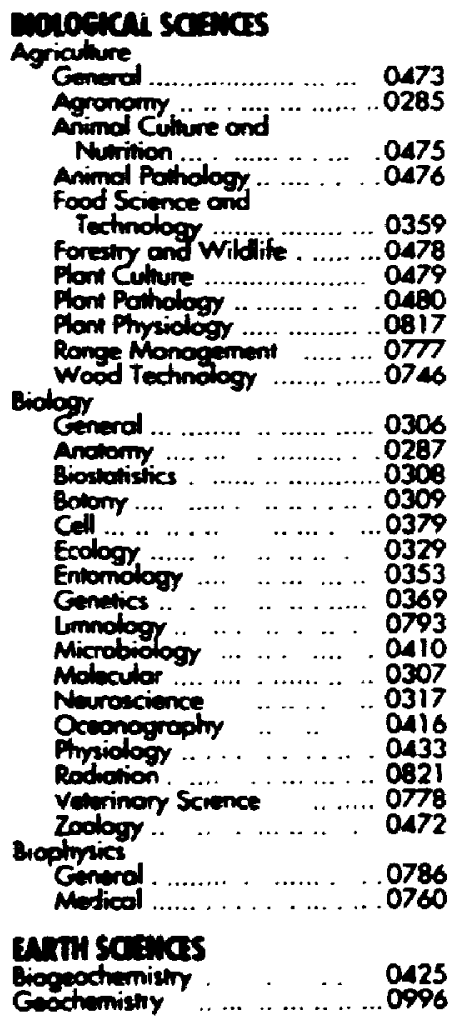

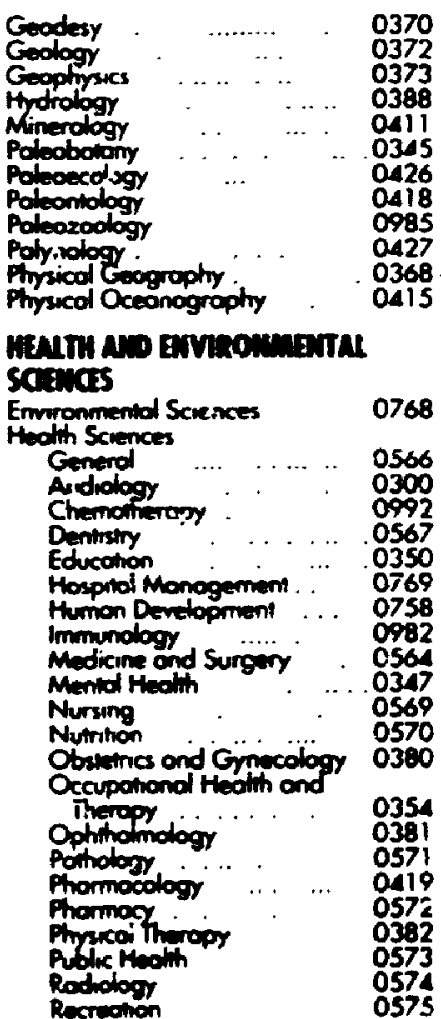

0460

0386

Home Economics

\section{misken satancs}

Pure Sciences

Chenwsiny

General

Agricutirual

broctiemisiny

inorgonic

Nucteo.

Orgonic

Phormoceutical

Physicol

Rodration

Momemotics

Prosics

Generol

Acoustics

Astronomy and

Astrophrass

Amospheric Scuence

Alomice

Fluctronucs and Eloctricin Elementory Portcles and

Hoph Enirgy

Fhid and Foumo

Molicutar

Nucleor

Ophes

Solvet Sion

Simpiencs

Apolind Sciencen

Applind Machonics

Compuner Serence

0345
Enguneering

Aerospoce

Agrueutural

Automotive

Biomedical

Chemical

Crmol

Electronics and Electricol

Heot and Thermodynomics

Hydroulic

Industrio

Morine

Makeridats Senence

Mochonical

Metollurgy

Mining

Poctoging

Peckoging

Sonitary and Municipol

Sryten. Scrence

Gootechnology

Operotions Resporch

Plashics Technotogy

Textile Technology

Sraweror

General

Clinical

Devolopmentel

Expermemal

Indusiniol

Persondity

Phyriological

Psychobrology

Pyychomemics: 
The undersigned hereby recommend to the Faculty of Graduate studies and Research acceptance of the tresis

"An Analysis of the ro-4 gene and its product in Neurospora crassa."

submitted by Margaret Ann wilson, B.Sc., B.Ed. in partial fulfillment of the requirements for the degree of Master of Science.
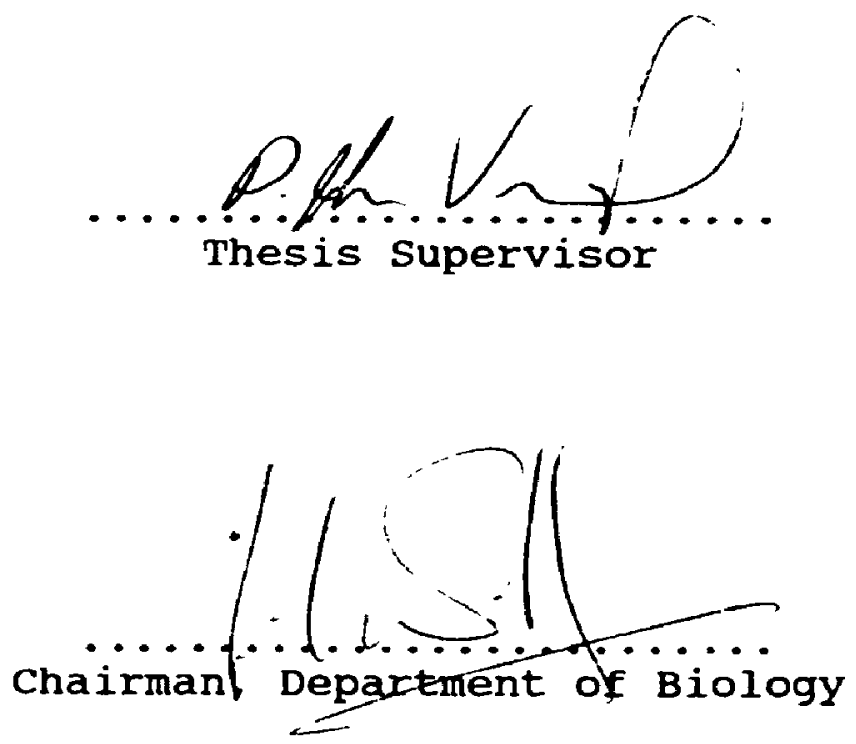

Carleton University

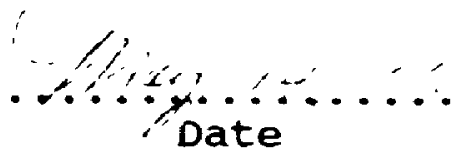




\section{Carleton University Ottawa, Canada K1S 5J7}

Thesis contains black and white and/or coloured graphs/tables/photographs which when microfilmed may lose their significance. The hardcopy of the thesis is available upon request from Carleton University Library. 


\section{Abstract}

The ropy mutations of Neurospora crassa are morphological mutations generally associated with a highly branched growth habit and aberrant nuclear distribution. The locus ro-4 has previously been found to encode an actin-related protein. The ro-4 gene of a mutant strain has been sequenced and found to contain a premature termination signal resulting from a frameshift mutation caused by a single base-pair deletion.

Antibodies to a synthetic peptide from the RO4 protein raised in rabbits and used to probe proteins from the wildtype as well as the ro-4 mutant strains, uniquely recognized a protein with an electrophoretic mobility slightly greater than the major actin, which was present in all strains tested. one strain designated as a ro-4 mutant shows typically ropy colony morphology when young but is similar to wild-type in growth rate and nuclear distribution and lacks the major actin epitope recognized by a generally reactive monoclonal antibocy. 
This thesis is dedicated

to my mother and father. 


\section{Acknow ledgenents}

To my supervisor Dr. P.J. Vierula I owe a huge debt of gratitude for his help and inspiration when it was needed most. I would also like to thank my advisors Dr. N. Chaly and Dr. G. Drouin for their insight and pertinent suggestions.

My stay at Carleton was made more enjoyable by my coworkers in ELBA, in particular Lot McColl who shared my trials and triumphs from the other side of the bench. I'm also grateful for the opvortunity to finally thank Joan Mallett for countless crises averted.

I couldn't have completed this were it not for the support of my husband Murray, and his parents. Thank you. 


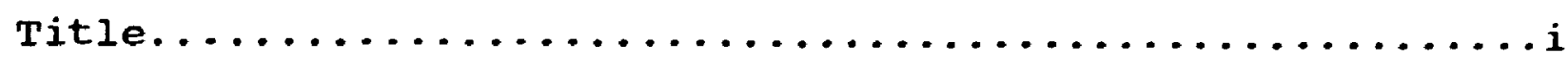

Acceptance page..........................

Abstract...............................

Dedication...............................

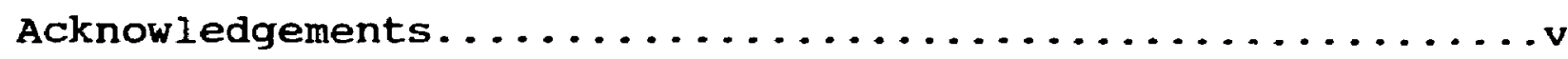

Table of Contents ........................

List of Tables.........................

List of Figures $\ldots \ldots \ldots \ldots \ldots \ldots \ldots \ldots \ldots \ldots \ldots \ldots \ldots \ldots \ldots \ldots$

List of Appendices.........................

List of Abbreviations.......................

I. Introduction

The mold Neurospora crassa...................

Nuclear movement in filamentous fungi $\ldots \ldots \ldots \ldots \ldots . . \ldots$

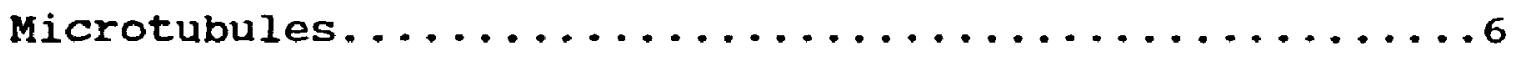

Motor proteins associated with microtubules........8

The dynactin complex....................

Insights into nuclear movement from yeast studies....11 Actin-related proteins..................

Regulation of nuclear movement..............

objectives.......................... 
II. Materials and Methods

Culturing of Neurospora crassa strains in liquid

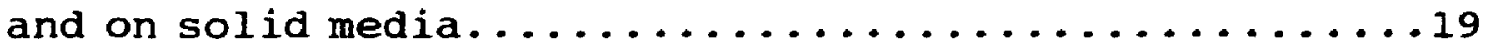

culturing of bacterial strains................21

Methods for DNA Analysis

Rapid preparation of DNA from filamentous fungi.....21

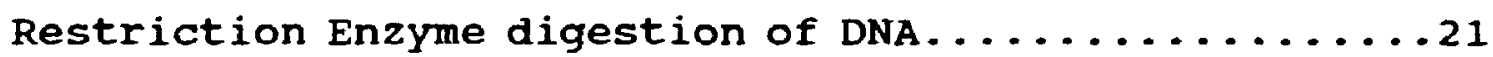
Amplification of DNA by Polymerase Chain Reaction. ...22 Separation of DNA by an agarose gel system.........22 Recovery of DNA from agarose gel fragment..........24 Recovery of DNA from agarose gel by the freeze-squeezemethod........................ 24 Phenol/chloroform extraction of DNA. ............ 25 Ethanol precipitation of DNA...............26 Preparation of vector DNA for ligation...........26 Ligation of DNA fragment into plasmid vector.......27 Transformation of $E . c o l i$ cells with foreign DNA and detection of transformed colonies............27 Rapid preparation of DNA from plasmids...........28

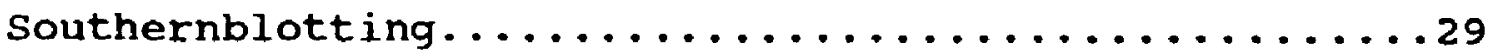
Transfer of bacterial DNA from replica plates

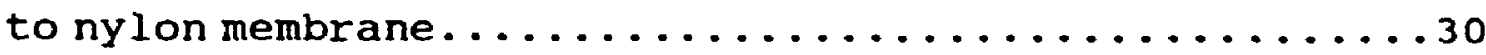
Preparation of digoxigenin-labelled probe for

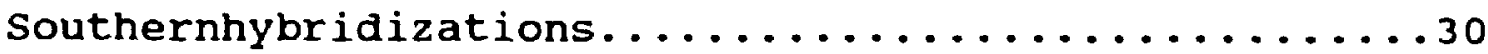
Probing of membrane-bound DNA with specific nucleic acid probes........................ 
Preparation of sequencing reactions............. 32 sequencing using the circumvent ${ }^{T M}$ cycle sequencing method....................... Preparing and running the sequencing gel...........34 Methods for RNA Analysis Extraction of total RNA from fungal cultures........35 Enrichment of total RNA for poly-A mRNA........... Separation of poly-A enriched mRNA................ 37

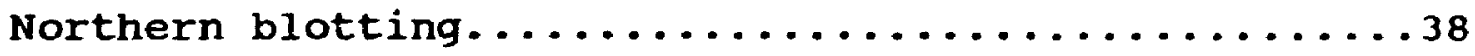
Preparation of radioactive RNA probe............... 38 Hybridization................................ Methods for Protein Analysis Preparation of fungal protein extracts for oneand two-dimensional polyacrylamide gel electrophoresis...........................40 One-dimensional polyacrylamide gel electrophoresis...40 Two-dimensional polyacrylamide gel electrophoresis....41 Fractionation of total proteins...............42 Western blotting.........................44 Western anilysis..........................44 Preparation of polyclonal antibodies from rabbits....45 Affinity-purification of polyclonal antibodies.....46 Methods for Phenotypic Analysis

Nuclear and germling staining................48 


\section{Results}

The ro-4 wild-type sequence

a) Sequencing of ro-4 cDNA for determination of

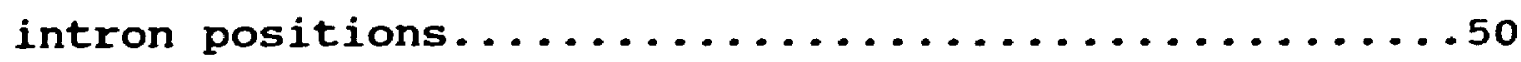

b) Comparison of ro-4 amino acid sequence with other Arps.......................... 53

Sequencing of the ro-4 mutant allele...............56 Restriction $f$ :agment length polymorphism analysis

of ro-4 mutant strains..................... 56 The expression of ro-4

a) ro-4 mRNA levels in the wild-type and three mutant strains..............................63

b) Predicted expression level of wild-type ro-4.....65 Protein Analysis of the wild-type and ro-4 mutant strains a) Western analysis of total proteins from wild-type and ro-4 mutant strains with a monoclonal anti-actin antibody................................66

b) Western analysis of wild-type and ro-4 mutant strains with a $R O 4$ antibody...................68 c) SDS PAGE and Western analysis of degraded wild-type proteins.................................69

d) SDS PAGE and Western analysis of fractionated proteins from the wild-type and ro-4 mutant strains...74 Phenotypic Characteristics of the wild-type and ropy strains

a) Nuclear staining of wild-type and ropy 
germlings.........................

b) Distribution of nuclear number in conidia.......77

c) Growth of the wild-type and ropy mutants at normal and high temperature...................

d) Colony morphology of wild-type and ropy mutant strains..............................

IV. Dicussion

Sequence features of the wild-type ro-4 gene in Neurospora

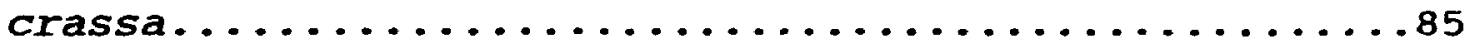

Sequence of the ro-4 mutant allele in strain $2980 \ldots \ldots \ldots 86$ Expression of ro-4 in the wild-type and ro-4 mutant

strains.............................

Protein analysis of the wild-type and ro-4 mutant strains

a. Western analyses using major actin antibody.........89

b. Western analyses using a RO4-specific antibody.......91

c. Analyses of fractionated proteins..............94

Phenotypic analysis of wild-type and ropy strains.......95

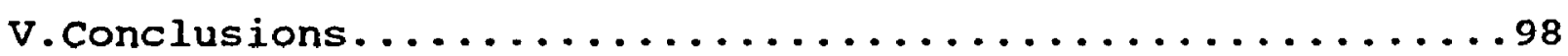

Appendices.................................. 100

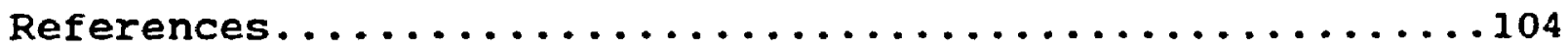




\section{List of Tables}

1.Strains of $N$. crassa used in this research...........20

2. Primers used in sequencing and amplifying ro-4........23

3. Restriction fragments recognized by the E2 probe......61 4. Restriction fragments recognized by the $4.3 \mathrm{~kb}$ probe.....62 


\section{List of Figures}

1. Colony morphology of $N$. crassa strains.............4 2. Comparison of amino acid sequences between Arpls......51 3. Map of the ro-4 gene.........................52

4 . Sequence features of the ro-4 gene.................54

5. The ro-4 mutant has a single base-pair deletion.......57

6. Putative amino acid sequerice of the ro-4 mutant.......58 7. Restriction fragment length polymorphism analysis......60 8. Northern analysis of ro-4 expression...............64 9. One and two-dimensional Western analysis of major actin..67 10a. Western analysis using $R O 4$ antibodies, trial 1......70 10b. Western analysis using $R 04$ antibodies, trial $2 \ldots \ldots \ldots 7$ 11.Silver-stained gel of degraded protıins.............72 12. Western analysis of degraded proteins.............73 13. Comparison of silver-stained proteins of cytosols.....75 14. Western analysis of fractionated proteins..........76 15. Nuclear distribution in $N$. crassa germlings.........78 16. Growth of $N$. crassa strains at normal temperature a.wild-type and ropy mutants.................80 b. wild-type and ro-4 mutants.................81 17. Growth of $N$. crassa strains at high temperature a. wild-type and ropy mutants................. 82 b. wild-type and ro-4 mutants.................83 


\section{List of Appendices}

Appendix I. Map of linkage group V.................100

Appendix II: Calculation of C.A.I. for ro-4..........101

Appendix III: Reference set for C.A.I. calculation.......102

Appendix IV: Distribution of nuclear number in conidia...103 


\section{Iist of Abbreviations}

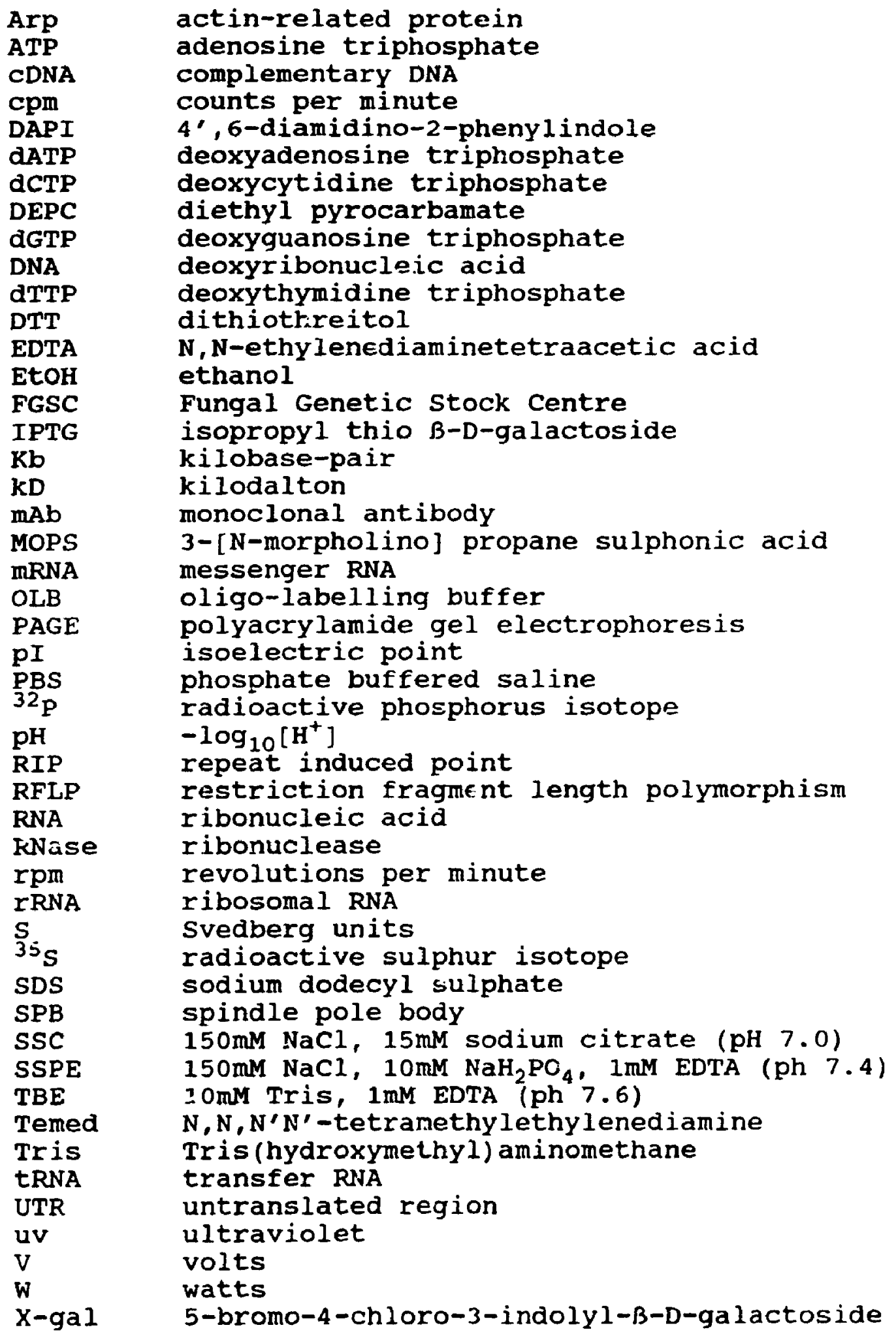




\section{Introduction}

The mold Neurospora crassa

N.crassa is a classic model system in the study of eukaryotic genetics. It was with this organism that Beadle and Tatum elaborated their one gene - one enzyme theory of inheritance in 1942. Neurospora is a filamentous ascomycete (order Sphaeriales, family sordariaceae) which occurs naturally on burned soil or vegetation in warm countries, but otherwise is better-known as a troublesome contaminant in bakeries and on stored bread.

Certain characteristics of this fungus recommend it for genetic studies. Its nutritional requirements are confined to simple mineral salts, a carbon source and biotin, which means that auxotrophic mutants are easily identified. It is haploid, meaning that mutations are not masked, and mutants are readily obtained by irradiation of conidia. Normally growth is rapid, with asexual reproduction possible within 24 hours, and this facilitates the study of segregation of genetic defects. The production of ordered tetrads during the sexual cycle illustrates the order of the 4 chromatids during the first meiotic division of ascus development.

Germlings arise from micro- or macroconidia, or from ascospures. Growth is by addition of material at the hyphal tips and by branching (Springer, 1993). At intervals of about $50 \mu m$, chitinous septa are laid down, although these contain a 
central pore that allows movement of both cytoplasm and nuclei (Springer and Yanofsky, i989). As the hyphae extend their tips into fresh areas of substrate, the nuclei must divide and distribute themselves along the length of the growing hypha, in order to continue to supply the tip with needed materials. The development of the asexual macroconidia can be induced by dessication or depletion of carbon from the medium, and begins with the growth of aerial hyphae. conidiation begins when an aerial hypha ceases to grow by apical extension but instead undergoes repeated apical budding. In the early stages of conidiation the constrictions between these buds are slight; at this stage of "minor constriction" the hypha may still revert to strictly vegetative growth. The hypha is committed when it exhibits "major constriction", in which the width of the joints between buds narrows considerably. Roughly 10 hours after induction, septal formation in these joints follows, completing the process (Springer and Yanofsky, 1989). The movement of nuclei during conidiation is finely regulated. Nuclei apparently enter the conidiophcre while it is being formed, but enter the bud only after it has finished growing (Springer and Yanofsky, 1989) and commonly undergo mitotic divisions to produce a multinuleate spore.

Mitosis in Neurospora is not accompanied by the breakdown of the nuclear membrane. The nucleolus breaks down first, and this event is followed by the division of the spindle Pole Body (SPB) residing outside the nucleus, and migration of its 
daughters to opposite poles (Webster, 1986). On the inner side of the nuclear membrane opposite these spindle bodies, microtubules appear which span the nucleus in a parallel bundle. The chromosomes are attached to these microtubules by kinetochores. The nucleus elongates and its membrane narrows in the middle to form two daughter nuclei, in each of which a nucleolus then appears (Webster, 1986).

A group of N.crassa mutants known to be nuclear distribution mutants are known by the older designation of ropy, named for the appearance of their hyphae. At least 7 genes are thought to be involved in the ropy phenotype: ro-1, $-2,-3,-4,-6,-7$, and -10 . The ropy strains are some of a large array of morphological mutants generated in $N$.crassa, mostly as a result of uv irradiation. Their curled, twisted hyphae are associated with slow growth and a striking "starburst" appearance of growth on solid culture media (Figure 1).

Nuclear movement in filanentous fungi

Much of the knowledze in this area has come to us from studies of mutant strains in two organisms: $N$. crassa and Aspergillus nidulans. In Aspergillus, mutant strains which show an inability to distribute nuclei properly are called nud (nuclear distribution) mutants. Five nud genes have been identified so far, nud $A, C, F, G$, and $H ;$ all are temperature sensitive. The elucidation of the mechanism of nuclear 
Figure 1. Colony morphology of the wild-type and ropy mutants: The cultures were grown on VMM at RT. They are:

$$
\begin{array}{lcr}
r o-1(146) & r o-2(52) & r o-3(43: \\
r o-6(3627) & r o-7(4025) & r o-10(36: 8) \\
r o-4(1511) & r o-4(1529) & \text { ro-4 (2980) } \\
\text { wild-type } & \text { ro-4 (1529) } & \text { wild-type } \\
& \left(2^{3} / 4 \text { days old }\right) & \text { (2 days old) }
\end{array}
$$

All cultures are four days old except where noted. 


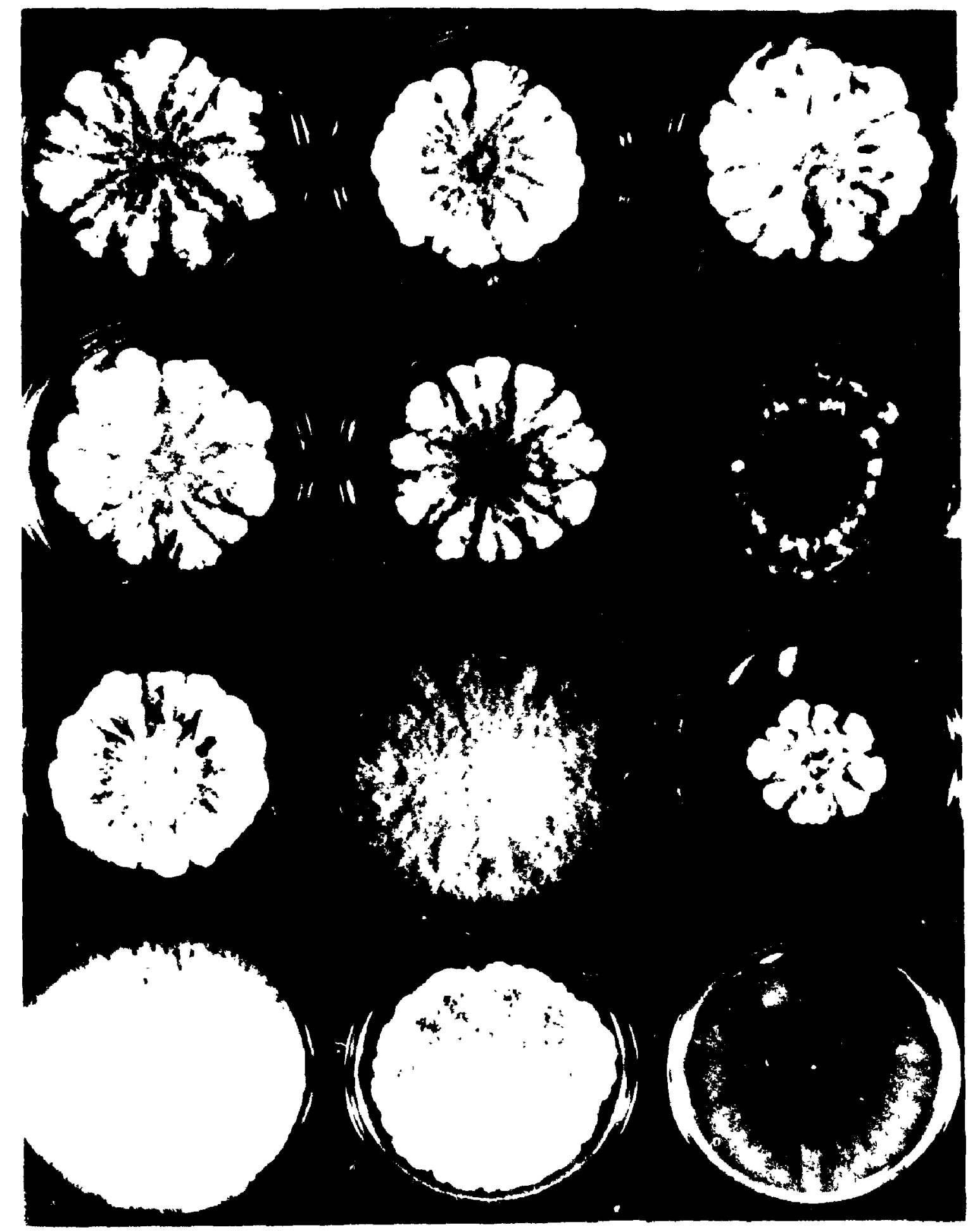


movement in fungi has been sought by looking for the products of these and of the N.crassa ropy genes. Both nudA (Xiang et al, 1994) and ro-1 (Plamann et al.,1994) have been found to code for the cytoplasmic dynein heavy chain of their respective organisms, implying that the microtubule system is the basis of nuclear migration.

The product of the nudC gene is a 22 or $23 \mathrm{kD}$ protein which exhibits similarity to an expressed sequence tag of Caenorhabditis elegans and is also conserved in rats and in Drosophila (Morris et al.,1995). In nudC mutants, microtubules form normally but nuclei are not distributed in the hyphae subsequent to mitosis (Osmani et al.,1990). Interestingly, the nudC mutation can be suppressed by the presence of nudF as an extra-copy on a flasmid (Morris et a1.,1995). At the same time, the levels of NUDF protein in the nudC mutant are decreased, even when an exogenous promoter controls the transcription of nudF. The two protein products do not co-sediment (xiang et al.,1995). The nudF gene, which codes for a $49 \mathrm{kD}$ protein, shows similarity to other genes involved in cell signalling, such as those for human LISI and the B-subunits of heterotrimeric $G$ proteins (Morris et a1.,1995). G protein a-subunits recently described in Neurospora crassa may regulate $\mathrm{Ca}^{2+}$ channels, by analogy with similar proteins in mammals. At least two colonial mutants in Neurospora are known to be deficient in $\mathrm{Ca}^{2+}$ in their growing tips, which seems to dictate their phenotype (Turner 
and Borkovich, 1993).

There are other $A$. nidulans genes (apsA and apsB) in which mutations affect nuclear migration during conidiation only and not during mycelial growth (Morris et al.,1995). In apsA mutants, nuclei usually fail to enter the primary sterigmata, thus preventing conidiation; however if one does reach this structure, the event is succeeded by normal conidiation, including migration of nuclei into the growing chain of spores (Fischer and Timberlake, 1995).

Further evidence for the involvement of the microtubule system came from studies of the "wall-less" mutant of N.crassa. In this as well as in hyphae and protoplasts, organelle movement was blocked by nocadazole but not affected by cytochalasin D up to $20 \mu \mathrm{M}$ (Steinberg and Schliwa, 1993). The rate of nuclear movement was measured as roughly $2 \mu \mathrm{m}$ per second.

\section{Microtubules}

Microtubules are hollow $24 \mathrm{~nm}$ polymers of tubulin, generaliy composed of 13 "protofilaments" of $\alpha / B$-tubulin dimers in a left-handed helix. The orientation of the heterod_mers in the molecule confers polarity, the "plus" end being more dynamic, where subunits are both added and removed faster than at the "minus" end.

A third form of tubulin, gamma-tubulin, is found exclusively in microtubule organizing centres (MTOCs). In 
fungi it is responsible for nucleating tubulin dimers on the spindle pole body by binding B-tubulin and possibly ensuring the polarity of the microtubule (Morris and Enos, 1992). However two different gamma-tubulin antibodies failed to label two sites of microtubule nucleation in Allomyces macrogynus (Roberson and Vargas, 1994).

There is some evidence that in fungal germlings, microtubules are nucleated at the apex of the hyphal tip rather than in the perinuclear region. In studies in which microtubules of Uromyces phaseoli germlings were destabilized and then allowed to re-polymerize, FITC-labelled anti-tubulin first appeared at the hyphal tip and extended rearward (Hoch and Staples, 1985). Similar studies done with Allomyces macrogynus suggest that microtubules are nucleated both from the spitzenkörper (an electron-dense apical body of growing hyphae) and from the centrosome (Roberson and Vargas, 1994). These studies indicated that the centrosome was responsible only for the nucleation of spindle microtubules, whereas cyioplasmic microtubules originated primarily from the spitzenkörper. However the centrosome may be the site of nucleation fo: a network of microtubules reported surrounding the nuclear envelope.

- re recently the role of microtubules in nuclear movement has been complicated by the discovery of a coldsensitive $\alpha$-tubulin mutation that results in fewer and more labile microtubules at both permissive and restrictive 
temperatures. In addition, at restrictive temperature, it apparently disrupts nuclear distribution, though in combination with mutations in nud genes $A, C, G$ and $F$ of $A$. nidulans it suppresses their phenotype. Low concentrations of the microtubult-inhibiting drug benomyl mimic this effect. (willins et al.,1995).

Oakley and Morris (1981) discovered a single heatsensitive mutation ('JenA33) in a B-tubulin which prevented both nuclear division and nuclear migration, though the microtubules are assembled normally. The authors hypothesize that it is the disassembly which is required for full function and which is prevented in this mutant.

Desai and Mitchison (1995) have proposed a mechanism for microtubule-based chromosome movement at Anaphase B whereby the kinetochore microtubule depolymerizes at the site of the kinetochore and motor proteins situated there couple this depolymerization to chromosome movement.

\section{Motor proteins associated with microtubules}

In addition to dynein one other motor protein associates with microtubules; kinesin. Kinesin generates force in the anterograde direction (from "+" end to "-" end) while dynein generates force in the opposite direction (Preston et al., 1990). Thus any organelle moved by kinesin will usually translocate from "-" to "+" end, while conversely dyneinassociated movement is normally "minus-end directed". 
Cytoplasmic dynein is known to be associated with kinetochores and the microtubules of the mitotic spindle. It consists of two large subunits ("heavy chains") of about $400 \mathrm{kD}$, three intermediate chains of about $74 \mathrm{kD}$ and four Iight chains of about 55kD. The two large subunits are positioned like antennae arising from the rest of the complex and are the "heads" which interact with the microtubules. Although much cytoplasmic dynein appears to be present in soluble form, able to be extracted by co-assembly with microtubules (Paschal et al.,1987), immunolocalization studies show also an association with membrane-bound structures (Collins, 1994). Dynein is actually capable of binding to pure phospholipid vesicles (Lacey and Haimo, 1992 in Ccllins, 1994).

The dynactin complex

Two polypeptides, $150 \mathrm{kD}$ and $45 \mathrm{kD}$, frequently copurify with cytoplasmic dynein (Paschal and Vallee, 1987). These are two components of the "dynactin complex" (for dynein activating, Gill et al, 1991), also known as the "Glued" complex as it was first named in Drosophila. The 150kD polypeptide ("dynactin") exists as a doublet comprising the "heads" of the complex, and in N.crassa is coded for by the ro-3 gene (Plamann et al, 1994). The remainder of the complex consists chiefly of a $10 \times 37 \mathrm{~nm}$ filament, a helix with a pitch very similar to that of the conventional f-actin (51.3 to 51 ). This filament is actually composed of the $45 \mathrm{kD}$ polypeptide 
(Schafer et al., 1994), which is an actin-related protein (Arp) whose sequence is similar to the ro-4 gene of $N$. crassa (Plamann et al,,1994). Both an $\alpha$ - and B-capping protein (37 and $32 \mathrm{kD}$ ) are found on the barbed end of the filament, and a 62kd component on its pointed end. Near the capping protein a thinner $24 \mathrm{~nm}$ long filament forms a sidearm to the main filament, ending in the two globular heads (Schafer et al., 1994). Recently p50 has been overexpressed with the result that mitosis was disrupted and spindles were distorted (Echeverri et al., 1996). The overexpression also reduced the association of dynactin and cytoplasmic dynein with kinetochores during prometaphase. The subunits p27 and p24 have not yet bee.l localized. All cosediment at 205 (LeesMiller et al.,1992).

Arp1 ( $\mathrm{pI}$ 6.8) and actin are present in the dynein activating complex in a ratio of about 10:1. In addition to these two $45 \mathrm{kD}$ proteins there is a third $45 \mathrm{kD}$ protein with pI 6.7. The rest of the components of the complex are present at about .7 of the amount of the combined actins, though on the whole they are present in the cell in much lower quantities (Paschal, 1993). While in vitro studies show purified dynein to be capable of moving along microtubules, the dynactin complex is required in order for dynein to power microtubule-based vesicle movements (Gill et al, 1991). 
Insights into nuclear movement from yeast studies

Saccharomyces cerevisiae has a single actin gene, ACT1, actin-related protein genes, ACT2, ACT3 (Harata et al.,1994), ACT3 (Clark and Meyer, 1994) and ACT5 (Muhua et al , 1994), two $\alpha$-tubulin genes (TUB1 and TUB3) and a B-tubulin gene (TUB2) (Barnes et al.,1990). The clark and Meyer ACT3 is classed as an Arp1 (Actin-related protein - see below) whereas the sequence of the Harata et al. ACT3 diverges greatly from known acti.ss.

The cytoplasmic dynein heavy chain in this yeast is encoded by the gene DYN1. Disruption of this gene results in misalignment of the spindle during budding with the subsequent production of binucleate mother cells and anucleate daughter cells (Eschel et al.,1993). The spindle elongates normally, and as anaphase $B$ progresses can be seen bent within the confines of the mother cell, unless it spontaneously becomes properly oriented. This phenotype is shared by a temperature sensitive tub2 mutant (tub2-401) in which spindle microtubules but not astral microtubules are assembled at the restrictive temperature (Sullivan and Huffaker, 1992). There was no evidence of exceptional chromosome loss in homozygous dyn1 diploids, implying either that cytoplasmic dynein is not involved in chromosomal migration to the poles, or that its role in this process is redundant (Eschel et a1.,1993). Conversely, reduced chromosome movement was evident in $s$. cerevisiae suffering from disrupted astral microtubules, 
whereas the spindle microtubules were not involved (Palmer et al.,1992). In the same study it was demonstrated that disruption of actin function also led to an increase in binucleate mother cells.

Similarly, migration of nuclei into mating projections of S. cerevisiae was defective in actin mutants, and tubulin mutants were both unable to move their nuclei into projections and to orient the SPB of the nucleus toward the projection tip (Read et al , 1992.).

Capping proteins have been studied in $s$. cerevisiae without as yet revealing an effect on nuclear migration (Amatruda et al.,1992, Amatruda and Cooper, 1992).

\section{Actin-related proteins}

Actin-related proteins are between 35 and $55 \%$ identical to conventional actin (Schroer et al.,1994), generally having conserved the nucleotide and divalent cation binding sites (Schafer et al, 1994). There are at least 5 classes of Arps, with similarity among the classes no greater than similarity to actin; probably each has a distinct function (schafer et al., 1994). The first class of Arps, "Arp1", of which RO4 is a member, is defined as being the most similar to conventional actin (47-56\% amino acid identity, schroer et al.,1994). This class also includes centractin, and both Act $3 \mathrm{p}$ and Act5p of Saccharomyces (Schroer et aI.,1994).

Centractin (obtained from an wDCK (canine) CDNA library) 
is expressed ubiquitousiy (across cells) at low levels. Indirect immunofluorescence indicated brightest staining in the perinuclear region of each cell against a faint cytoplasinic background stain, and occasionally two bright perinuclear spots, a pattern similar to that of centrosomes (Clark and Meyer, 1992).

Act 3 of Saccharomyces cerevisiae encodes a nonessential polypeptide which in mutant strains results in a misalignment of the spindle in budding cells, yet not in an increase of anucleate or multinucleate cells (Clark and Meyer, 1994). Conversely, the Act5 gene is responsible for both of these phenomena when mutated. When in addition the dynein heavy chain gene of these cells is mutant their phenotype is unchanged, pointing to a shared function (Muhua et al .,1994).

Whereas conventional actins have a pI of 5.4-5.9, that of actin-related proteins is higher, around 6.2 in the case of an Arp from a human carcinoma cDNA (Lees-Miller et al., 1992a). Most of the non-conserved amino acids (compared to actin) are in surface loops of the actin structure. Conservation occurs in the nucleotide- and cation-binding regions (clark and Meyer, 1992), and in sites involved in actin polymerization and in interaction with myosin alkaline light chain, but not the myosin head (Lees-Miller et al, 1992a).

In $N$. crassa, the characteristics of the ro-4 mutation can also be shown by "ripped" strains. Ripping (for repeatinduced point mutation) is a function of the organism 
Neurospora crassa which occurs between fertilization and nuclear fusion. At that point, any duplications of sequence (with the exception of rRNAs) will be subject to numerous, scattered point mutations, predominantly G-C to $A-T$ transitions (Selker et al.,1988) as well as to extensive cytosine methylation (selker et al.,1993). Thus by transforming the wild-type $N$.crassa strain with the ro-4 gene and then performing sexual crosses, four "ripped" strains were obtained (Robb, 1993) which share the ropy phenotype.

Two strains originally described as ro-5 and ro-8 and mapped to distal regions of the fifth linkage group (see Appendix 1) were subsequently identified as alleles of ro-4 (Perkins, 1969). The gene encoded by ro-4 has strong similarity to other actin-related proteins (Robb, 1993; Plamann et al.,1994)

\section{Regulation of nuclear movement}

In cultured fibroblasts binding of dynein to lysosomes has been shown to be inhibited by either serum starvation, low extracellular calcium, or okadaic acid, a phosphoprotein phosphatase inhibitor (Lin and Collins, 1993, Lin et al., 1994). This dissociation was associated with an increase in phosphorylation of the dynein heavy chain, leading Lin et al. (1994) to venture the theory that regulation of retrograde organelle movement may be dependent on alterations in membrane binding. However Dillman and Pfister (1994) found that the 
dynein heavy chain (of bovine brain tissue) was phosphorylated to a lesser extent in an anterograde (presumably inactive) pool than in the entire cellular pool, suggesting that phosphorylation is a feature of active dynein. In transport of pigment granules, protein dephosphorylation is required for microtubule-based minus-end directed motility (cited in Dillman and Pfister, 1994).

An aberrant distribution of nuclei is associated with a highly-branched growth habit in the ropy mutants of $N$. Crassa. Dicker and Turian (1990) were able to achieve excessive branching in the wild-type by application of the calcium channel blocker Verapamil, and refined these results further by restoring a wild-type morphology to hyper-branching $N$.crassa mutants ("frost" and "spray") by addition of calcium to the medium. The loss of a calcium ion gradient in hyphal tips by application of an ionophore is associated with loss of apical dominance of the tip, manifested by emergence of multiple branches from just behind the tip, whereas when external $\mathrm{Ca}^{2+}$ was decreased and surface-bound $\mathrm{Ca}^{2+}$ lost, the hyphae became stubby (Schmid and Harold, 1988).

Both of these studies call into question an earlier conclusion that $\mathrm{Ca}^{2+}$ induces branching in N.crassa (Reissig and Kinney, 1983) based upon the increase in branching with application of the same ionophore, but also upon the observation that prior calcium starvation of the medium reduced this effect. The authors also note that cAMP reduces 
the branching response as well.

Calcium is the predominant second messenger in cells. It is associated with $\mathrm{IP}_{3}$ and diacylgiycerol in a cascade distinct from the one involving cAMP. Both paths share a dependence on $G$ proteins for their initial transduction of the signal from the receptor. The mode of action of calcium may be from binding directly to a regulatory site of the protein involved in the response, or by activating a protein kinase which then phosphorylates (activates) the protein in question. A common intermediate (at least in plant and animal cells) is calmodulin, which when binding $\mathrm{Ca}^{2+}$ ions can alter the activity of many enzymes in the cell; principally the cakinases (for calcium/calmodulin-dependent). These kinases phosphorylate serine and threonine residues of proteins.

\section{objectives}

The wild-type ro-4 cDNA was sequenced in order to confirm that the positions of the introns were as postulated by Robb (1993). A comparison between the ro-4 sequence and other Arp sequences was pursued with the intent of finding shared functional domains, or conversely divergent regions which might be indicative of unique features.

The phenotype of the ro-4 mutant strains differs markedly from wild-type (Figure 1). The bulk of the research herein was pursued to examine the genetic basis of this phenotype. It was of interest then, to obtain the sequence of the mutant 
allele of strain (Fungal Genetics stock centre number) 2980 to be able to relate the altered sequence to its particular phenotype, which is the most extreme of the three mutant strains. These three ro-4 mutants (Table 1) are all products of uv-irradidation, so it was presumed that their mutations were probably point mutations produced as a result of faulty repair of thymine-dimers. Since the mutant strain 2980 had been shown to have reduced ro-4 mRNA levels (Robb et al , 1995) it was possible that its mutation occurred in the promoter region. The other mutants 1511 and 1529 were expected to also suffer point mutations and thus the restriction fragments produced by digestion of their DNA were not expected to vary from wild-type. This was tested by southern analysis.

The sequence data indicated that the product of the ro-4 gene would be mising in strain 2980. This was tested by Western analysis first using an antibody against the major actin, and secondly using purified polyclonal antisera raised against a synthetic peptide from the F.O4 protein.

Four "RIP" strains in which the ro-4 gene was effectively knccked out (Robb, 1993) were expected to have reduced InRNA levels (comparable to that of 2980 ) as a result of point mutations in the promoter (among other regions) or which resulted in premature stop codons. The latter are associated with early degradation of mRNA (Muhua et al.,1994). Conversely, the mutants 1511 and 1529 would be expected to have levels similar to those of wild-type. These theories 
were tested by a Northern analysis in which ro-4 antisense RNA was used as a probe. A theoretical estimate of expression was obtained based on codon usage.

The results of the Western analysis, together with the early mapping data of the mutant strain 1529 led us to question its designation as a ro-4 mutant. Phenotypic studies were carried out to allow comparisons of this strain to wildtype and to other ropy mutants. These included nuclear distribution in germlings and in ungerminated conidia, growth at normal and high temperatures, and culture morphology. 


\section{Methods}

Culturing of Neurospora crassa strains in liquid and on solid media

N.crassa strains (Table 1), were grown on VMM (Vogel's Minimal Medium) slants from silica stocks by shaking a few grains of silica onto the surface of the slant, shaking the tube to expose the maximum surface to the medium, and incubating at room temperature. These were subcultured each month onto fresh slants. To obtain mycelium for the purposes of extracting DNA or protein, conidia obtained from the slant cultures, or from $50 \mathrm{ml}$ solid VMM cultures were used to inoculate $50 \mathrm{mls}$ of liquid VMM. These liquid cultures were incubated with shaking $(250 \mathrm{rpm})$ for 1 to $2 \frac{1}{2}$ days, after which the mycelium was strained out, pressed to expel excess liquid, frozen and dessicated in a speed-Vac (Savant sc100).

For studies on growth rate and colony morphologies, $8 \mathrm{~cm}$ petri dishes containing about $20 \mathrm{ml}$ solid VMM were inoculated in the centre and incubated at room temperature $\left(\mathrm{ca} .25^{\circ} \mathrm{C}\right)$ for the duration of the study, or up to 4 days for photographs.

strains will hereafter be referred to by their FGSC stock number, except wild-type, which will be designated WT. In addition to those listed in Table 1, four strains generated by "ripping" (Robb, 1993) were used and designated R1, R2, R4 and R5. 
Table 1: Strains of Neurospora crassa used in this research

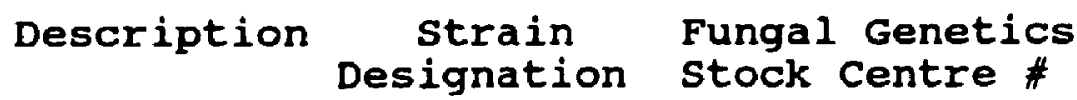

wild-type

ro-1

ro-2

ro-3

ro-4 $(=\mathrm{ro}-8)$

R2520

R2428

B3 8

R2431

R2470

AR7
987

146

52

43

1511

1529

2980

3627

4025

3618
Genetic

Background

st. Lawrence

*

st. Lawrence 3

Lindegren

Mauriceville

Mauriceville

st. Lawrence

St. Lawrence 3

st. Lawrence 5

Mauriceville

* Background not given in Fungal Genetics stock Centre Catalogue of strains, 1990

All of the mutants were generated by ultra-violet irradiation. 


\section{Culturing of bacterial straing}

Escherichia coli strains BB4 and DH5 $\alpha F^{\prime}$ were streaked on LB plates, or grown in liquid LB medium in shaker baths (250 rpm), all at $37^{\circ} \mathrm{C}$. Stocks of these cultures were transferred to $10 \%$ glycerol and stored at $-70^{\circ} \mathrm{C}$.

Methods for DNA Analysis

Rapid preparation of DNA from filamentous fungi:

About $50 \mathrm{mg}$ lyophilized mycelium was ground in a $1.5 \mathrm{ml}$ microfuge tube and suspended in extraction buffer ( $0.2 \mathrm{M}$ Tris, pH $8.5,0.25 \mathrm{M} \mathrm{NaCl}, 25 \mathrm{mM}$ EDTA, $0.5 \%$ SDS) with pronase added at $0.5 \mathrm{mg} / \mathrm{ml}$. After 15 minutes the mixture was extracted with phenol-chloroform and spun for 60 minutes at $13000 \mathrm{rpm}$ in an eppendorf Centrifuge 5415c. The aqueous phase was then transferred to a new tube and treated with RNase for 30 minutes at $37^{\circ} \mathrm{C}$. One volume of phenol-chloroform was used to extract the solution which was spun for 10 minutes at 13000 rpm. A 0.54 volume of isopropanol was added to the aqueous phase to precipitate the DNA, which was pelleted by a 5 second spin. The pellet was then washed with $70 \%$ ethanol, dxied and resuspended in $T_{1} E_{0.1}$ (Raeder and Broda, 1985).

Restriction enzyme digestion of DNA

Digestion of DNA with restriction enzymes was carried out according to the specifications provided by New England Biolabs using the appropriate NEB buffer provided and approximately 1 unit of enzyme for every $5 \mu \mathrm{g}$ of plasmid DNA, or $2.5 \mu \mathrm{g}$ of genomic DNA. 


\section{Amplification of DNA by Polymerase Chain Reaction}

In each reaction, $30 \mathrm{ng}$ of template DNA (in a volume of $3 \mu 1)$ and 25 pmoles of each specific primer were used. The balance of the reaction mix consisted of $0.6 \mu l$ of a $15 \mathrm{mM}$ stock of dNTPs, 5 HI of the 10X PCR buffer provided with the enzyme, all in a thin-walled $0.5 \mathrm{ml}$ tube. $\mathrm{MgCl}_{2}$ at $1.5 \mathrm{mM}$ was added when the polymerase used was Taq $^{T M}$ rather than Vent ${ }^{T M}$. Sterile distilled water was added to a final volume of $50 \mu l$, and this was overlaid with $30 \mu l$ sterile mineral oil. The tubes were placed into the wells of a Perkin-Elmer Cetus Thermocycler, sealed with a dab of mineral oil, and subjected to 36 cycles of : 1 minute at $95^{\circ} \mathrm{C}$ (in the first cycle this step was extended to 5 minutes), 1 minute at $55^{\circ} \mathrm{C}$, and 1.5 minutes at $72^{\circ}$ followed by a cold soak at $4^{\circ}$ until they were collected. $(2.5 \mu l$ enzyme was added immediately after the initial 5 minutes at $95^{\circ} \mathrm{C}$.) The reactions were then extracted with $50 \mu l$ of chloroform and the aqueous phase retained following a quick spin. Eight microlitres of reaction product was run on a $0.8 \%$ agarose inini-gel to determine the presence or absence of product and its size.

The template DNA was genomic, or CDNA obtained by priming a pool of polyA-enriched 74A mRNA with polyT Race Primer (Frohman, 1990) in the case of RT (Reverse Transcriptase PCR). Beparation of DKA by an agarose gel system

A $0.8 \%$ agarose gel containing $0.05 \%$ ethidium bromide was prepared in $0.5 \times$ TBE buffer. The DNA sample was mixed with a 
rable 2: Primers used in sequencing and amplifying ro-4

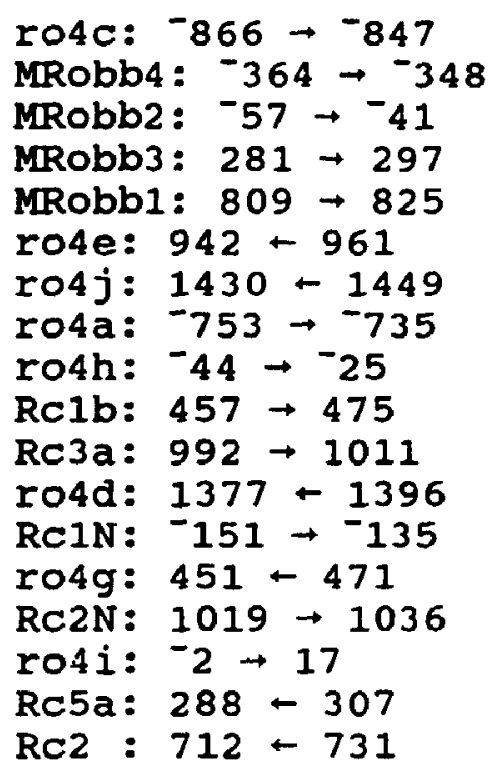

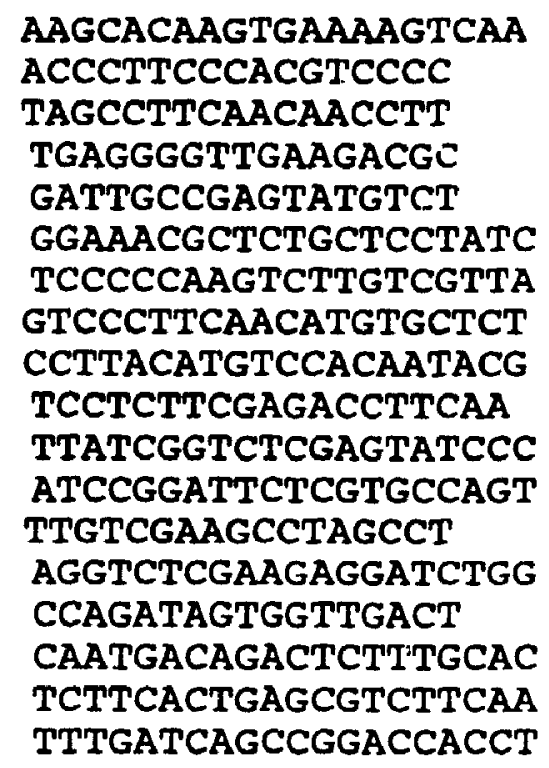

Positions are given relative to the first nucleotide of the first exon. 
third of its volume of $6 \mathrm{X}$ loading buffer and $10 \mu \mathrm{l}$ loaded into the well. A marker consisting of $10 \mu 1$ of Lambda phage DNA cut with HindIII $(2 \mu 1$ Lambda/HindIII stock, $2 \mu 1$ NEB buffer 3, $16 \mu 1 \mathrm{dH}_{2} \mathrm{O}, 6 \mu \mathrm{l} 6 \mathrm{X}$ loading buffer) was also loaded.

Recovery of DNA from agarose gel fragment

The desired band was sliced from the gel using a clean razor, placed into a $1.5 \mathrm{ml}$ microfuge tube with $2.5-3 \mathrm{x}$ its volume of $6 \mathrm{M} \mathrm{NaI}$ solution, and heated at $50^{\circ} \mathrm{C}$ with occasional tapping until dissolved about 5 minutes later. Five microlitres of Glass Milk $^{\mathrm{TM}}$ was then added, mixed by tapping and the tube left on ice for 5 minutes. A 5 second spin produced a pellet which was washed three times (by drawing the suspension up and down a $1000 \mu \mathrm{l}$ pipette tip) with $400 \mu \mathrm{l}$ New Wash $^{T M}$ after discarding the supernatant. After each wash the mixture was spun briefly (1-2 seconds) to collect the pellet, and finally the pellet was resuspended in $10 \mu \mathrm{I} \mathrm{dH}_{2} \mathrm{O}$ and incubated at $50^{\circ} \mathrm{C}$ for $3-5$ minutes to release the DNA into solution. After a 30 second spin the supernatant was carefully removed with a pipette and transferred to a fresh microfuge tube, where it was stored at $4^{\circ} \mathrm{C}$.

Recovery of DNA from agarose gel by the Freeze-squeeze Method

The desired band was cut out of the gel illuminated by longwave uv light, and equilibrated in $0.3 \mathrm{M}$ NaOAC $\mathrm{pH} 7,1 \mathrm{mM}$ EDTA for 15-45 minutes. A $0.5 \mathrm{ml}$ microfuge tube was partly stuffed with silanized glass wool and a hole punched in the bottom. The gel fragment was added and this tube then placed 
inside a $1.5 \mathrm{ml}$ eppendorf and frozen at -70 or $-20^{\circ} \mathrm{C}$. Once frozen the tube was centrifuged for 10 minutes at $12000 \times 9$ to allow the DNA to collect in the bottom of the larger tube. To this eluted DNA 0.01 volume of $1 \mathrm{M} \mathrm{MgCl}_{2}$ in $10 \%$ acetic acid was added and mixed, followed by 2.5 volume of EtOH. The mixture was allowed to sit on ice for 1 hour after which it was centrifuged 20 minutes at $12000 \times g$ and the supernatant replaced with $70 \%$ ethanol, $0.1 \mathrm{M}$ NaOAC $\mathrm{pH}$ 6. After another spin the supernatant was replaced with $100 \%$ EtOH and the tube subjected to a final spin before the supernatant was poured off and the pellet dried in a dessicator. The pellet was cutomarily resuspended in 5 to $10 \mu l \mathrm{~T}_{1} \mathrm{E}_{0.1}$.

Phenol/Chloroform extraction of DNA

A preparation of DNA was brought up to $100 \mu l$ by the addition of TE. To this was added an equal volume of phenol/chloroform (1:1) which was mixed to an emulsion by vortexing. This was centrifuged at $12000 \times \mathrm{xg}$ for 15 seconds and the aqueous phase withdrawn by pipetting. The aqueous phase was then subjected to the same procedure as above, once or twice more. In some cases, another $100 \mu 1 \mathrm{TE}$ was added to the phenol/chloroform remaining after the first aqueous phase has been removed to further extract any remaining DNA. The resulting aqueous phases were pooled and an equal volume of chioroform added, mixed in, and then separated by centrifugation as above. The final aqueous phase was again withdrawn by pipette and the DNA recovered by Ethanol 
precipitation.

Ethanol precipitation of DNA

The volume of a solution of DNA was measured and 0.1 volume of $3 \mathrm{M}$ NaOAC $\mathrm{pH} 5.2$ was added. This was mixed together and then twice the total volume of EtoH was added and also mixed. This was left on ice or in the refrigerator for at least one hour, and then centrifuged for 10 minutes at $12000 \times 9$. The supernatant was poured off and the pellet washed with $70 \%$ ethanol, and then dried under vacuum. The dry pellet was resuspended in $10-20 \mu l \mathrm{~T}_{1} \mathrm{E}_{0.1} \cdot$

Preparation of vector DNA for ligation

The Bluescript TM SK plasmid was digested with a restriction enzyme(s) appropriate for its ligation with the DNA to be introduced. In the case in wirich sticky ends were produced by the PstI digestion, re-ligation was prevented by treating the digested plasmic with calf intestinal alkaline phosphatase (CIP) which removes 5' phosphate groups. The plasmid DNA was extracted from the digestion mix with phenolchloroform and precipitated with ethanol. It was resuspended in $90 \mu 1$ of $10 \mathrm{mM}$ Tris $(\mathrm{pH} 8.3)$ and $10 \mu 1$ of $10 \mathrm{X}$ CIP dephosphorylation buffer (10mM $\mathrm{ZnCl}, 10 \mathrm{mM} \mathrm{MgCl}_{2}$ and $100 \mathrm{mM} \mathrm{Tri}$; $\mathrm{pH} 8.3)$ and 0.023 units of $\mathrm{CIP}$ were added and the reaction incubated for 30 minutes. Following this SDS to $0.5 \%$ and EDTA (pH 8) to $5 \mathrm{mM}$ were added and mixed. Proteinase $\mathrm{K}$ was then added to a final concentration of $100 \mu \mathrm{g} / \mathrm{ml}$ and incubation at $56^{\circ} \mathrm{C}$ proceeded for 30 minutes, after which the reaction was 
cooled to RT and extracted with phenol followed by phenolchloroform. The DNA was precipitated with ethanol and $3 \mathrm{M}$ NaAC pH 7 .

\section{Iigation of DHA fragment into plasmid vector}

To clone the $3^{\prime}$ end of the ro4 gene $26 \mathrm{ng}$ of PstI/BamHI digested Bluescript ${ }^{\mathrm{TM}}$ was 1 igated with $22 \mathrm{ng}$ of $2 \mathrm{~kb}$ PstI/BgIII fragments from the mutant 2980 . The reaction was carried out overnight at $15^{\circ} \mathrm{C}$ in a $10 \mu l$ volume including $1 \mu l$ of $10 \mathrm{X}$ Ligase Reaction buffer and $0.2 \mu l \mathrm{~T}_{4}$ DNA Ligase.

In cloning the $5^{\prime}$ end of the gene it was necessary to combine $7.5 \mathrm{ng}$ of PstI/CiP-treated Bluescript ${ }^{\mathrm{TM}}$ and $36 \mathrm{ng}$ of $1.2 \mathrm{~kb}$ PstI digested 2980 DNA (roughly a 2:1 insert:vector ra-io) in a $20 \mu l$ reaction volume containing $4 \mu 1$ of $5 \times$ Ligase reaction buffer and $0.5 \mu 1 \mathrm{~T}_{4}$ DNA Ligase. Ligation proceeded for 5 hours at room temperature, after which the DNA was precipitated with $3 \mathrm{M}$ NaOAC ( $\mathrm{pH} 5.2$ ) to $10 \%$ and absolute ethanol to three times the volume. The dried pellet was resuspended in $5 \mu l \quad T_{1} E_{0.1}$ and used directly in the electroporation procedure.

Transformation of $E$. coli cells with foreign DNA and detection of transformed colonies

i) Preparation of competent cells

Competent cells were obtained by inoch: ating $500 \mathrm{ml}$ of $\mathrm{LB}$ broth with $5 \mathrm{ml}$ of . fresh overnight culture of DH5 $\alpha \mathrm{F}^{\prime}$ cells derived from a single colony. The culture was incubated on a shaker bath at $37^{\circ} \mathrm{C}$ until an $\mathrm{Abs}_{600}$ of 0.2 to 0.5 was reached. 
The culture was then chilled on ice for 15 to 30 minutes, then decanted into two cencrifuge tubes and spun at $4000 x \mathrm{x}$ for 15 minutes in a cold rotor. The supernatant was allowed to drain off, and the cells resuspended in the same volume of ice-cold, sterile 10\% glycerol. These sirspensions were spun at $4000 \times 9$ for 15 minutes two more times, resuspending in $100 \mathrm{ml}$ and 10 ml cold sterile glycerol respectively. The suspension was then aliquoted into microfuge tubes and stored at $-70^{\circ} \mathrm{C}$.

\section{ii) Transformation of competent cells}

To transform these cells, $40 \mu l$ of cell suspension was mixed with $2 \mu l$ of transforming DNA and the mixture transferred to a $0.1 \mathrm{~cm}$ electroporation cuvette and kept on ice. The cuvette was then placed in the electroporation chamber and subjected to a voltage of $180 \mathrm{kV}$. Immediately, the mixture was removed and $1 \mathrm{ml}$ of soc medium added. The soc nedium consisted of $2 \%$ Bacto-tryptone, $0.5 \%$ Bacto yeast extract, $10 \mathrm{mM} \mathrm{NaCl}, 2.5 \mathrm{mM} \mathrm{KCl}, 10 \mathrm{mM} \mathrm{MgCl}_{2}$ and $20 \mathrm{mM}$ glucose.

After a 60 minute incubation at $37^{\circ} \mathrm{C}$, the cell mixtures were plated onto LBA (LB + ampicillin) supplemented with X-gal and IPTG in volumes of 10 to $50 \mu l$ respectively, and incubated at $37^{\circ} \mathrm{C}$ until blue or white $\mathrm{col}^{1}$ ies formed. The white colonies were replica-plated onto IRS and then transferred to nylon membranes to be probed.

\section{Rapid preparation of DWA from plasmids}

A single colony from a lresh plate of $D H 5 \alpha F^{\prime} E$. coli was used to inoculate $2 \mathrm{mls}$ of LB or LBA liquid medium and 
cultured overnight at $37^{\circ} \mathrm{C}$ with shaking. The next day, 1.5 $\mathrm{mls}$ of the culture was centrifuged in a $1.5 \mathrm{mi}$ microfuge tube for 60 secorids and the supernatant poured off. The cells were resuspended in $100 \mu I$ TE buffer and left at RT 5 minutes, then $200 \mu \mathrm{I}$ of $0.2 \mathrm{~N} \mathrm{NaOH,} 1 \%$ SDS was added and the tubes placed on ice for 5 minutes. Next $150 \mu l$ of $3 M \mathrm{KAC}$ ( $\mathrm{pH} 4.8$ ) was added and the mixture vortexed at high speed for two minutes and left on ice for a further 5 minutes. After a 4 minute spin the supernatant was mixed with $900 \mu l$ EtoH and allowed to sit 10 minutes to an hour at RT. The nucleic acids were then pelleted by a short (1-2 minute) spin and washed with $70 \%$ ethanol, then dried and resuspended in $20 \mu l T_{1} E_{0.1}$. For sequencing reactions, these were digested with $10 \mu \mathrm{g}$ of RNase A for 30 minutes to 2 hours (at $37^{\circ} \mathrm{C}$ ), then collected by phenol-chloroform extraction and ethanol-precipitation.

\section{southern blotting}

The agarose slab gel was immersed in denaturing solution (1M NaCl, $0.4 \mathrm{M} \mathrm{NaOH)} \mathrm{with} \mathrm{shaking} \mathrm{for} \mathrm{about} 40$ minutes, then in neutralizing solution (1M Tris-Cl ph 7.4-7.5, 1.5M NaCl) for about 20-30 minutes. The gel was then placed onto a 0.5 cm thick plexiglass slab which was wrapped in 1 thickness of Whatman 3MM filter paper and partially jmmersed in $2 \mathrm{X}$ SSC. A similar-sized piece of Hybond-N nylon membrane (Amersham) which had been erililibrated in $2 \mathrm{X}$ SSC was laid on top of the gel, followed by two pieces of filter paper and a stack of paper towels about $10 \mathrm{~cm}$ thick. The dish and its contents was 
wrapped in plastic wrapping and a weight (glass baking dish) placed on the top. Transfer of the DNA by capillary action was allowed to proceed overnight. The next morning the pile was taken apart, the gel discarded and the nylon membrane allowed to air-dry, then baked at $80^{\circ} \mathrm{C}$ for about 2 hours. Transfer of bacterial DNA from replica plates to rylor membrane

One Hybond-N nylon membrane (Amersham) was laid directly onto the LB plate containing the bacterial colonies, and allowed to rest there 1-2 minutes, until the colonies adsorbed to it. The membrane was then lifted off and laid (colony side up) onto filter paper saturated with 10\% sDs for 3 minutes, then onto filter paper saturated with denaturing solution (0.5N NaOH, $1.5 \mathrm{M} \mathrm{NaCl}$ ) for 5 minutes, then onto a filter paper saturated with neutralizing solution (1.5M NaCl, $0.5 \mathrm{M}$ Tris-Cl $\mathrm{pH} 7.4)$ for 5 minutes, and finally onto a filter paper saturated with $2 \mathrm{X}$ sSC for 5 minutes. The membrane was allowed to air dry and was then baked at $80^{\circ} \mathrm{C}$ for 15 minutes.

Preparation of a digoxigenin-labelled probe for southern hybridizations

Eighty nanograns of the desired DNA fragment in $8 \mu \mathrm{L}$ was boiled for 10 minutes with $5 \mu l \mathrm{dH}_{2} \mathrm{O}$ and $2 \mu l$ of $\mathrm{dp}(\mathrm{N})_{6}$ at 40 ng/m1. The mixture was then chilled quickly on ice, spun down, and to it was added $2 \mu l$ of $10 x$ oligolabelling buffer, $1 \mu l$ Klenow enzyme (DNA Polymerase I, large fragment, 5000 units/ml, NEB) and $2 \mu l$ digoxigenin labelling mix (Boehringer 
Mannheim). This was incubated at $37^{\circ} \mathrm{C}$ for 1 hour and placed on ice. Half a microlitre of $0.5 \mathrm{M}$ EDTA, $3 \mu 1$ of tRNA at 10 $\mathrm{mg} / \mathrm{ml}$, and $76 \mu \mathrm{l}$ of STE (100mM Nacl, $10 \mathrm{mM}$ Tris pH8, 1mM EDTA) was added and the probe collected by running this mixture through a sephadex column packed in a sterile pasteur pipette plugged with silanized glass wool.

Probing of membrane-bound DNA with specific nucleic acid probes

The nylon membranes from either colony lifts or gel transfers were pre-hybridized by dipping them briefly (about 5 seconds) in a solution of $0.1 \%$ gelatin (melted and cooled to RT). They were then inserted into hybridization chamber tubes and hybridization solution (5X SSC, $0.1 \% \mathrm{~N}$-laurylsarcosine, $0.02 \%$ SDS, $2 \%$ dried skimmed milk powder, with $0.2 \%$ salmon sperm DNA and about $0.3 \%$ probe, boiled together for $5 \mathrm{minutes,}$ in volume equal to $0.05 \mathrm{ml}$ per $\mathrm{cm}$ of membrane) was added. Hybridization proceeded overnight, and the next morning the membranes were washed in 2 XSC with $0.1 \%$ SDS ( $2 \times 15$ minutes), $0.1 X$ SSC with $0.1 \%$ SDS ( $2 \times 15$ minutes), and washing buffer (0.3\% Tween-20 in $100 \mathrm{mM}$ maleic acid and $150 \mathrm{mM} \mathrm{NaCl,} \mathrm{pH} 7.5$ ). They were then incubated for 30 minutes first in buffer $2(1 \%$ milk powder in buffer 1 (100mM naleic acid and $150 \mathrm{mM} \mathrm{NaCl}$ )), then for 30 minutes in buffer 2 with anti-dig-AP added at a rate of $1: 10,000$. Following this incubation they wers again washed in washing buffer (2X15 minutes), and finaliy equilibrated briefly ( 5 minutes) in buffer 3 (100mM Tris-Cl pH 
9.5, $100 \mathrm{mM} \mathrm{NaCl}, 50 \mathrm{mM} \mathrm{MgCl}_{2}$ ). They were then placed, DNA side up, in clear plastic sheet protectors and 1 to $2 \mathrm{mls}$ of Lumigen PPD (Boehringer Mannheim) diluted in buffer 3 ( 1 part of $10 \mathrm{mg} / \mathrm{ml}$ stouk in 100 parts buffer 3) was dropped onto them and distributed evenly as the sheet protector was closed and smoothed flat. The sheet protector was placed in a photographic cassette and incubated for 10 minutes at $37^{\circ} \mathrm{C}$ after which a piece of Kodak film was placed on top and the whole left in the dark for exposure to take place overnight. Preparation of sequencing reactions

For each template/primer combination the following steps were followed. To denature the template, 1.5 to $2 \mu \mathrm{g}$ DNA in $8 \mu \mathrm{l}$ was added to $2 \mu \mathrm{l} 2 \mathrm{M} \mathrm{NaOH}$ and incubated 10 minutes at room temperature. The denatured DNA was precipitated by mixing in $3 \mu \mathrm{l}$ of $3 \mathrm{M}$ NaOAC $(\mathrm{pH} 4.8)$ and $7 \mu \mathrm{l} \mathrm{dH}_{2} \mathrm{O}$, followed by $60 \mu \mathrm{IEtOH}$ and leaving on ice for 15 minutes. The mixture was then centrifuged 10 minutes, the supernatant poured off and the pellet resuspended in $7 \mu \mathrm{I} \mathrm{dH}_{2} \mathrm{O}$.

To this was added $1 \mu l$ primer (40ng) (Table 2) and $2 \mu l$ of reaction buffer provided in the USB "Sequenase 2" sequencing kit. Annealing occurred after this mixture was heated to $65^{\circ} \mathrm{C}$ for two minutes and then allowed to slowly cool to below $35^{\circ} \mathrm{C}$. This preparation was then spun down, cooled on ice and lised within 4 hours.

For each template/primer combination four tubes were prepared by adding $2.5 \mu \mathrm{l}$ of one of A,C,G or T labelling mix 
(provided in kit) to each, and allowing them to reach $37^{\circ}$ in a heat block.

To each annealed template/primer combination was added 1 $\mu l$ of $0.1 M$ DTT (dithiothreitol), $2 \mu l$ of labelling mix (provided in kit and diluted $5 \mathrm{X}$ in water), $0.5 \mu 1$ of ${ }^{35} \mathrm{SdATP}$ and $2 \mu 1$ Sequenase ${ }^{T M}$ Version 2 T7 polymerase (provided and diluted $8 \mathrm{x}$ in dilution buffer). This mixture was incubated 5 minutes at room temperature and then $3.5 \mu \mathrm{l}$ of it was added to each tube of $A, C, G, T$ and the polymerizing reaction allowed to proceed at $37^{\circ} \mathrm{C}$ for 5 minutes, after which it was ended by adding $4 \mu 1$ of stop solution (provided).

These reactions were stored in the freezer, and heated at $80-95^{\circ} \mathrm{C}$ for $2-5$ minutes prior to loading.

\section{sequencing using the circumvent cycle sequencing method}

Template DNA obtained from $P C R$ was first purified in a Centricon spin filter (molecular weight cut-off 125 nucleotides double-stranded) according to the instructions provided.

Three microlitres of $A, C, G$ and $T$ sequencing mixes (provided) were placed into four $0.5 \mathrm{ml}$ thin-walled microcentrifuge tubes.

In a $0.5 \mathrm{ml}$ microfuge tube $100 \mathrm{ng}$ of iemplate DNA was mixed with 1.2 pmole primer (Table 2), $1.5 \mu 1$ 10X Circumvent ${ }^{\mathrm{TM}}$ Sequencing Buffer, $1 \mu 130 x$ Triton $x-100$ and distilled water to $12 \mu 1$. Two microlitres of $\left[\alpha-{ }^{35} \mathrm{~S}\right] \mathrm{dATP}$ and 2 units of Vent $^{\text {TM }}($ exo-) DNA polymerase was added and $3.2 \mu l$ of the 
resulting solution added to each of the four $A, C, G$ and $T$ tubes. Each reaction mixture was then overlaid with sterile mineral oil and the tubes then put in the thermocycler and run through 20 cycles of : 20 seconds at $95^{\circ} \mathrm{C}, 20$ seconds of $55^{\circ} \mathrm{C}$, 20 seconds of $72^{\circ} \mathrm{C}$. The reactions were terminated by adding $4 \mu l$ of stop/Loading dye (provided) to each and stored in the freezer. They were run as above, after a 2 to 5 minute heating at $80-95^{\circ} \mathrm{C}$.

\section{Preparing and running the sequencing gel}

A 6\% acrylamide gel was prepared by dissolving $33.6 \mathrm{~g}$ urea in $8 \mathrm{mls}$ 10X TBE (9M Tris,9M Boric acid,20mM EDTA) and $32.4 \mathrm{mls} \mathrm{dH}_{2} \mathrm{O}$, then adding $11.5 \mathrm{mls}$ of $40 \%$ acrylamide (including 2\% bis-acrylamide) and degassing for 5 minutes. The solution was filtered through whatman \#1 in a buchner funnel and $24.5 \mu I$ TEMED and $600 \mu l$ of $10 \%$ ammonium persulphate was added. Using a $50 \mathrm{ml}$ pipette the solution was dropped between two gel plates (the snorter siliconized and the taller etched with $\mathrm{NaOH}$ ) spaced $0.5 \mathrm{~mm}$ apart with plastic spacers, and taped sides and bottom. Well combs were placed flat against the top and the gel was alllowed to set for at least one hour. Prior to running the sequencing reactions the well combs were removed and the top of the gel flushed with $0.5 \times$ TBE. The tape was removed and the gel was placed in the sequencing apparatus, the upper and lower buffer chambers filled with TBE and the well combs inserted between the plates to provide 100 wells. The gel was pre-run at 60w constant 
power for about half an hour. Then $1.5-2.5$ kl of each sequencing reaction was pipetted into each well, and the gel run again at $60 \mathrm{w}$ for between 1 and 5 hours.

After the run the shorter gel plate was removed and the gel was fixed in methanol and acetic acid for 15 minutes while resting on the taller plate. It was then transferred to $3 \mathrm{MM}$ filter paper, covered in plastic wrap and dried in a gel dryer under vacuum for an hour. The plastic wrap was removed and the gel inserted into a film cassette with a piece of Kodak film and left in the dark to expose for between 4 days and 2 weeks.

Methods for RNA Analysis

Extraction of total RNA from fungal cultures

Mycelia of isolates grown in liquid culture (500 mls LB) for 34 to $58 \mathrm{~h}$ was harvested by straining through "MiraclothTM" and expressing the excess liquid between paper towelling. The mycelium was then cut into squares and frozen at $-20^{\circ} \mathrm{C}$, after which it was dried in a speed-Vac. The dried mycelium was ground with roughly one gram of acid-washed sea sand and quickly mixed with $20 \mathrm{mls}$ of a $1: 1$ mixture of extraction buffer (100mM sodium-acetate, pH 5.0, $1 \mathrm{mM}$ EDTA, 5\%SDS) and phenol/chloroform /iscpentyl alcohol (P/C/I at $26: 25: 1)$.

The mixture was then centrifuged at $10,000 \mathrm{rpm}$ for 10 minutes at $4^{\circ} \mathrm{C}$, after which the aqueous phase was mixed with $1.2 \mathrm{mg}$ pre-digested pronase and left to incubate $1 \mathrm{~h}$ at room 
temperature. This $\mathrm{P} / \mathrm{C} / \mathrm{I}$ extraction was repeated twice more and the RNA was precipitated with 2 volumes of ethanol. The resulting pellet was resuspended in $1.8 \mathrm{mls}$ DEPC-treated water at $4^{\circ} \mathrm{C}$, then re-precipitated with 3 volumes of $4 \mathrm{M}$ sodium acetate, $\mathrm{pH} 6.0,10 \mathrm{mM}$ EDTA. After sitting at $4^{\circ} \mathrm{C}$ for 10 minutes the suspension was centrifuged at $10,000 \mathrm{rpm}$ for 20 minutes at $4^{\circ} \mathrm{C}$. The pellet was then rinsed with $70 \%$ EtOH, and resuspended in $2 \mathrm{ml}$ DEPC-treated water containing $0.5 \%$ SDS. A final precipitation was performed with $1 / 13$ th volume of the above sodium acetate solution and 2 volumes EtOH, and finally resuspended in DEPC-treated water to a concentration of 2 $\mathrm{mg} / \mathrm{ml}$ and frozen at $-70^{\circ} \mathrm{C}$.

One total RNA preparation was prepared for each of isolates WT, 1511, 1529, 2980, R1, R2, R4, and R5.

Enrichment of total RHA for poly-A mRNA

For each RNA preparation referred to above, one Dispocolumn (BioRad) was loaded with $3 \mathrm{mls}$ of oligo(dT)cellulose (packed volume) and washed with $10 \mathrm{mls}$ sterile water. Each column was then washed with sterile $1 \mathrm{x}$ columnloading buffer (20mM Tris-cl ( $\mathrm{pH} 7.6), 0.5 \mathrm{M} \mathrm{NaCl}, 1 \mathrm{mM}$ EDTA (pH 8), $0.1 \%$ sodium lauryl sarcosinate) until the $\mathrm{pH}$ of the effluent was reduced to below 8 . The total RNA extract was heated to $65^{\circ} \mathrm{C}$ for 5 minutes, then cooled to RT and ciiiuted 1:1 with $2 x$ column-loading buffer. This solution was poured into the column, followed by about $3 \mathrm{mls}$ of $1 \times$ column-loading buffer, and the eluate collected, heated to $65^{\circ} \mathrm{C}$ and again 
passed through the column. The column was then washed with 40 to $50 \mathrm{mls}$ of $1 \times$ column-loading buffer until the flow-through demonstrated an $\mathrm{ABS}_{260}$ of +0.0005 or less. The poly-A enriched mRNA was then eluted by adding roughly $9 \mathrm{mls}$ of sterile elution buffer (10mM Tris--cl pH 7.6), 1mM EDTA (pH 8 , $0.5 \%$ SDS). The eluate was collected and precipitated with $1 / 13$ th volume of $4 \mathrm{M}$ sodium acetate $(\mathrm{pH} 5.2)$ and 2.5 volumes of ethanol. After 30 minutes the mixture was centrifuged at $10,000 \times \mathrm{g}$ for 15 minutes at $4^{\circ} \mathrm{C}$ and the pellet rinsed with $75^{\circ}$ ethanol. The pellet was then air-dried and resuspended in 400 $\mu 1$ of DEPC-treated water. The absorbance at $260 \mathrm{~nm}$ of a $200 x$ dilution was taken to estimate yield.

separation of poly-A enriched mRNA

An agarose/formaldehyde gel was prenared in formaldehyde gel-running buffer (0.02M MOPS (pH 7), $8 \mathrm{mM}$ sodium acetate, $1 \mathrm{mM}$ EDTA ( $\mathrm{pH} 8$ )) to provide a $1.2 \%$ agarose gel with $2.2 \mathrm{M}$ formaldehyde. A volume of poly-A enricred mRNA solution sufficient to provide $20 \mu \mathrm{g}$ of $\mathrm{mRNA}$ was dried in a speed vac and resuspended in $20 \mu l$ of sample buffer $(2 \mu 15 x$ formaldehyde gel-running buffer, $3.5 \mu l$ formaldehyde, $10 \mu l$ formamide, $4.4 \mu \mathrm{l}$ water, $10 \mu \mathrm{g} \mathrm{EtBr}$ ). Before loading the samples were incubated for $15 \mathrm{minutes}$ at $65^{\circ} \mathrm{C}$ aid inen chi 1 led on ice, and the gel was pre-run at $5 \mathrm{~V} / \mathrm{cm}$ for 5 minutes. FInally $2 \mu l$ of formaldehyde gel-loading buffer ( $50 \%$ glycero: , IMM EDTA (pH 8), $0.25 \%$ bromophenol blue, $0.25 \%$ xylene cyanol FF) was added to each sample and they were loaded into the 
wells. A marker provided by Boehringer Mannheim Was treated in the same way as the samples (but with only $10 \mu \mathrm{g}$ used per lane) and also loaded. The gel was run at $70 \mathrm{~V}$ for $3 \mathrm{~h}$, with the buffer in the two chambers mixed at the half-way point. At the end of the run the RNA was transferred to nylon membrane.

\section{Northern blotting}

Following the gel run, the mRNA gel was soaked for 15 minutes in DEPC-treated water to remove formaldehyde, then for 45 minutes in $20 X \operatorname{SSPE}$ ( $3 \mathrm{M} \mathrm{NaCl}, 0.2 \mathrm{M} \mathrm{NaH} \mathrm{PO}_{4} \cdot \mathrm{H}_{2} \mathrm{O}, 20 \mathrm{mM}$ EDTA) . The gel was then placed on a plexiglass support wrapped in $3 \mathrm{MM}$ filter paper and a piece of Amersham HybondN nylon membrane (cut to fit) laid on top. A test tube was used to roll out any bubbles that may have come between the gel and the membrane. Over this was placed two squares of filter paper the same size as the gel and over these a stack (roughly 5-6 cm) of paper towels. The entire package was placed in a glass baking dish with $20 X$ SSPE added to the level of the gel. Plastic wrap was used to prevent evaporation, and another glass baking dish was placed on top to ensire good contact. Transfer of RNA was allowed to occur overnight, after which the stack was dissembled and the membrane soaked briefly in $6 \mathrm{x}$ SSPE to remove agarose, air-dried and baked $1-2$ hours at $75^{\circ} \mathrm{C}$. Preparation of radioactive RWA probe

The template consisted of the $\mathrm{E} 2$ fragment of the ro-4 gene (Figure 3) cloned into the Bluescript vector. Two 
micrograms of template DNA was linearized by digestion with SmaI, which is distal to the $\mathrm{T} 7$ promoter site, and treated with Proteinase $\mathrm{K}(\mathrm{e} 100 \mu \mathrm{g} / \mathrm{ml}$ overnight; to remove RNases. It was then extracted with phenol/chloroform and precipitated with ethanol. The pellet was resuspended in RNase-free water. This template was combined with NTPs, $\left[\alpha-{ }^{32}\right.$ P $]$ UTP and T7 RNA polymerase as per the instructions given with the Maxiscript kit (Ambion), and the reaction allowed to proceed for one hour. Residual DNA was digested with DNaseI and the probe was purified by passing through a spin column (Sephadex G-50) with $5 \mu g$ yeast tRNA to improve recovery.

\section{Hybridization}

The nylon membrare to which the mRNA had been bound was pre-hybridized at $68^{\circ} \mathrm{C}$ overnight in $0.2 \mathrm{ml} / \mathrm{cm}^{2}$ of $6 X \mathrm{SSPE}, 5 \mathrm{X}$ Denhardt's reagent, $0.5 \%$ SDS and $100 \mu \mathrm{g} / \mathrm{ml}$ salmon sperm DNA in a Hybridization Incubator (Model 310, Robbins Scientific).

Probe having at least $1-2 \times 10^{7} \mathrm{cpm}$ was added directly to the pre-hybridization solution and allowed to hybridize overnight at $68^{\circ} \mathrm{C}$. The blot was then washed in four changes of $5 X$ SSPE, two of which were left on for 15 minutes, then washed in $1 X$ SSPE, $0.1 \%$ SDS for half an hour, then in $0.1 X$ SSPE, $0.1 \%$ SDS for 15 minutes. The b]ot was then air-dried briefly and placed in a sheet protector between two intensifying screens in a cassette with a piece of film. Exposure took place overnight. 
Methods for Protein Analysis

Preparation of fungal protein extracts for one- and twodimensional polyacrylamide gel electrophoresis

Fungal isolates were grown in liquid VMM (Vogel's Minimal Meidum) on shaker baths for 1 to 3 days. The mycelium was ther: filtered through Miracloth ${ }^{\text {TM }}$, rinsed with distilled water and the excess moisture pressed from it. The resulting cake was cut into small squares and frozen. Before use, one or two squares were placed in a microfuge tube and dried fully in the speed-Vac. The resulting material was ground in protein extraction buffer containing 10mM Tris pH7.6, 1mM EDTA, 2mM DTT, $0.5 \%$ SDS, $1 \mu \mathrm{M}$ leupeptin, $1 \mu \mathrm{L}$ pepstatin and $1 \mathrm{mM}$ PMSF (phenylmethylsulfonylfluoride).

Eventually, a more complete protease inhibiting mixture was used, containing 1mM PMSF, 1mM Benzamidine, 1mM eamino-ncaproic acid, $2 \mathrm{mM}$ DTT, and $1 \mu \mathrm{g} / \mathrm{ml}$ ech of pepstatin, leupeptin, TPCK (n-tosyl-L-phenylalanine chloromethyl ketone) and aprotinin.

One-dimensional polyacrylamide gel electrophoresis

Acrylamide slab gels $(0.75 \mathrm{~mm})$ were prepared according to the instructions (BioRad Minigel) to provide a $4 \%$ stacking gel and $10 \%$ resolving gel. The resolving gel was made with 3.64 $\mathrm{ml} \mathrm{dH}_{2} \mathrm{O}, 2.5 \mathrm{ml}$ of $1.5 \mathrm{M}$ Tris $(\mathrm{pH} 8.8), 100 \mu \mathrm{l}$ of $10 \%$ SDS and $3.33 \mathrm{ml}$ of $30 \%$ acrylamide (2.67\% bis-acrylamide) added just prior to de-gassing for 15 minutes. To induce polymerization $50 \mu l$ of $10 \%$ ammonium persulphate and $5 \mu l$ of TEMED were added 
before pipetting the solution between the gel plates. The resolving gel was overlaid with water as it polymerized. The stacking gel consisted of $6.1 \mathrm{ml} \mathrm{dH}_{2} \mathrm{O}, 2.5 \mathrm{ml} 0.5 \mathrm{M}$ Tris ( $\mathrm{pH}$ $6.8), 100 \mu l$ and $1.3 \mathrm{ml}$ of $30 \%$ acrylamide (2.67\% bisacrylamide), mixed with $50 \mu l$ of $10 \%$ ammonium persulphate and $10 \mu l$ TEMED after de-gassing.

Extracts of total protein were prepared at $2 \mu \mathrm{g} / \mu 1$, and mixed 1:1 with $2 x$ gel-loading buffer. These mixtures were boiled 5 minutes and then 10 to $15 \mu l s$ loaded in each lane. The gel was run in buffer conisting of $3 \mathrm{~g}$ Tris, $14.4 \mathrm{~g}$ Glycine and $1 \mathrm{~g}$ SDS per litre at $180 \mathrm{~V}$ for 45 minutes to 1 hour, then stained with Coomassie Blue, or soaked in transfer buffer if a Western analysis was to follow. The transfer buffer consisted of $3 \mathrm{~g}$ Tris, $1.4 .4 \mathrm{~g}$ Glycine and $200 \mathrm{ml}$ methanol per litre.

Two-dimensional polyacrylamide gel electrophoresis

Protein was extracted from lyophilized cubes of mycelium in a buffer containing $10 \mathrm{mM}$ Tris-Cl (pH 7.6), $5 \mathrm{mM} \mathrm{MgCl}, 0.25$ $\mathrm{mg} / \mathrm{ml}$ RNase A, $0.5 \mathrm{mg} / \mathrm{ml}$ DNase I, $0.1 \%$ SDS and $1 \mathrm{mM}$ PMSF. Tube gels were prepared according to instructions provided with BioRad's Mini-Protean II 2-D gel apparatus. The gel solution contained $5.5 \mathrm{~g}$ urea, $1.33 \mathrm{ml}$ acrylamide $(28.38 \mathrm{~g}$ acrylamide with $1.62 \mathrm{~g}$ bis-acrylamide), $2 \mathrm{ml}$ of $10 \%$ deionized Triton $\mathrm{X}-$ $100,400 \mu 1$ Bio-lyte 5/7, $100 \mu l$ Bio-Lyte $3 / 10$ and $1.97 \mathrm{ml}$ $\mathrm{dH}_{2} \mathrm{O}$. It was warmed at $45^{\circ} \mathrm{C}$ to dissolve the urea and degassed 15 minutes, after which $10 \mu \mathrm{\mu l}$ each of $10 \%$ ammonium 
persulphate and TEMED was added. The upper buffer was 100mM $\mathrm{NaOH}$ in $250 \mathrm{ml} \mathrm{dH}_{2} \mathrm{O}$ de-gassed thoroughly, and the lower was $10 \mathrm{mM} \mathrm{H}_{3} \mathrm{PO}_{4}$ de-gassed thoroughly. The tubes were preelectrophoresed for $200 \mathrm{~V}$ for 10 minutes, $300 \mathrm{~V}$ for 15 minutes and $400 \mathrm{~V}$ for 15 minutes before having the upper buffer withdrawn and replaced with the protein samples. These were suspended $1: 1$ in $2 \mathrm{X}$ sample buffer of $9.5 \mathrm{M}$ urea, $2 \%$ Triton $\mathrm{X}-$ 100, 5\% B-mercaptoethanol, $1.6 \%$ of Bio-Lyte $5 / 7$ and $0.4 \%$ of Bio-Lyte 3/10, and incubated at RT 15 to 20 minutes. Twentyfive micrograms of total protein extract was commonly loaded into each tube and overlaid with overlay buffer. This was comprised of $9 M$ urea, $0.8 \%$ Bio-Lyte $5 / 7,0.2 \%$ Bio-Lyte $3 / 10$ and $500 \mu \mathrm{I}$ of a $0.05 \%$ Bromophenol blue stock solution in 10 $\mathrm{ml}$. In most cases it was then diluted $1: 1$ with $\mathrm{dH}_{2} \mathrm{O}$ to achieve the proper density. Tubes were then preelectrophoresed at $500 \mathrm{~V}$ for 10 minutes and elestrophoresed at $750 \mathrm{~V}$ for $3.5 \mathrm{~h}$. Following separation the gels were ejected carefully from the glass tubes and stored individually at $20^{\circ} \mathrm{C}$. To obtain the second dimension a tube gel was laid across the surface of a $10 \%$ polyacrylamide mini-gel (1 mm thickness, prepared by doubling the recipe given above) and the usual current applied.

\section{Fractionation of total proteins}

About $1 \mathrm{~g}$ fresh, pressed fungal mycelium was ground with $1 \mathrm{~g}$ washed sand and $10 \mathrm{~mL}$ protein extraction buffer (with full range of protease inhibitors as above). The slurry was 
centrifuged 10 minutes at $2,500 \mathrm{rpm}(700 \times \mathrm{g})$ in a Sorval ss -34 rotor at $4^{\circ} \mathrm{C}$. The supernatant was poured off (to obtain three other fracticns from it) and the pellet washed in $3 \mathrm{mls}$ of buffer and retained for later use.

The supernatant was centrifuged 20 minutes at $9500 \mathrm{rpm}$ (10,000xg) in the same conditions as above. The new supernatant was poured off and retained while the pellet was washed in $2 \mathrm{mls}$ buffer and spun again to collect, then resuspended in $500 \mu \mathrm{L}$ sucrose buffer $(0.25 \mathrm{M}$ sucrose, $50 \mathrm{mM}$ Tris $\mathrm{pH} 7.6,50 \mathrm{mM} \mathrm{KCl}$ ) to provide the $10 \mathrm{~K}$ fraction.

The most recent supernatant was then centrifuged 60 minutes at $27,000 \mathrm{rpm}(100,000 \mathrm{xg})$ in a Beckman sw40 rotor, at $4^{\circ} \mathrm{C}$. The resulting supernatant was poured of $f$ and became the cytosolic fraction. The pellet was resuspended in $500 \mu 1$ sucrose buffer (100K fraction).

To obtain soluble proteins representing the nuclear fraction, $0.6 \mathrm{~g}$ of the first pellet was mixed with $1 \mathrm{ml}$ protein extraction buffer, incubated 15 minutes on ice and tren centrifuged 4 minutes at $7,000 \mathrm{rpm}$ and 15 minutes at $14,000 \mathrm{rpm}$. The resulting supernatant was referred to as the nuclear fraction.

Each fraction was analysed by spectrophotometry to determine the concentration $\left(183 A_{230}-75.8 A_{260}=\mu \mathrm{g} / \mathrm{ml}\right.$ protein) and dilutions were made to $2 \mathrm{mg} / \mathrm{ml}$ protein. PAGE gels using fractionated proteins were loaded with $10 \mu \mathrm{g}$ per lane. 
western blotting

The gel was equilibrated in transfer buffer (25mM Tris, $192 \mathrm{mM}$ glycine, 20\% methanol) for 15-30 minutes. One piece of nitrccellulose membrane (Hybond-ECL, Amersham) and 6 pieces of filter paper, all cut to the same size as the gel, were also wetted in transfer buffer. Using the Trans-Blot semi-dry electrophoretic transfer cell (BioRad), the membrane was placed atop 3 pieces of filter paper, and overlaid with the gel and the other three filters. Air bubbles were rolled out after each layer. Transfer was accomplished at 10-15 V for about 20 minutes (for mini-gels), or $20 \mathrm{~V}$ for 50 minutes (for larger gels). Following transfer the membrane was stained with Ponceaus $(0.2 \%$ in $0.3 \% \mathrm{TCA})$ to assess completeness of transfer, and the gel was stained in coomassie (coomassie Brilliant Blue R250 in $10 \%$ Acetic acid, $40 \%$ methanol) and in some cases silver-stained according to the instructions (BioRad).

\section{Western analysis}

The nitrocellulose membrane was blocked in TBS-T (Trisbufferred saline with $0.1 \%$ Tween 20 ) containing $2 \%$ skimmed milk powder for $2 \mathrm{~h}$. This liquid was then replaced with 1\% skimmed milk in TBS-T containing the primary antibody at 1:500 dilution, and the blot incubated for 1 hour. The blot was then washed $4 \times 15$ minutes with TBS-T before being incubated in the appropriate (anti-rabbit or anti-mouse) secondary antibody at a 1:2000 dilution in TBS-T and 1\% skimmed milk. Four more 
15 minute washes in TES-T followed this step, after which the antibody-labelled proteins were dete-ted using the Enhanced Chemi-Luminescence method of Amersham (according to the instructions accompanying the kit). All incubation steps were carried out with gentle shaking at room temperature.

The monoclonal anti-actin antibody was catalogue number 1378996 from Boehringer Mannheim.

\section{Preparation of polyclonal antibodies from rabbits}

Two peptides were chosen from the ro-4 sequence (Figure 2) and synthesized by the Peptide Synthesis Lab (ottawa Centre for Cancer Research, University of Ottawa, 451 Smythe Road, ottawa) on an 8-branch lysine tree. The choice of peptides was made on the basis of hydrophilicity of the region to ensure that it would represent an exposed epitope, and relative uniqueness. The latter consideration was examined by sending the sequences ( 11 and 13 amino acids, respectively) to GenBank (Bethseda, Md) to search for similar sequences. None were found. The peptide preparations were resuspended to a concentration of $10 \mathrm{mg} / \mathrm{ml}$ and stored at $4{ }^{\circ} \mathrm{C}$. Two New zealand White rabbits per antigen were each injected subcutaneously with $0.25 \mathrm{mg}$ of antigen suspended in $1 \mathrm{ml}$ of RIBI Adjuvant (MPL+TDM+CWS Emulsion, R-730, from RIBI Immunochem Research, Inc., 533 old Corvallis Road, Hamilton, MT). Four weeks later each received a booster injection of the same composition. Pre-bleeds of $2 \mathrm{ml}$ per rabbit were conducted prior to the first injection, and post-bleeds began two weeks after the 
first boost.

\section{Affinity purification of polyclonal antibodies}

As a preliminary purification step, antiserum was either heated to $56^{\circ} \mathrm{C}$ for 30 minutes, or run through a DEAE (diethylaminoethyl) Affi-gel Blue Gel ${ }^{T M}$ (Bio-Rad) to remove albumin and other proteins w:th dinucleotide folds. Affinity chromatography using the peptides as ligand was carried out on Affi-gel 10 according to instructions from BioRad.

First $30 \mathrm{mg}$ of ligand was dissolved in $2 \mathrm{mls}$ of $0.1 \mathrm{M}$ MOPS $\mathrm{pH}$ 7.5. Coupling to $1.3 \mathrm{ml}$ of Affi-gel 10 as allowed to proceed for $4 \mathrm{~h}$ at $4^{\circ} \mathrm{C}$ with gentle agitation. Then $300 \mu \mathrm{l}$ of $1 M$ ethanolamine $(\mathrm{pH}$ 8) was added to block unreacted sites; this proceeded under the same conditions for $1 \frac{1}{2}$ hours. The gel bed was then added to a column and washed with 15 to 25 mls of the elution solution: $0.1 \mathrm{M}$ glycine-HCl pH 2.5. Five mls of previously-heated serum was then poured through the column which was then washed with about $50 \mathrm{mls}$ PBS. The nowspecific antiserum was eluted with $2.5 \mathrm{ml} 0.1 \mathrm{M}$ Glycine-HCl $\mathrm{pH}$ 2.5 into a falcon tube containing $67 \mu \mathrm{\mu l} 1.5 \mathrm{M}$ Tris-Cl $\mathrm{pH} 8.8$ to neutralize the $\mathrm{pH}$, and dialysed against 1 litre PBS for 2 days.

Ten mls of rabbit serum was dialysed against application buffer (20mM Tris-HCl pH $8.0,25 \mathrm{mM} \mathrm{NaCl}, 0.02 \% \mathrm{NaN}_{3}$ ) for 2 days.

The DEAE Affi-Gel Blue Gel bed was prepared by washing the gel with 5 volumes of pre-wash buffer $(0.1 \mathrm{M}$ acetic acid, 
1.4M Nacl, $40 \%$ isopropanol) followed by 10 volumes of application buffer $(0.02 \mathrm{M}$ Tris-Cl pH $8.0,0.025 \mathrm{M} \mathrm{NaCl}, 0.02 \%$ $\mathrm{NaN}_{3}$ ), then transferring it to the column. Once in the column, it was eluted with 3 volumes (105 $\mathrm{ml})$ of application buffer, after which $13 \mathrm{mls}$ of serum was added. The gel was then eluted with 3 more volumes of application buffer which were collected in $10 \mathrm{ml}$ fractions and tested for light absorbance at 260 and $280 \mathrm{~nm}$ to monitor the progress of the elution. The first $50 \mathrm{mls}$ was then passed through the secondepitope coupled column. This column was washed with PBS and eluted with $2.5 \mathrm{mls} 0.1 \mathrm{M}$ Glycine-HCl $\mathrm{pH} 2.5$ as above. The eluate was neutraiized and dialysed against PBS.

Unfortunately, the preliminary Glycine-HCl wash of the RANRDTAAQIL column was mistakenly omitted so the final eluate may have contained uncoupled ligand as well as antibodies. However the early results (including dot blots) of this preparation were more promising than those using the antisera derived from the KEEKEWAAAKMDP peptide, so the former was used in the western analyses presented here.

The DEAE Affi-Gel Blue Gel TM column was regenerated with 2 volumes of regeneration buffer (2M guanidine $\mathrm{HCl}$ in application buffer) followed by 3 volumes of application buffer. 


\section{Methods for Phenotypic Analysis}

\section{Nuclear and germling staining}

Conidia were obtained from slant cultures grown 10 days to 3 weeks by adding 1 to $2 \mathrm{ml} \mathrm{dH}_{2} \mathrm{O}$ to the slant and vortexing to loosen conidia from the culture. The resulting suspensions were kept refrigerated in eppendorfs for up to 2 weeks. For nuclear staining, $60 \mu \mathrm{L}$ of settled conidia were mixed with $500 \mathrm{~mL}$ PBS then sp'dn very briefly (about a second) in a microcentrifuge. The supernatant was poured off and $20 \mu 1$ of $10 \mu \mathrm{g} / \mathrm{ml}$ DAPI was added to the roughly $20 \mu l$ remaining. The mixture was allowed to incubate at room temperature for 10-15 minutes, then spun again as briefly, tipped to pour off the supernatant which was replaced with $500 \mathrm{~mL} \mathrm{dH}_{2} \mathrm{O}$ to wash the conidia. After a final brief spin the supernatant was poured off and about $6 \mu l$ was smeared onto a slide in two smears. To each smear about $10 \mu l$ of $90 \%$ glycerol was added and a coverslip dropped on top and sealed with nail polish. For septal staining $10 \mu \mathrm{l}$ of a $10 \mu \mathrm{g} / \mathrm{ml}$ stock solution of calcofluor was added prior to applying the coverslip.

Conidia were inoculated onto slides smeared with two drops of liquid VMM (about $20 \mu l$ per drop) and left at room temperature to incubate for 4 to 5 hours ( $3 \mathrm{~h}$ for wild-type). Dessication was prevented by keeping the slides on moist filter paper in petri dishes. After incubation the smears were carefully washed by pipetting about 100-500 $\mu 1$ of PBS onto the slide and then pipetting or wicking it off with torn 
filter paper. Ten microlitres of $10 \mu \mathrm{g} / \mathrm{ml}$ DAPI was then added to each smear, left to incubate 10-20 minutes, this rinsed off with $\mathrm{dH}_{2} \mathrm{O}$ in the same manner as the PBS rinse. Cover slips were affixed with $10 \mu 1$ of $90 \%$ glycerol and sealed with nail polish.

The slides were viewed on a Zeiss microscope equipped with a mercury burner. 


\section{Results}

\section{The ro-4 wild-type sequence}

\section{a) Bequencing of ro-4 oDNA for deterwination of intron} positions:

It was necessary to amplify ro-4 cDNA directly from a $N$. crassa cDNA pool in order to perform sequencing reavtions, as previous attempts to obtain a ro-4 cDNA clone by screening three different cDNA libraries had failed (Robb, and Vierula, personal communications). Amplification of ro-4 cDNA was achieved using the Polymerase chain Reaction and a total cDNA pool The primer pair ro4h and ro4d yielded a product just over Ikb (the expected size for that region) which hybridized strongly with the E2 probe (see Figure 3 and Table 2 for location of primers and probes). The primer pair ro4h and ro4g yielded a slightly larger product when WT genomic DNA was used as template, than when WT CDNA was used. Both products bound the $\mathrm{E} 2$ probe in Southern blots.

The product was sequenced using circumvert cycle Sequencing to establish the positions of the three introns in the ro-4 gene by comparison with the genomic sequence. The successful primers were situated between 300 and 500 bp upstream of each intron. The comparison confirmed that the introns began and ended where Robb (1993) had postulated (Figures 2 and 3 ). The introns do not interrupt any major secondary structures (Fighre 2). 
Figure 2. Comparison of amino acid sequence between Arp1s: Approximate binding sites for calcium ion (c), nucleotide ( $n$ ), actin (a) and myosin (m) are noted below each comparison block, as are secondary structure features or $\alpha$-helices and bstrands (with refersnce to $\alpha$-actin, Weber and Kabsch, 1994). The sequences are: ro-4 (ro4, Robb, 1993), actin-related protein vertebrate (rpv, Lees-Miller et al.,1992b), the veast actin-related protein 5 (ac5, Muhua et al.,1994), Drosophila Actr87c (D87, Fyrberg et al.,1994) and Aspergillus gamma actin (Asg, Fidel et al.,1988). Similar residues conserved across the four Arpis are given in bold. The five residues at which ro-4 differ's from the other three Arpls are underlined. The 11 and 13 amino acid regions printed in italics are the two peptides against which antibudies were raised.

The last residice of each exon of ro-4 is marked with ",". 
rO4 M.T. . DS . . LHNAPIVLDNGSGTIRAGFAGDDVPKCHFPSFVGRPRHLRVLAGALEGE YPV MESY.DV . . IANQPVVIDNGSGVIRAGFAGDQIPKYCFPNYVGRPRHVRVMAGALEGD AC5 MDQLSDSYALYNQPVVIDNGSGIIKAGFSGEERPKALEYCLVGNTKYDKVKLEGLOGD D87 MEPY. DV . VV . NQPVVIVIGSGVIRAGFAGEHIPRCRFPNYRGRPRHVRVMAGALEGD ASg ME. . . EF . . . VAALVIDNGSGMCKAGPAGDDAPRAVFPSIVGRPRHH . . . . GIMIG.

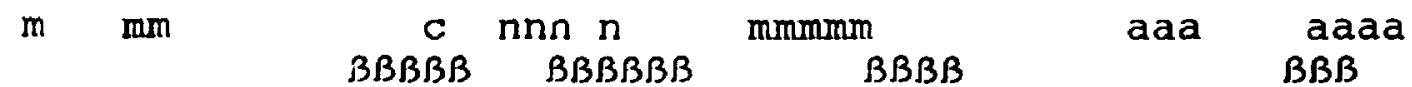

rO4 VFIGQK. . . A. . ASELRGLLKIRYPLEHGIVTDWDDKEKIWAYVY. . D. EGLKTLSE rPV IFIGPK. . . . . . AEEHRGLLSIRYPMEHGIVKDWNDMERIWQYVYSKD . . QLQTFSE AC5 TFIGN' . . . . . . AQKLRGLLKLRYPIKHGVVEDWDSKELIWSYVL. NEVLQLQNIG. D87 IFVGPK. . . . . . AEEHRGILSIRYPKEHGIVTDWNDYERIWSYIYSKA. . QIATFTE ASg . . KGQKDSYVGDEAQSKRGIL'TLRYPIEHGVVTNWDDMEKIWHHTFYNELRVAPE . . . $B \beta$ maa $\quad \alpha \alpha \alpha \alpha \alpha \alpha \alpha \alpha \alpha \alpha \alpha \alpha \alpha \mathrm{mmm}$

rO4 EHPVLL . TEPPLNPRANRDTAAQI LFETFNVPALYT SIQAVLSLYASGRTTGVVLDSG rPV EHPVLL. TEAPLWPRKARERAAEVFFETFNVPALF I SMQAVLSL YATGRTTGVVLDSG ac5 EHP. LL ITEAPMONLLAREQMAQVLFETFDVSAL YVSNPAVLSLXASGRTTGCVVDLG d87 DHPVLL. TEAPLWPRRIREKAAEFFFEGINAPALFVSMQAVLSLYATGRVT . VVLDSG asp EHPVLL . TEAPINPKSNREKMTQIVFETFNVPAFYVSIQAVLSLYASGRTTGIVLDSG aaa

C
$B B B \quad B B$
$\alpha \alpha \alpha \alpha \alpha \alpha \alpha \alpha \alpha \alpha \alpha \alpha \alpha \alpha$
$\beta B \beta B B B \alpha \alpha \alpha \alpha \alpha \alpha \alpha \alpha$
$B B \beta B B B$

rO4 DGVSHAVPVYQGFTVPNSIRRIDVAGRDVTEYLQTLL . RKS . GYVFHTSAEKEIVRLI rPI DGVTHAVPIYEGFAMPHSIMRIDIAGRDVSRFLRLYL.RKE. GYDFHSSSEFEIVRAI 3C5 EGYCSTVPI YDGFALPASYMRYDIGGADITEQLQFQL . RKSAGVSLFSSSEREIVRTM D87 DGVTHAVPIYEGF AMPHSIMRVDIAGRDVTRYLKT. LIFRE. GFNFRSTAEFEIVRSI asp DGVTHVVPIYEGFALPHAISRVDMAGRDLTDYLMKILAFR . . GYTFSTTAEREIVRDI nnn aaaaaaa $B B B B B B B$

$\alpha \alpha \alpha \alpha \alpha \alpha \alpha \alpha \alpha \alpha \alpha \alpha \alpha$

aa a aaaaa $\alpha \alpha \alpha \alpha \alpha \alpha \alpha \alpha \alpha \alpha \alpha$

rO4 KESVTYVAHDPRKEEKEWAAAKMDPAKIAEYVLPDGNKLKIGAERPRAPEILFDPEII rPV RERACYLSINPQRDE. . TL . . . . ETEK. AQVYLPDGSTIEIGPSRFRAPELLFRPDLI aC5 KE. VCYLAKNIKREEEKYLQGTQDL. . ISTFKLPDGRCIEVGNDRYRAPEILFSPQII D87 REKVCYLATNPQREE. . TV. . . . ETEKFA. YKLPDGKIFEIGPARFRAPEAVFRPDLL asp KEKLCYVALDFEQ EIQTASQSSSLEKS. . YELPDGQVITIGNERFRAPKALFQPSVL $\mathrm{nn}$ $\alpha \alpha \alpha$ aaa $\beta \beta \beta \beta \quad \alpha \alpha \alpha \alpha \alpha \alpha \alpha \alpha \alpha \alpha$ a a

rO4 GLEYPGVHQIVVDSINRTDLDLRRULYSNIVLSGGSTLTKGFGDRLLTEVQKLAVKDM rPV GEESEGIHEVLVFAIQRSDIDLRRTLFSNIVLSGGSTLFRGFGDRLLSEVKKLAPKDV ac5 GLGYDGLSDMCMQSIWKVDLDLRKPLLSSIILSGGTTTLRGFGDRYLWDLEALTKGTS D87 GEECEGIHDVLMYSIERSDYDLRKMI YQNIVLSGGSTLFRGFGDRLLSELKKHSAKDL asp GLESGGIHVTTFNSIIRCDVDVRKDLYGNIVMSGGTTMYPGISDRMQKEITALAPSSM ata aaaaa nnnnn aaa

$$
\text { BBBB } \quad \alpha \alpha \alpha \alpha \alpha \alpha \alpha \alpha \alpha \alpha
$$

TO4 RIKIFAPP ERKYSTWIGGSILAGLS'دFRḰ'MVIDDDWHENPDI . I . HTK . FT IPV RIRISAPQERLYSTWIGGSILASLDTFKRMNVSKKEYEEDGARSI . HRKTF

aC5 RIKIIAPSERKYTTWIGGSILTGLSTFQRLWTKKSDWLEDSTKVYSNLM D87 KIRIAAPQERLYSTWMGGSILASLDTFKRM ISKREYEEEGQK . AVHRKTF ASg KVIII APPERKY EVIIGGSILASLSTFQQMWI SKQEYDE . SGPSIVHRKCF $B B$ $\mathrm{mm}$ $\mathrm{n}$ mmmmm $\alpha \alpha \alpha \alpha \alpha \alpha \alpha$ 


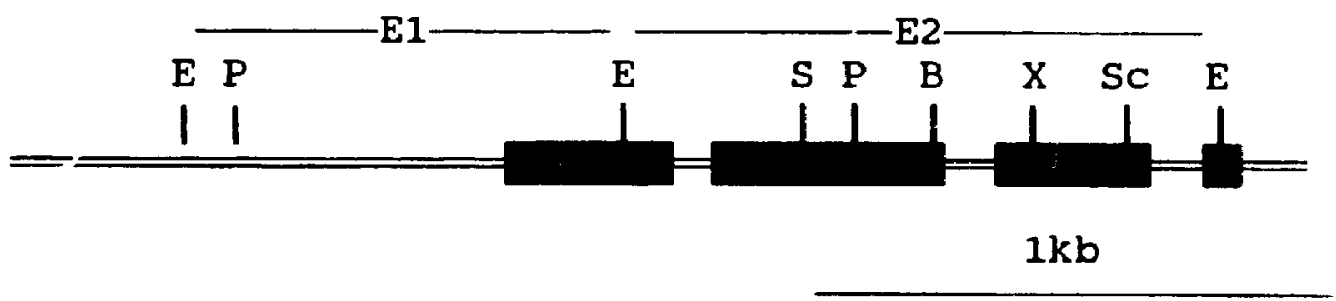

Figure 3. Map of the ro-4 gene: There are four exons at. positions $1 \rightarrow 308,393 \rightarrow 848,943 \rightarrow 1257$ and $1358 \rightarrow 1417$. The cutting sites of the restriction enzymes EcoRV (E), PstI (P), SphI (S), BamHI (B), XhoI (X) and ScaI (SC) are as marked. The segments $E 1$ and $E 2$ are restriction fragments produced by ECORV. In addition the region is bounded by an lipstream SmaI site and a BglII site downstream, roughly $1.6 \mathrm{ko}$ from the end of the coding region. 
The translation initiation start site diverges from consensus for $N$. crassa at only 3 of 10 bases. The 5'-intron donor sites and $3^{\prime}$ acceptor sites agree with consensus at $76 \%$ and $67 \%$ of nucleotides respectively, across the th-ee introns (Figure 4). In contrast the internal branchpoints of the introns agree closely $(90 \%)$ with the consensus.

b) Comparison of ro-4 amino acid sequence with other Arp1s Using the similarity criteria of Lees-Miller et al. (1992a), the five residues at which ro-4 differs from the other Arpls (Figure 2) are also different from analagous residues in $\alpha$ - and $\beta$-centractin (Clark et al., 1994), Schizosaccharomyces pombe act2 (=Arp3, Lees-Miller et al, 1992a), Saccharomyces cerevisiae ACT2 (=Arp2, Schwob and Martin, 1992), both Arp2* and Arp3 from Acanthamoeba castellani (Kelleher et al., 1995), Saccharomyces cerevisiae $\mathrm{ACJ}^{\prime}$ * (in Harata et al.,1994), Drosophila melanogaster actinrelated proteins Act5C, Act53D, Actr14D and Actr66B (in addition to Actr87C shown in the comparison, Fyrberg et al., 1994 ) and major actins from Oxytricha nova, Tetrahymera thermophila, Trypanasoma brucei*, schizosaccharomyces pombe and human cytoplasmic gamma actin (Lees-Miller et al., 1992a). Interestingly, maize major actin shares the $T_{173}$ with ro-4, and three others (marked with asterisks above) have a serine at that site. One actin-related protein which shares two of the five residues with ro-4 $\left(\mathrm{T}_{18}\right.$ and $\left.\mathrm{T}_{173}\right)$ is saccharomyces cerevisiae ACT3, which is the most distantly related of actin- 
Figure 4: Sequence features eir the ro-4 gene as compared with consensis for Neurospora crassa genes (Edelmann and staben 1994). Bold lettering designates ro-4 sequence while consensus is given in normal type. 
Consensus translation initiation site compared with that of ro4:

CAMIATGGCT

AACAATGACA $(-7$ to +6$)$

Consensus 5'-intron donor site compared to that of ros:

first intron: G^GTrCGTrCTCCCA

second intron: G^GTATGTTAAGTTT

third intron: G^GTATGTCCTCACA

ro4 consensus: G^GTWYGTYMNBHYm

G^GTAAGTnNYCnYY

Consensus internal branchpoint:

first intron: AGCTAACAACGGGTCC second intron: TACTGACACCCACCAA third intron: TGCTAACAAATGTGTG

ro4 consensus: WRCTRACAMMBRBBHV

WRCTRACMnnNINnYY

Consensus 3'acceptor site:

first intron: GCTAGa second intron: cAAAGa third intron: AACAGa ro4 consensus: VARAGa WACAG^

$$
\text { where } \begin{aligned}
Y & =C, T \\
R & =A, G \\
M & =A, C \\
K & =G, T \\
W & =A, T \\
S & =G, C \\
D & =A, G, T \\
H & =A, C, T \\
V & =A, C, G \\
B & =C, G, T \\
N & =\text { any base }
\end{aligned}
$$


related proteins (Kelleher et al., 1995), yet the Arpl most closely related to ro-4, Pneumocystis carinii actinII, shares only the $\mathrm{T}_{137}$ with it (Genbank Accession data).

The lysine at position 365 (which is replaced in ro-4 by isoleucine) is conserved identically in all other proteins listed here, except $D$ melanogaster Actr53D which is only expressed in testes (Fyrberg et al., 1993), and Pneumocystis carinii actinII. The first four residues $(18,137,170$ and 173) are similar to actin-rpv in $61 \%, 100 \%, 96 \%$ and $56 \%$ of proteins listed above. All five of these sites reside in the same quadrant of the three-dimensional structure at which the carboxy and amino termini are located, both of which are also relatively unconserved in ro-4 (Figure 2). The proposed binding sites of many actin-binding proteins, including myosin, are located in this quadrant (Hennessy et al .,1993).

Another feature of interest in the sequence comparison is the absence in ro-4 of the conserved peptide $R K(A, C, T) F$ at the carboxy terminus which has been proposed to determine the folding pathway by binding to a peptide in the chaperonin complex (Burns and Surridge, 1994). Chaperonin-folded actinrpv has been shown to be capable of co-polymerizing with actin filaments (Melki et al,, 1993), although Acathamoeba castellani Arps 2 and 3 display the same peptide yet are probably unable to interact with actin as more than a barbed end nucleator (Kelleher et al., 1995). A profilin binding site that is conserved in Arp2s (Kelleher et al., 1995) is 
absent from ro-4 and the other Arpls presented in Figure 2. sequencing of the ro-4 mutant allele:

The strain 2980 is a uv-induced mutant whose mutation was mapped to a loclis designated ro-4 (Garnjobst and Tatum, 1967, Appendix I). It was desirable to obtain the sequence for this allele in order to gain insight into how the mutated protein gives rise to the mutant phenotype.

Genomic DNA from this strain was cut into two ro-4 fragments which were cloned into the Bluescript TM plasmid and sequenced.

The strain 2980 was found to contain a single deletion (Figure 5) within the first exon of the gene. The remainder of the coding region of the gene was found to be identical to the wild-type sequence. To confirm this result, a PCR was carried out using freshly prepared 2980 DNA as template and the region of the deletion was then sequenced using circumvent ${ }^{T M}$ Cycle sequencing.

The result of this deletion is a frameshift mutation which codes for several mis-sense amino acids and then a premature termination codon (Figure 6). If translated, the mutant protein would be only $8.2 \mathrm{kD}$ in size.

Restriction fragment length polymorphism analysis of ro-4 mutant strains:

The three ro-4 mutant strains were expected to have single point mutations as a result of uv-irradiation. This 
Figure 5. The ro-4 mutant has a single base-pair deletion: The sequence on the left is that of the $N$. crassa ro-4 mutant 2980 , the corresponding region of wild-type sequence is on the right. The arrow marks the position of the adenine deletion in the ro-4 mutant. Above (downstream of) the deletion the mutant sequence is frame-shifted relative to wild-type. 


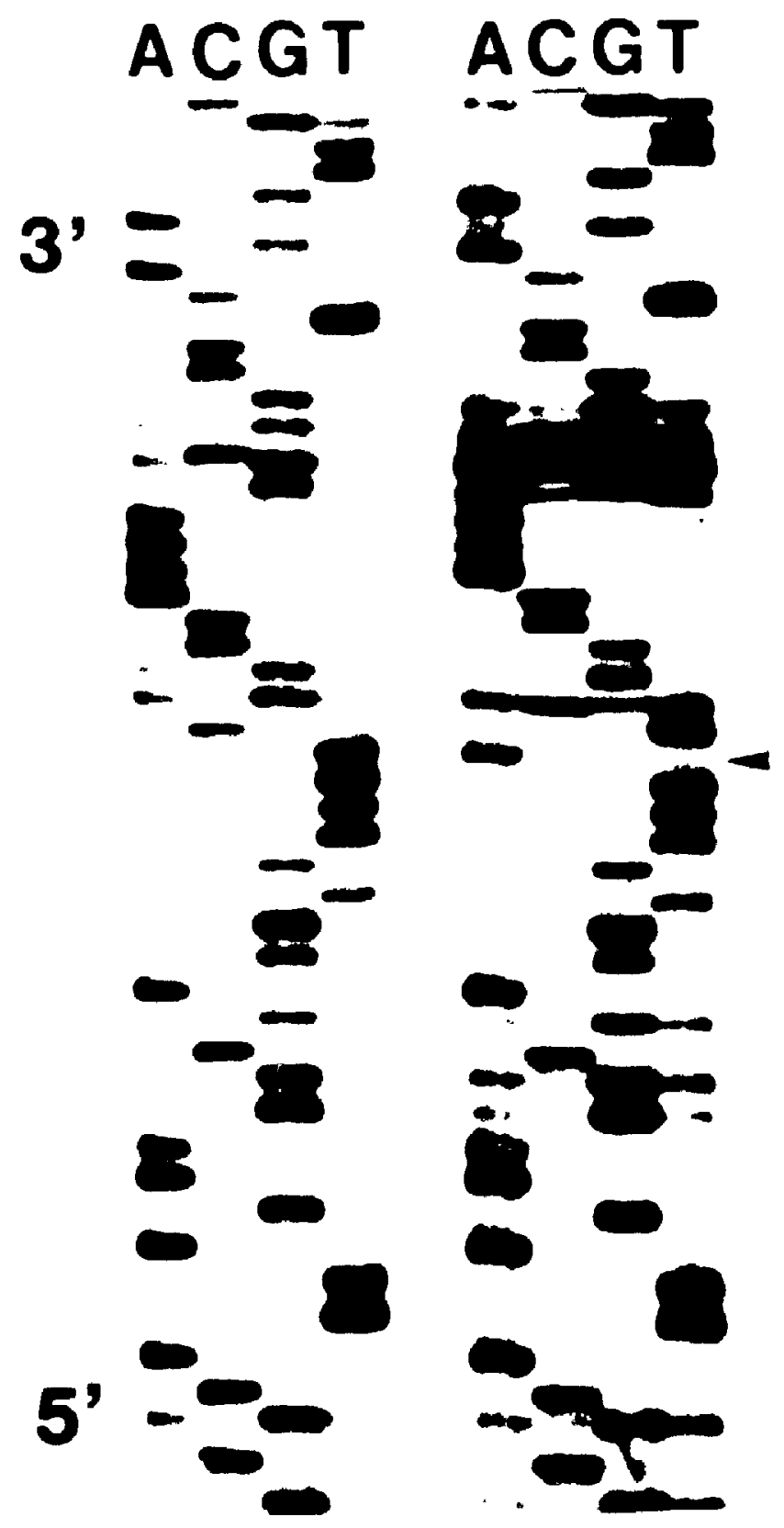


Figure 6. Putative amino acid sequence of the ro-4 mutant: The nucleotide sequence of the first exon and part of the first intron of ro-4 is presented, followed by the amino acid sequence of the wild-type (in bold) and mutant (in normal type) The prematurely terminated ro-4 sequence codes for a mutant protein of 78 amino acids and $8.2 \mathrm{kD}$ molecular weight, compared to the wild type protein of 380 amino acids and roughly $42.8 \mathrm{kD}$ weight.

* site of mutation 
ATG ACA GAC TCT TTG CAC AAC GCG CCC ATT GTG CTC GAC AAT

GGC TCG GGC ACC ATT CGC GCC GGC TTC GCG GGA GAC GAC GTA CCA

AAA TGC CAC TTC CCC TCC TTC GTA GGG AGG CCA AAG CAC CTA CGA

GTG CTG GCC GGC GCA TTA GAA GGC GAG GTG TTT ATC GGC CAA AAg

GCG GCC TCA GAG TTG CGC GGA CTG CTC AAG ATC CGA TAT CCG CTG

GAG CAC GGC ATC GTG ACG GAT TGG GAC GAT ATG GAG AAg ATT TGG

GCA TAT GTA TAC GAT GAG GGG TTG AAG ACG CTC AGT GAA GAG

GTTCGTTCTCCCATATTCTTTTGGTCAGAACAAGACAAAAAAAAAAAAAAAAAAGCGGTA

MTDSLHNAPIVLDNGSGTIRAGFAGDDVPKCHFPSFVGRPKHLRVLAGALEGEVFSANRRPQ MTDSLELAPIVLDNG8GTIRAGPAGDDVPKCHPPSFVGRPKHIRVLAGALEGEVFIGQKAAS SCADCSRSDIRWSTAS

ELRGLLKIRYPLEAG IVTDWDKEKIWAYVYDEGLKTLSE EHPVLLTEPPLNPRANRDTAAQ ILFETFNVPAL YTSIQAVLSLYASGRTYGVVLDSGDGVSHAVPVYQGFTVPNSIRRIDVAGR DVTEYLQTLLRKSGYVFHTSAEREIVRLIKESVTYVAFDPRKEERETAAAKIDPARIAEYVL PDGNKLKIGAERFRAPEILFDPEIIGLEYPGVHQIVVDSINRTDLDLRRDLYSNIVLSGGST LTKGFGDRLLTEVQRIAVKDYRIRIFAPPERKYSTWIGGSILAGLSTFRKWNVIDDWHENP DIIBTRET 
was tested by southern analysis of restriction fragments generated by four restriction enzymes, in the wild-type and three mutants. Although this will not prove the existence of a point mutation it can demonstrate that no major deletions or infertions are present.

The fragments produced by four restriction enzymes known to have sites within the gene were probed first with the E2 probe (see Figure 3) to reveal changes within the coding region, and secondly with a $4.3 \mathrm{~kb}$ probe (from the cosmid originally used to transform ro-4) which recognizes the surrounding sequence.

The fragment produced by the enzyme ECORV spans $90 \%$ of the coding region of the gene and migrates the same distance in all four strains (Figure 7, upper panel, Table 3) indicating the absence of major deletions or insertions within this region. Within this $90 \%$, the strains 1529 and 2980 are similar to wild-type in their pattern of restriction fragments (Figure 7, Table 3). The strain 1511 differs in the fragments produced by PstI, ScaI and XhoI, however in each case one fragment is shared with the other strains and thus at least two recognition sites are probably undisturbed. (The pattern of fragments produced by digestion of wild-type DNA with ScaI can be deduced from the results shown in the lower panel.)

When a larger probe was used, again it was seen that at least one fragment was shared across all strains, however differences (from wild-type) existed in fragments from 1529 
Figure 7. Restriction fragment length polymorphism analysis: Genomic DNA of the strains WT (a), 1511 (b), 1529 (c) and 2980 (d) was digested with each of the following enzymes: ECoRV (E), PstI (P), ScaI (S) and XhoI (X). The probe used in the upper panel was an E2 fragment which includes $90 \%$ of the coding region of the ro-4 gene. The lower panel was probed with a $4.3 \mathrm{~kb}$ fragment oric nating from a cosr.id clone which contains the entire gene. The size markers are $y$ iven in $k b$. The sizes of the restriction fragments are given in Tables 3 and 4 . 


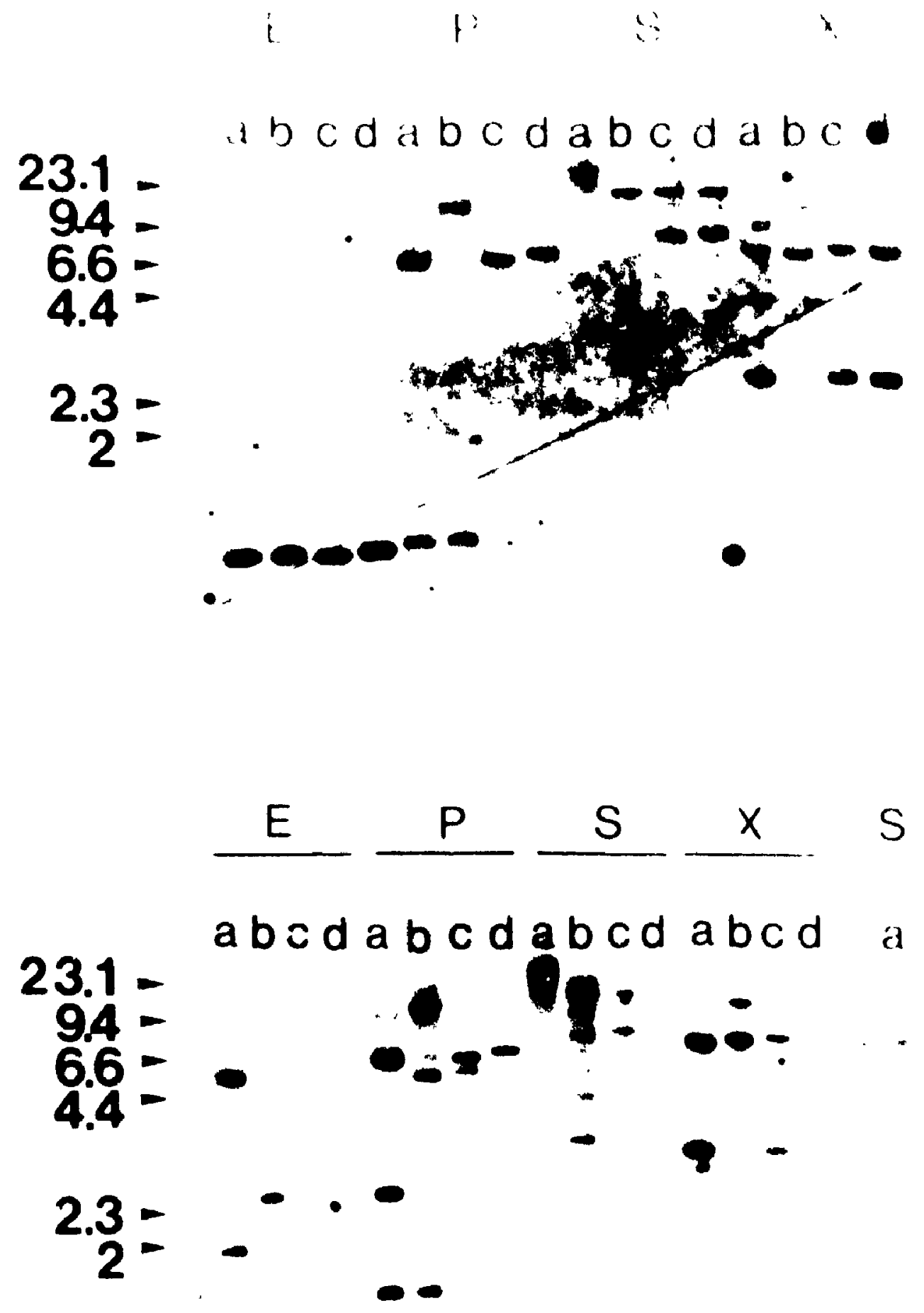


Table 3: Restriction fragments recognized by the E2 probe. Both strain 1511 ant 1529 are from a Mauriceville genetic background, while WT and 2980 are derived from St. Lawrence. The estimated sizes of fragments generated by the enzymes ECORV (E), PstI (P), SCaI (S) and XhoI (X) and detected using the E2 probe, were calculated using the DNAfrag program.

Fragments given in brackets are assumed to be undigested genomic DNA. 


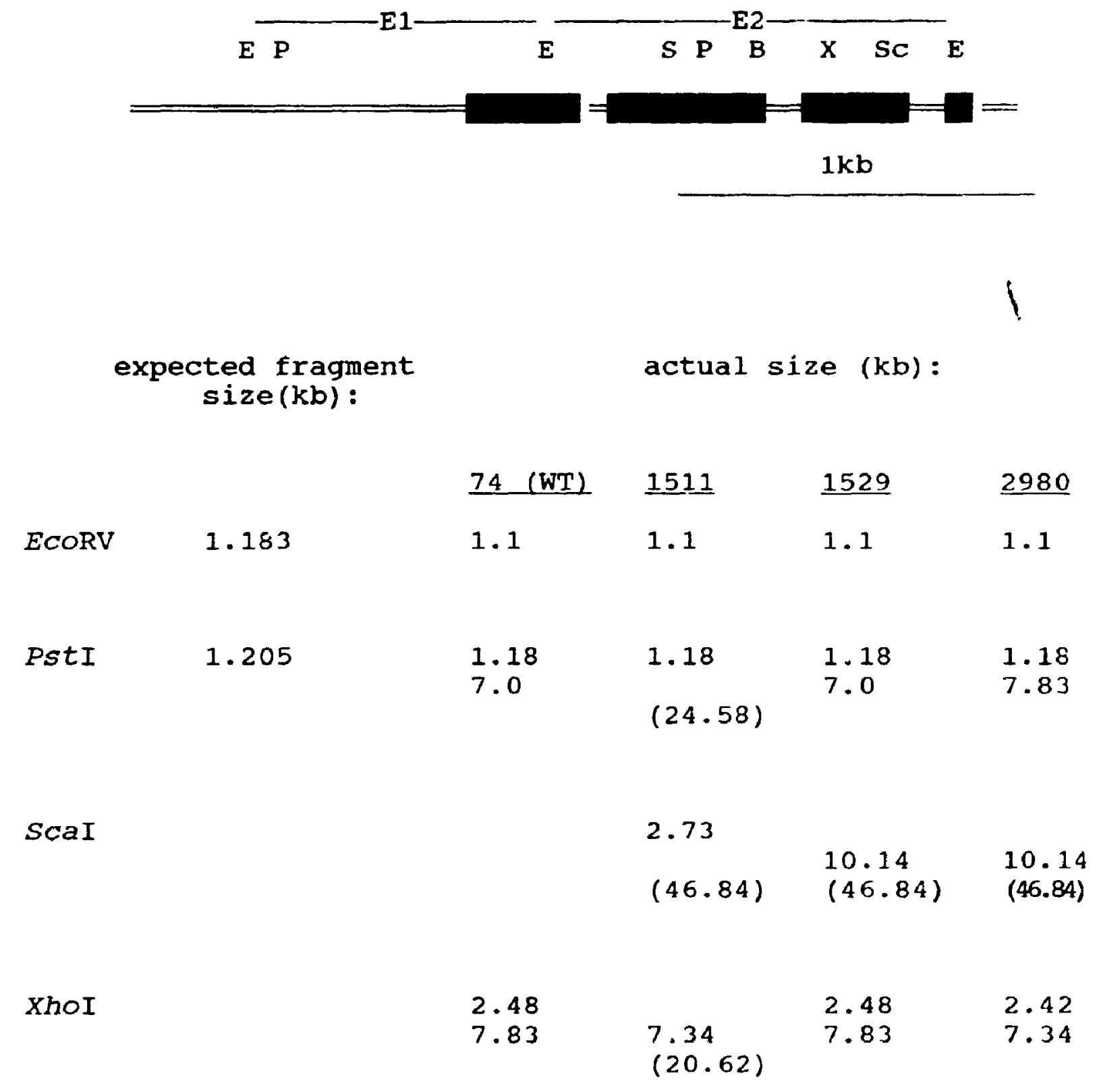


Table 4: Restriction fragments recognized by the $4.3 \mathrm{~kb}$ probe. Both strain 1511 and 1529 are from a Mauricevilie genetic background, while WT and 2980 are derived from st. Lawrence. The estimated sizes of fragments generated by the enzymes ECORV (E), PstI (P), ScäI (S) and XhoI (X) and detected using the $4.3 \mathrm{~kb}$ probe, were calculated using the DNAfrag program. Fragments given in brackets are assumed to be undigested genomic DNA. 


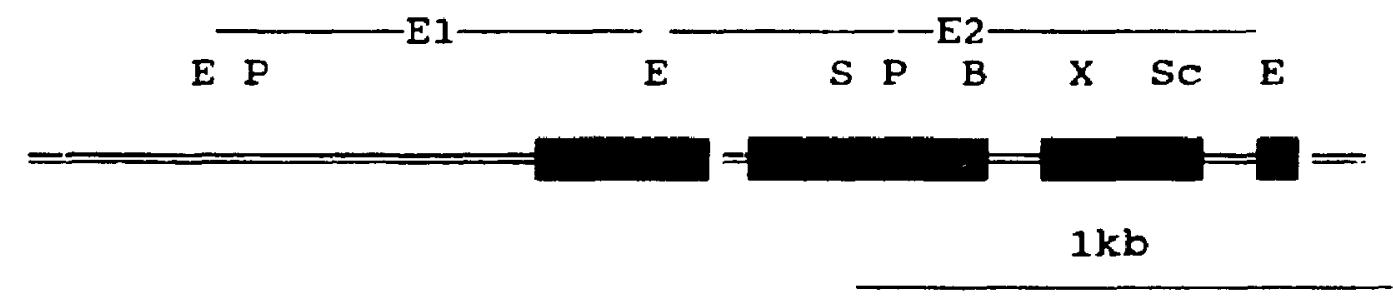

expected fragment size (kb) :

actual size $(\mathrm{kb})$ :

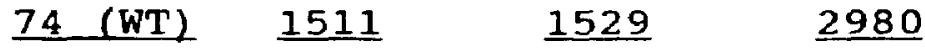

ECORV

0.923

1.08

$1 \cdot 1$

1.08

1.08

1.183

1.31

1.2

1.64

1.3

1.31

$1 \cdot 3$

1.64

1.7

2.1

4.35

4.98

4.98

5.41

PstI

1.205

1.38

2.14

1.38

1. 38

1.42

5.86

4.98

5.19

5.15

6.15

6.72

ScaI

2.93

4.06

8.39

(23.25)

8.39

(28.11)

9.46

(35.5)

10.21

(35.5)

XhoI

2.74

2.74

8.39

2.74

7.52

8. 39

(23.25)

8.39 
and especially 1511 (Figure 7, lower panel). Some of these can probably be attributed to the genetic background of these two strains, which is Mauriceville as opposed to the st. Lawrence background of wild-type.

The largest "fragments" (above $20 \mathrm{~kb}$, see Tables 3 and 4) are probably undigested DNA. All four enzymes are palindromic six base-pair cutters, so that we can predict a mean fragment size of about 5000 bp in a random sequence of nucleotides (calculated as the reciprocal of the probability of finding a restriction site: $\left.\left(\frac{3}{4}\right)^{6}\right)$. In fact the mean size of fragments binding the E2 probe is $4.36 \mathrm{~kb}$ ( \pm 3.4 ) and that of fragments binding the larger $4.3 \mathrm{~kb}$ probe (a BglII to NotI cosmid fragment) is $3.97( \pm 2.85)$.

The E2 probe did not label the $2 \mathrm{~kb}$ PstI fragment seen in the wila-type lane labelled with the $4.3 \mathrm{~kb}$ probe, suggesting that an additional PstI site near the gene is upstream of the 5' end PstI site.

The expression of ro-4

The abundance of the ro-4 mRNA was expected to be lower than wild-type in the RIP strains, yet comparable with the wild-type in strains 1511 and 1529 .

a) ro-4 mRNA levels in the wild-type and three mutant strains:

A Northern analysis was performed on polyA-enriched RNA extracted from WT, 1511, 1529, 2980, and the RIP strains R1, R2, R4 and R5. The probe used was a ro-4 antisense RNA. 
Figure 8. Northern analysis of ro-4 expression: The left panel illustrates the position of the 265 and 175 ribosomal RNAs remaining in the ethidium bromide-stained preparations of polyA-enriched RNA, as visualized on a nylon membrane by uv light. The right panel is an astoradiograph taken after the nylon membrane was probed with a ${ }^{32} \mathrm{p}-1 \mathrm{abel}$ led anti-sense RNA probe representing the E2 fragment of ro-4.

Lanes $a, b, c$ and $d$ contain mRNA extracted from the RIP strains $R 5, R 4, R 2$ and $R 1$; columns $e, f$ and $g$ represent the ro-4 mutant strains 2980, 1529 and 1511, and column $h$ is wildtype. 


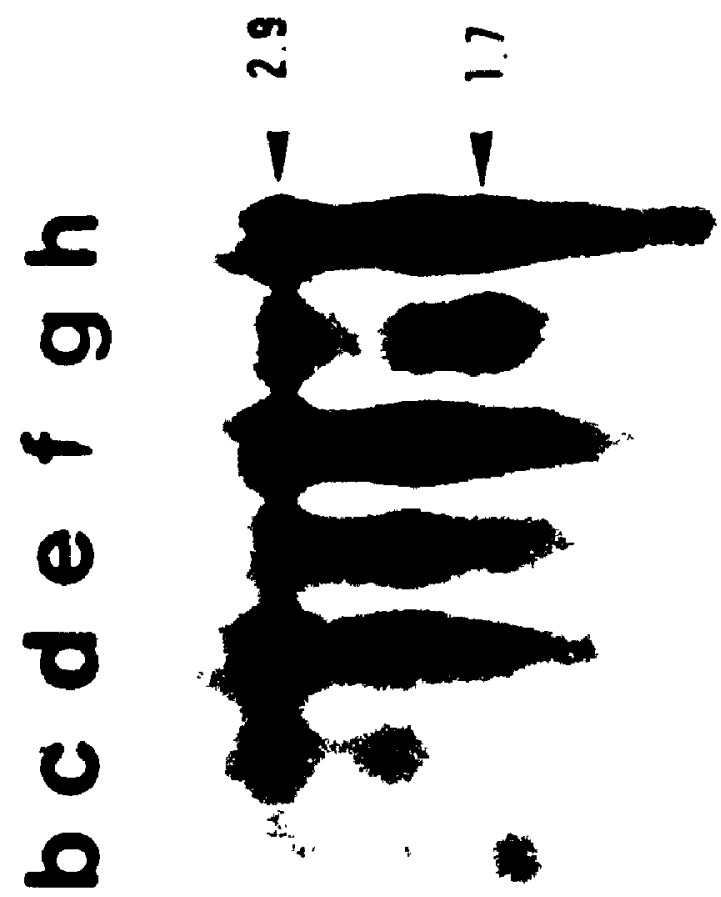

(1)

ᄃ

क)

$\div$

(1)

- 8

$\mathcal{u}$

ص

(

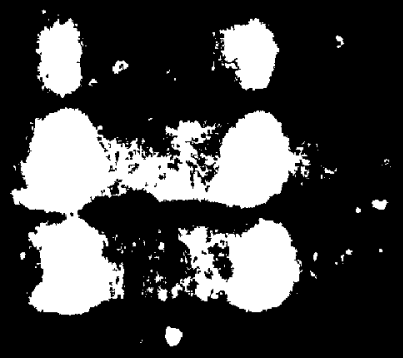


Three bands appeared in the wild-type lane on the Northern blot (Figure 8) with approximate sizes $2.9,2$ and $1.65 \mathrm{~kb}$. The two largest bands appeared in all other strains, with the possible exception of $R 1$ whose lane is smudged. However the intensity of the lowest band varied across the strains; it is extremely faint in 2980 and R5, and is absent in $\mathrm{R} 2$. The strain $\mathrm{R} 4$ has additionally a band smaller than even the smallest of wild-type. The largest of the three wild-type bands migrated at the same rate as one of two bright bands, presumed to be ribosomal RNA (26S and 175 species), which were visible on the nylon transfer (viewed under uv, Figure 8). However the intensity of the labeling did not correspond to the intensity of the ethidium bromide staining in these two bands, suggesting that the rRNA was not recognized by the probe. This is consistent witr the fact that the lower of the two bright bands seen on the nylon transfer did not appear to label at all with the probe, and is situated between the two smaller wild-type bands seen on the Northern.

b) Predicted expression level of wild-type ro-4:

The codon adaptation index (C.A.I.) was calculated for ro-4 based on a reference set of three highly expressed $N$. crassa genes (see Appendices II and III). The rusult was a value of 0.489 . This is only slightly lower than the value for the most lowly-expressed histone proteins in yeast $(0.532)$, whereas the lowest value for C.A.I. among the yeast 
genes was 0.098 and the highest was 0.929 (Sharp and Li, 1987). This suggests that ro-4 may be expected to have a moderate level of expression.

Protein analysis of the wild-type and ro-4 mutant strains Intially an antibody to conventional actin was used in Western analyses on proteins of the WT ard ro-4 mutant strains in the hope that it would recognize the RO4 protein. Although this approach yielded some interesting findings, eventually we determined to develop a more specific antibody with which to seek the RO4 protein. Ideally such an antibody would enable us to compare the size, pI and cellular location of a mutant allele with the wild-type version, and in particular confirm that the $R 04$ protein is absent in tae strain 2980, as the sequence tata suggests.

a) western analysis of total proteins from wild-type and ro-4 mutant strains with a monoclonal anti-actin antibody:

PAGE-separated total proteins of WT, 1511, 1529 and 2980 were transferred to nitrocellulose and probed with Boehringer-Mannheim monoclonal anti-actin (1 378 996) in a western analysis. Only one band was clearly labelled, of a mass consistent with actin. This band appeared in all strains except 1529 (Figure 9), though polyclonal anti-actin as well as polyclonal anti-tubulin labelled all four strains.

When the same antibody was used to probe 2-dimensional separations of total proteins, a single, elongated spot 
Figure 9. One and two-dimensional western analysis of major actin: Western analysis of the major actin in the wild-type and three ro-4 strains. A monoclonal anti-actin was used to probe one- and two-dimensional blots of total proteins (upper panel). In the lower panel the blots were probed with both the monoclorial anti-actin and a polyclonal anti-tubulin. In the 2-D blots the proteins were separated by iso-electric focusing followed by denaturing SDS PAGE. The position of the tubulin is marked with an arrow. Size markers are given in kD. 

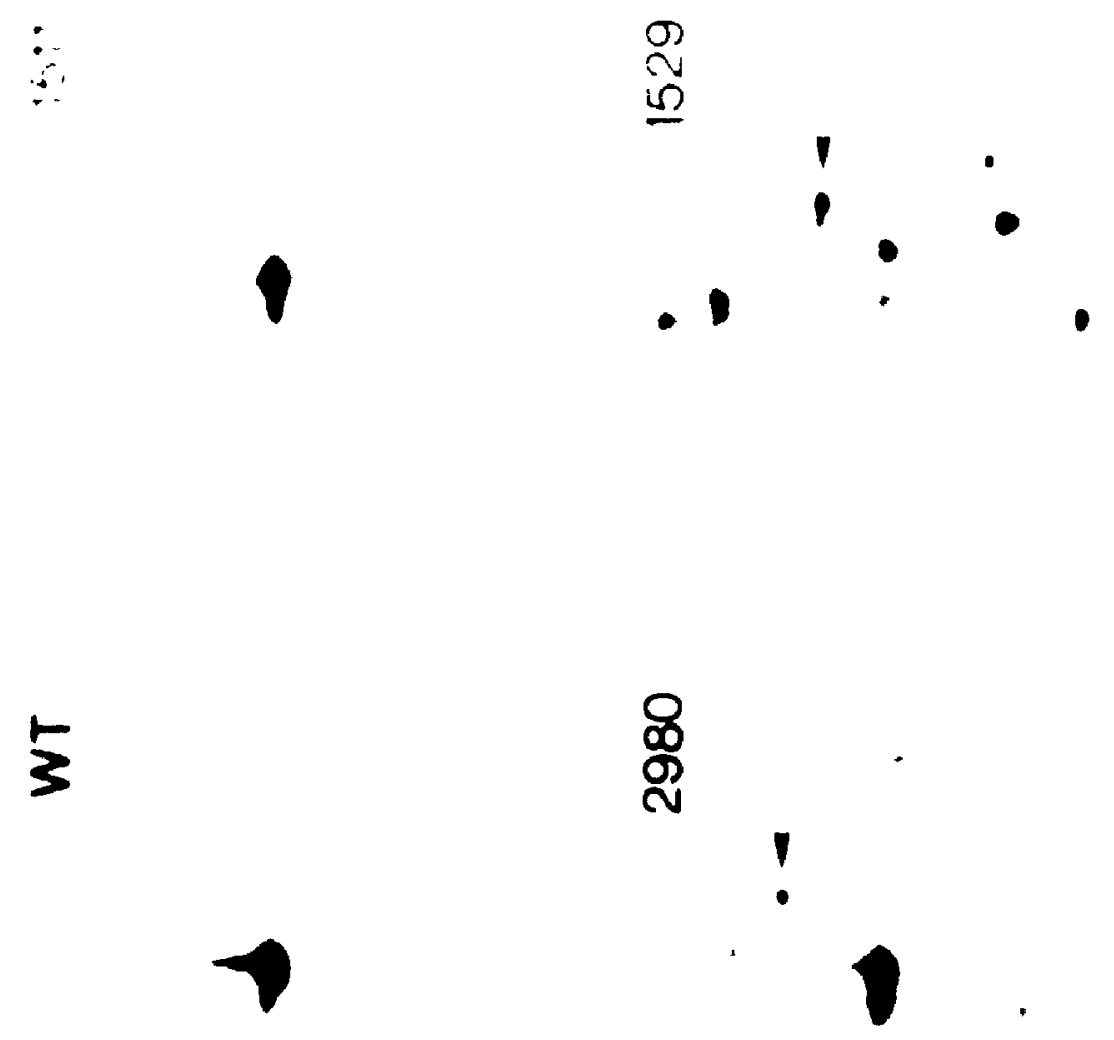

1

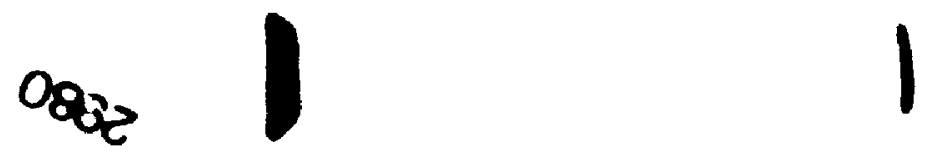

Cटs,

"s,

$\ln 1$

के

ஜ $\dot{\%}$ 
suggestive of two equal sized isoforms was labelled in WT, and could also be seen in 1511 and 2980 , but not in 1529 . This spot appeared in the centre of the blot, implying a nearneutral pI. When this antibody was combined with polyclonal anti-tubulin, another spot appeared above $t^{2} . e$ major actin and offset to the acidic side (the basic side of the gel can be identified by the dark vertical band representing the top of the tube ge1).

b) Western analysis of wild-type and ro-4 mutant strains with a RO4 antibody:

A synthetic peptide representing sequence from a region of the RO4 protein (Figure 2) was injected into rabbits to raise antibodies against $R 04$. The peptide occurred after the point of premature termination later discovered in the strain 2980 allele of ro-4. When bleeds indicated the serum could recognize dot blots containing $20-200$ ng of the antigen the rabbits were bled and the serum collected. The serum was purified against DEAE-Affigel Blue Gel and against the antigen coupled to Affi-gel in an affinity column.

since serum commonly contains antibodies against actin (unpublished results, Pollard, pers.comm.) it was necessary to probe blots of separated proteins with both pre-immune serum and with immune serum, and compare the results. Proteins that are only labelled in the immune serum are more likely to exhjbit the epitope against which the antibody was raised.

Using immune serum to probe a blot of wild-type and ro-4 
mutants (10 $\mu \mathrm{g}$ total protein per lane), two bands unique to the immune vs the pre-immune and having a mass estimated by the program BANDSIZE at 41.6 and $40.3 \mathrm{kD}$ were seen (Figure 10a). The lower of these two bands occurred only in the wildtype and strains 1511 and 1529 (the pattern expected of RO4), whereas the upper appeared across ali lanes. When I attempted to repeat this result (Figure 10b), the two bands were estimated at 42.3 and $40.4 \mathrm{kD}$ and both appeared across all strains, though the lower was faint in 2980 and the RIP strains. Although the latter migrated at the same distance as a protein labelled faintly by the pre-imm'dne serum, this could merely be due to the similarity between the major actin (to which many animals harbour antibodies) and RO4.

\section{c) SDB PAGE and Western analysis of degraded wild-type} proteins:

To determine if degradation of protein extracts was playing a role in the lower molecular weight bands seen in the blots probed with immune serum, wild-type protein extracts were subjected to varying degrees of degradative conditions, then separated by PAGE and probed with pre-immune and immune sera. Although the silver-stained gel revealed the disappearance with time (more pronounced in the absence of protease inhibitors) of a protein of the same $M W$ as artin (Figure 11), no difference was seen between the degradation conditions in the resulting western analysis probed with either pre-immune serum or anti-RO4 antibody (Figure 12). 
Figure 10a. Western aralysis using RO4 antibocies, trj il 1: Both panels are western analyses detected by the chemiluminescent method, and contain separatrd total proteins (10 $\mathrm{\mu g}$ per lane) from the wiid-type, the three ro-4 strains and four ro-4 RIP strains. The left panel was proved rith pre-immune serum while the right was probed with serum from the same rabbit after it had been immunized with a ro- 4 peptide. This serun was purified auginst DEAE Affi-gel and by affinity chromatography with the peptide itself.

The positions of molecular waight markers are given in kD. The two bands marked with arrows are estimated to be 41.6 and $40.3 \mathrm{kD}$ by the BANDSIZE program. 

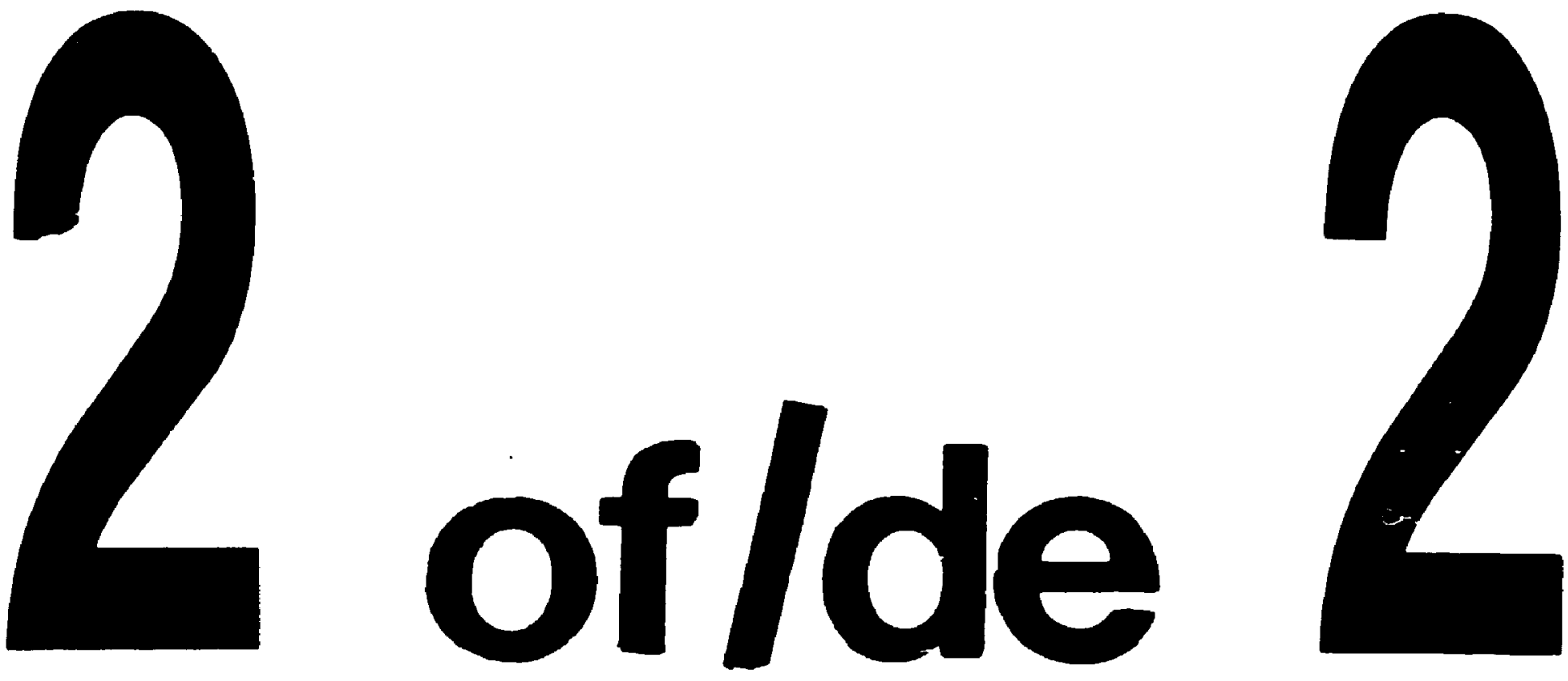

Ph:-1 31/2"X4" PHOTOGRAPHIC MICROCOPY TARGET NBS 1010a ANSI/ISO \#2 EQUIVALENT

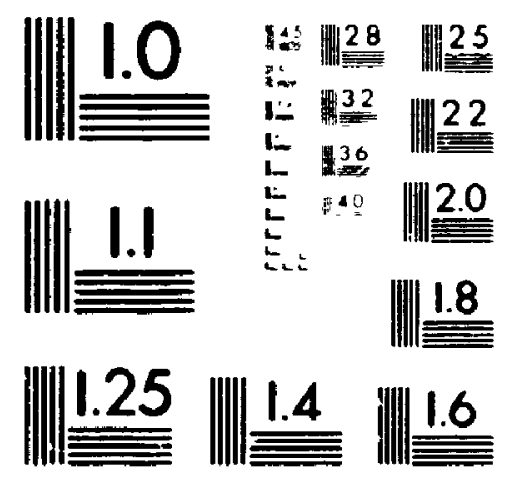

PRECISIONSM RESOLUTION TARGETS 


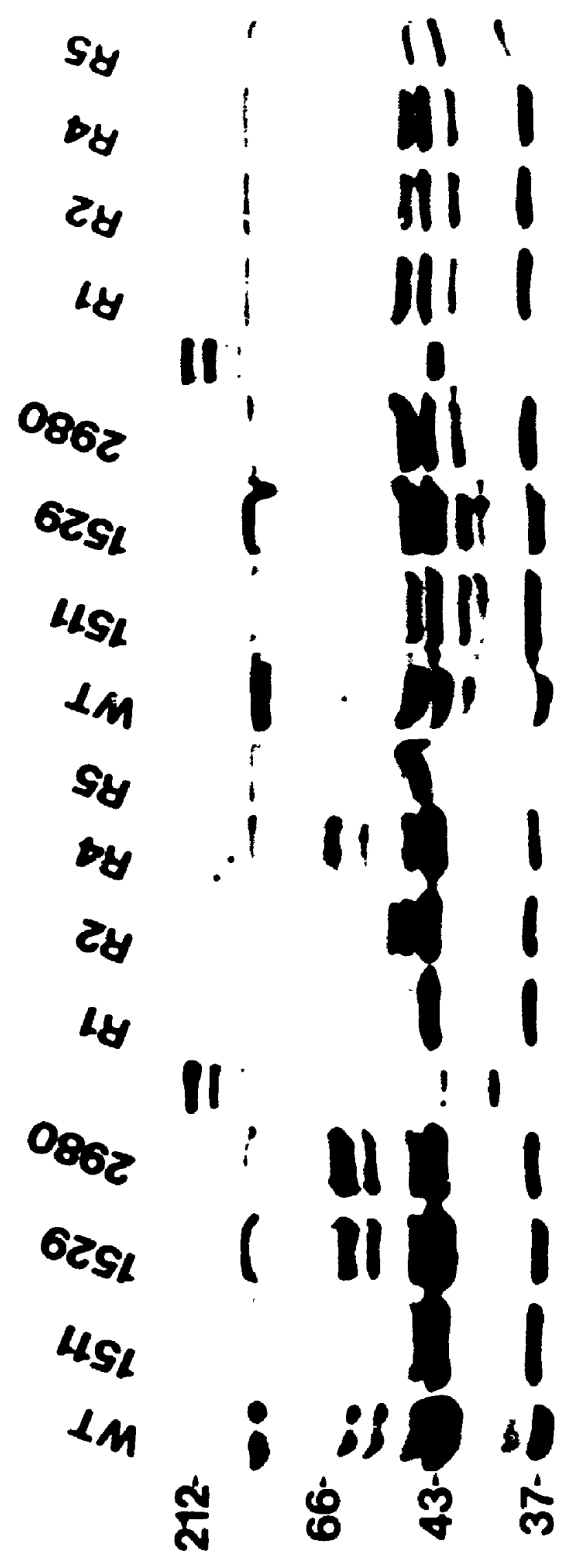


Figure 10b. Western analysis using RO4 antibodies, trial 2: Both panels are western analyses detected by the chemiluminescent method, and contain separated total proteins (10 $\mathrm{kg}$ per lane) from the wild-type, the three ro-4 strains and four ro-4 RIP straiiss. The left panel was probed with pre-immune serum while the right was probed with serum from the same rabbit after it had been immunized with a ro-4 peptide. This serum was purified against DEAE Affi-gel and by affinity chromatography with the peptide itself.

The positions of molecular weight markers are given in kD. The two bands marked with arrows are estimated to be 42.4 and $40.4 \mathrm{kD}$. 


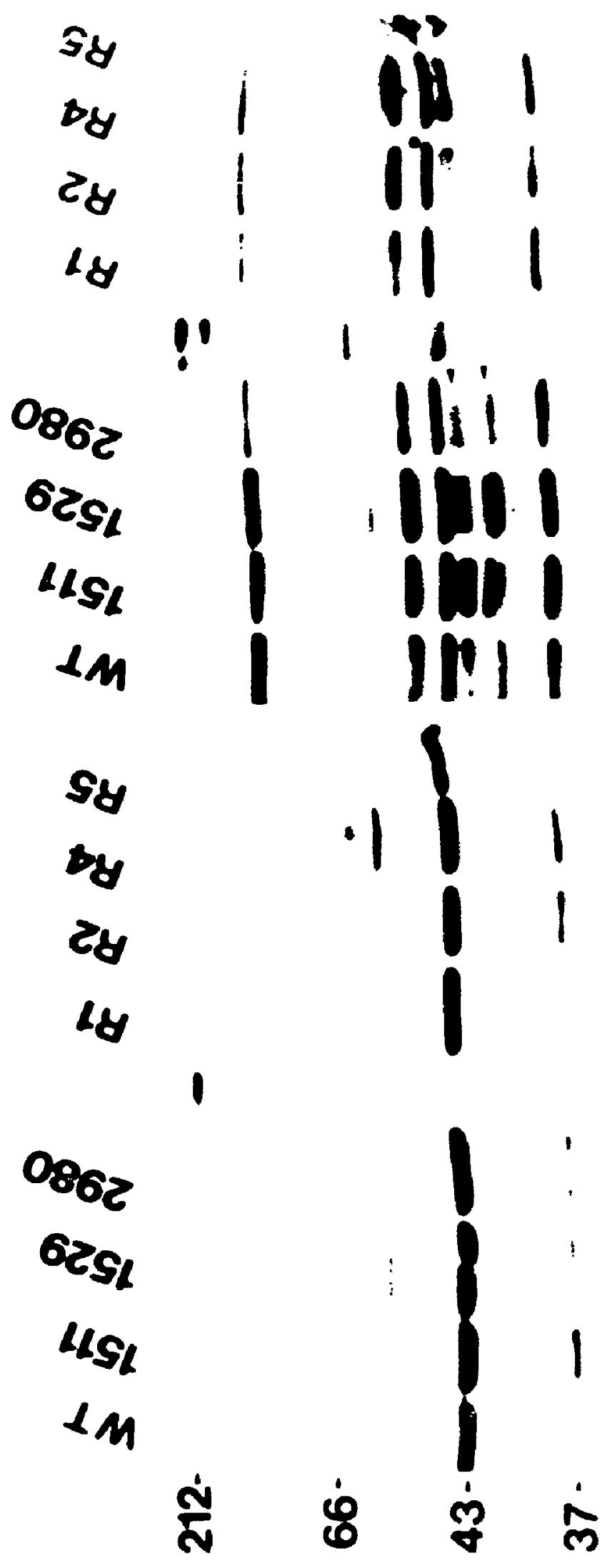


Figure 11. Silver-stained gel of degraded proteins: Proteins of the WT $N$.crassa were extracted in either TE with protease inhibitors, or TE with no inhibitors, and allowed to sit at roor temperature (or $37^{\circ} \mathrm{C}$ in one of the $2^{\circ}$ hour treatments) for between 0 and 24 hours before being loaded into an SDS polyacrylamide gel. The size markers are given in kD. 
ath inhibitors

110 $1114110 ! ?$

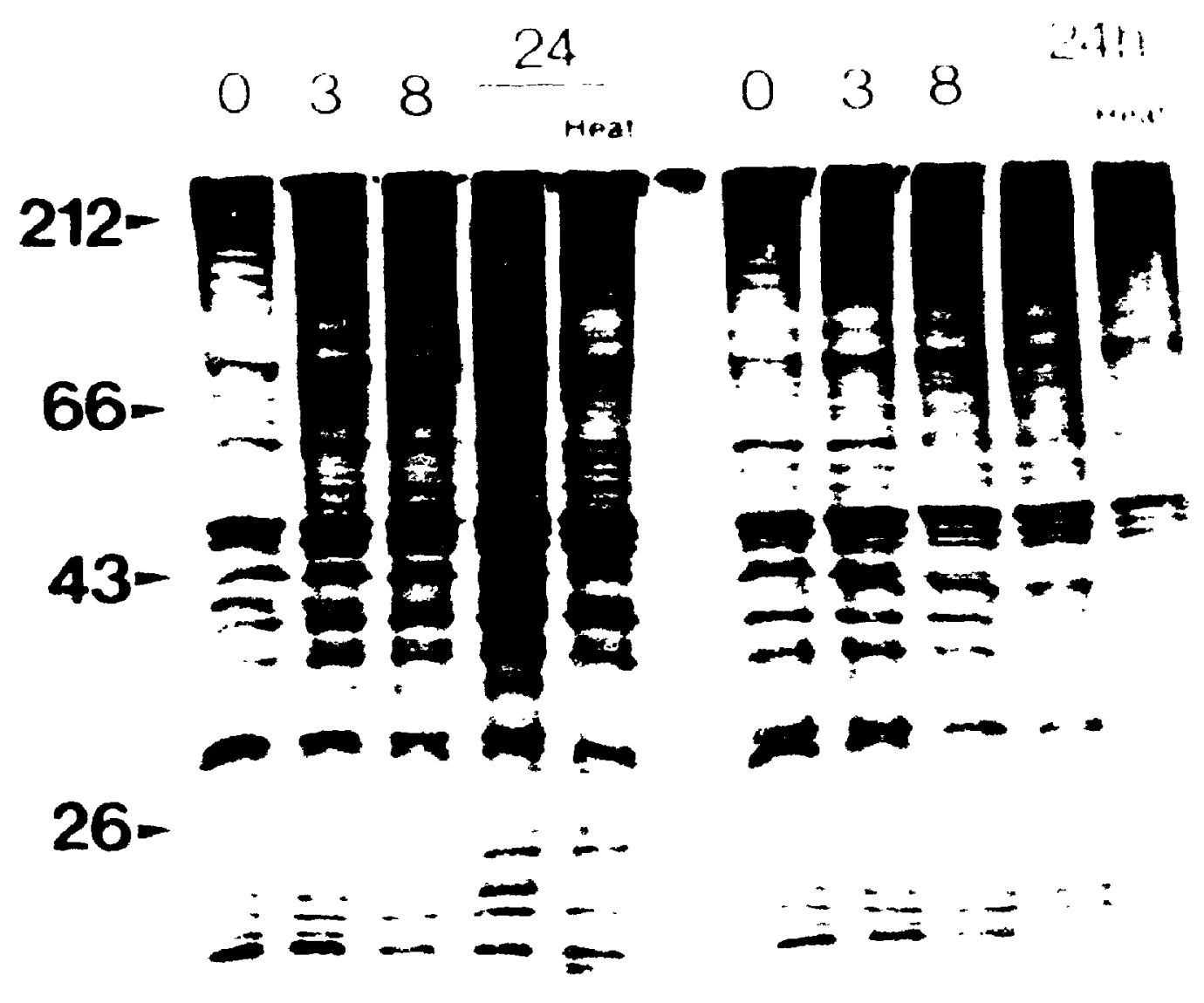


Figure 12. Western analysis of degraded proteins. Proteins from the gel shown in Figure 11 were transferred to nitrocellulose and probed with pre-immune (left panel) or immune (right panel) serum raised against a $R O 4$ peptide. The size markers are given in $\mathrm{kD}$. 


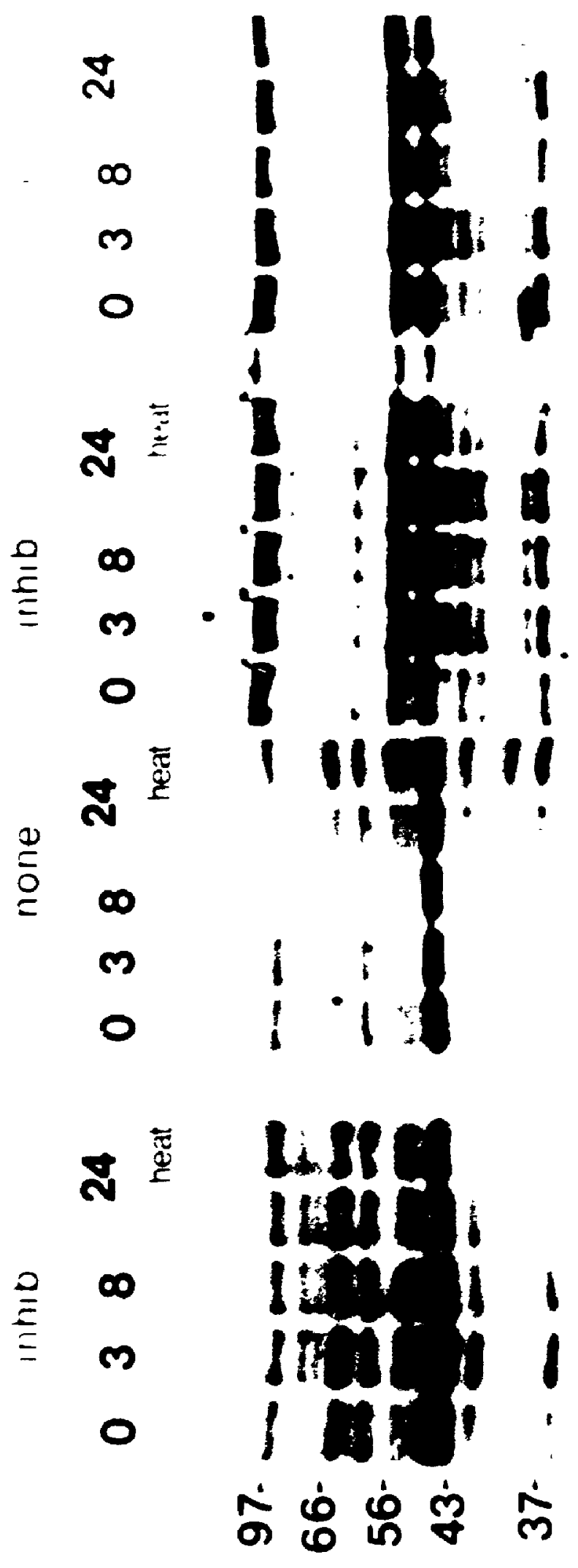


d) SDS PAGE and nestern analysis of fractionated proteins from the wild-type and ro-4 mutant strains:

A comparison of PAGE-separated, silver-stained proteins from the cytosolic (100K supernatant) fraction of wild-type and the ro-4 mutant strains very clearly indicates the absence of a protein or proteins roughly the molecular weight of actin in the lanes of 2980 and the RIP strains R2 and R4, which is present in the wild-type and the other ro-4 mutant strains (Figure 13).

When four fractions were probed with the anti-RO4 antibody in a Western analysis a faint band unique to the immune serun was visible in both the nuclear and cytosolic fractions (Figure 14), of all strains tested, but not in the 1.0K nor $100 \mathrm{~K}$ pellet fractions.. The molecular weight of this band was estimated at 40.75 to $42.2 \mathrm{kD}$ by the BANDSIZE program.

Two-dimensional blots were loaded with $25 \mu \mathrm{g}$ of cytosolic fraction proteins and probed with pre-immune and immune sera, however the results were too faint to be interpreted.

Phenotypic characteristics of the wild-type and ropy strains

The strain 1529, classified as a ro-4 mutant (Perkins, 1969) in contravention of mapping data (Appendix I) was shown by Western analysis to have a mutation in the major actin gene. Furthermore, its colony morphology appeared typically 
Figure 13. Comparison of silver-stained proteins of cytosols. The silver-stained SDS PAGE gel was loaded with $15 \mu \mathrm{g}$ of cytosolic protejns. The sizes of marke: bands in lane a are given in kD. Lane $b$ is WT, $c$ is 1511, $d$ is 1529, e is 2980, $f$ and $g$ are the RIP strains R2 and R4. 


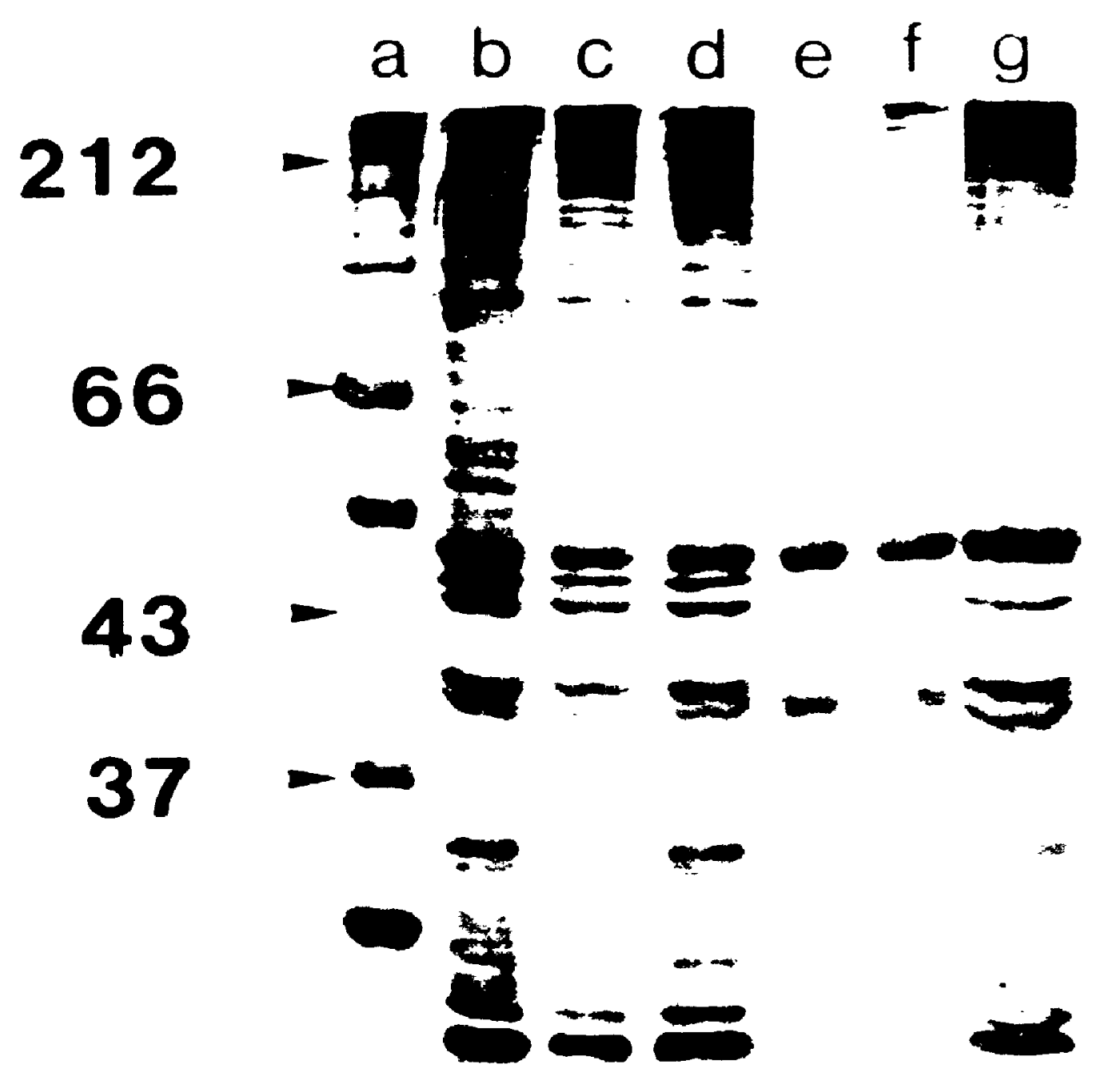


Figure 14. Western analysis of fractionated proteins: Panel A portrays pre-immune (left side) and immune-probed (right side) lanes of cytosolic proteins from 1511 (a) and 1529 (b). Panel $B$ shows pre-immune (left side) and immune-probed (right side) nuclear fraction proteins from the same two strains. Panels $C$ and D are analagous results in which WT (c) and 2980 (d) proteins are probed. The arrow heads mark the position of the $43 \mathrm{kD}$ marker. 


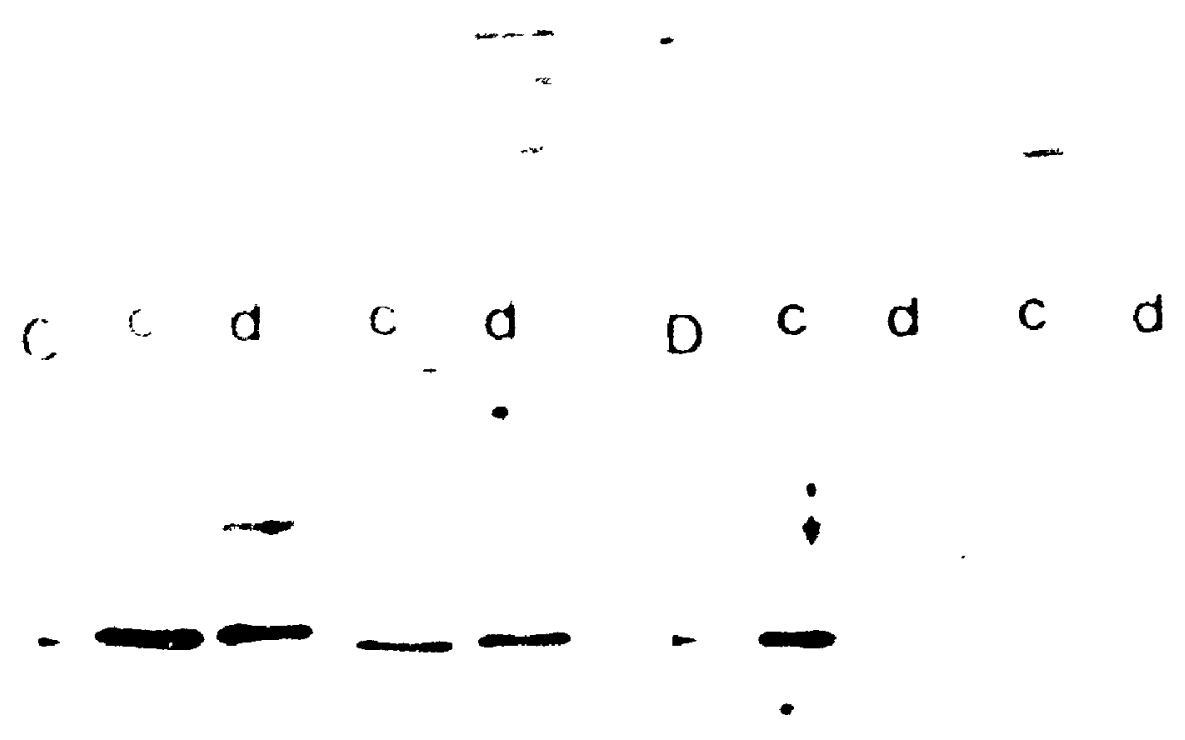


ropy only briefly, as it soon colonized the entire petri dish and became indistinguishable from wild-type. It occurred to us that its mutation might actually be in the major actin gene which must therefore be very close to the ro-4 lccus.

Four phenotypic characteristics were examined in order to more accurately describe the strain 1529 and either support or oppose its present classification.

\section{a) Nuclear staining of wild-type and ropy germlings:}

Four to five-hour germlings of ropy mutants were stained with DAPI or DAPI and calcofluor in order to assess the: capacity for proper nuclear distribution, in comparison wi : wild-type germlings grown for 3 hours. All exhibited poor distribution with the exception of the strain 1529, which appeared wild-type (Figure 15).

The position of the nuclei in mutant germlings was almost exclusively along the perimeter of the wall furthest from the point of emergence of the germ tube.

\section{b) Distribution of nuclear number in conidia:}

For each ropy mutant strain, including 3 ro-4 mutants and one RIP strain, the number of nuclei were counted in 200 conidia where any could be seen (proving that they were stained successfully), and means and standard deviations calculated (Appendix IV). The wild-type was distinguished by few nuclei per conidium and very low deviation from the mean $(1.87 \pm 0.67)$. In comparison, all the ropy mutants including strain 1529 showed large standard deviations from the mean, 
Figure 15. Nuclear distribution in N.crassa germlings: Germlings of wild-type, 2980 and 1511 were stained with DAPI and calcofluor; all others were stained with DAPI only. The small dash in the ro-7 panel indicates the tip of the germ tube. The scale bar given in the third panel represents $10 \mu \mathrm{m}$ and applies to all.
Wild-type
wild-type
ro-4 (1529)
ro-4 (2980)
ro-4 (2980)
ro-4 (1511)
ro-1 (146)
ro-2 (52)
ro-3 (43)
ro-6 (3627)
ro-7 (4025)
ro-10 (3618) 


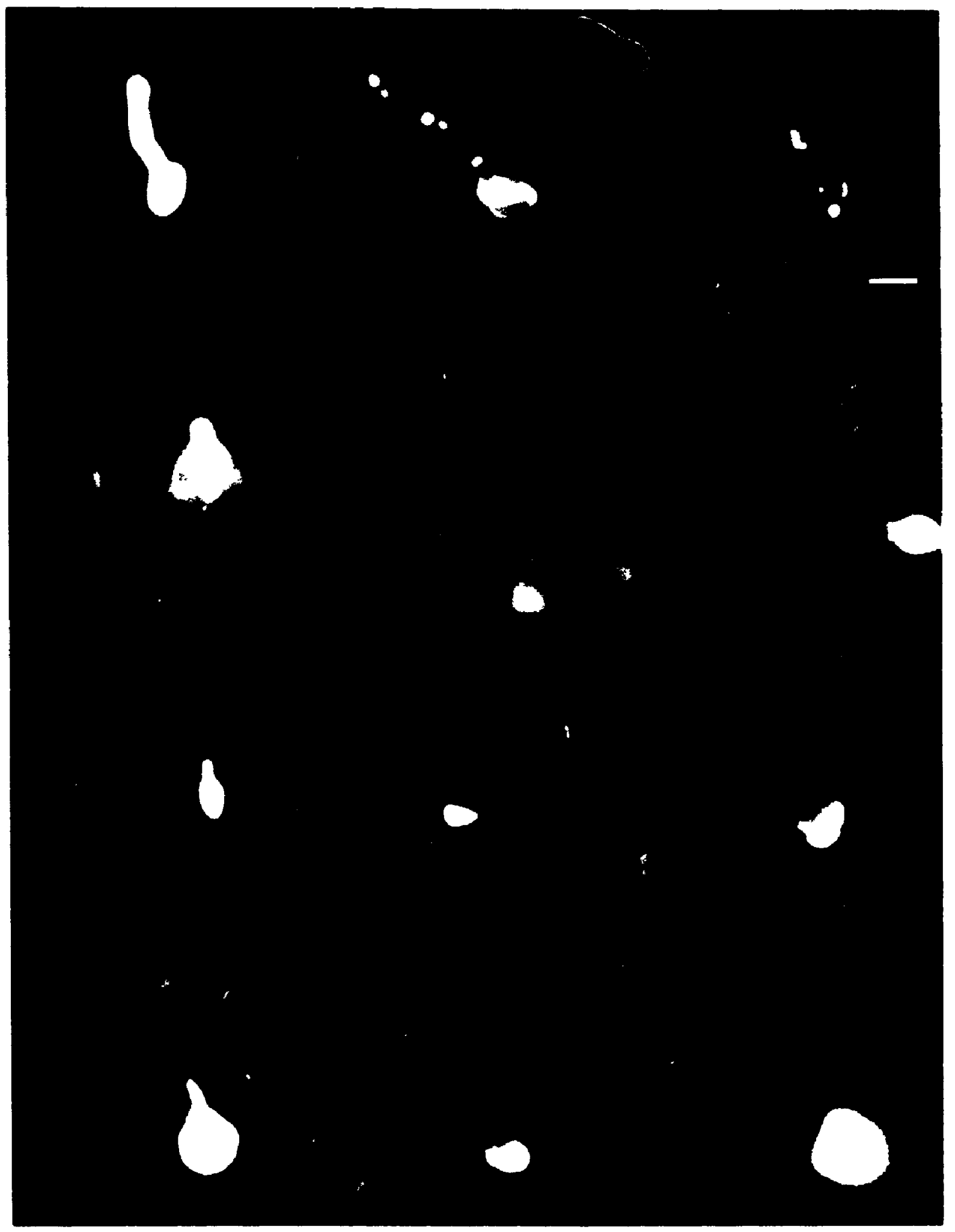


which were however not statistically significant except in the case of strain $52(r o-2)(F=35.29, p<0.05)$. This result implies that the mechanism for moving discrete numbers of nuclei into the immature conidia is deficient in the strain 52 compared to wild-type.

c) Growth of the wild-type and the ropy mutants at normal and high temperatures:

As seen in Figure 16a, the wild-tyF= strain grew very quickly, around $0.17 \mathrm{~cm} / \mathrm{hr}$. For the most part, the ropy mutants exhibited a considerably slower rate of growth, with the exception of the ro-4 mutant strain 1529 (Figure 16b), which grew as quickly as the wild-type. Interestingly, the ro-4 RIP strains were intermediate in their rate of growth between the wild-type and the two ro-4 mutant strains 1511 and 2980 (Figure 16b).

At high temperatures $\left(40^{\circ} \mathrm{C}\right)$ the RIP strains showed distinct responses (Figure 17b). R4 was affected severely and did not exhibit appreciable growth until about three days had passed, at which point it was distinguished by an unusual degree of mycelium within the agar. Conversely, R2 and R5 showed no inhibition of growth and the effect on RI was intermediate.

Among the ropy mutants the difference in growth rate at the two temperatures was less pronounced (Figure 17a), although 3627 nearly approached the wild-type growth rate at higher temperatures. 
Figure 16a: Growth of wild-type and ropy mutant strains at room temperature. Cultures were grown on Vogel's Minimal medium at between $23^{\circ}$ and $25^{\circ} \mathrm{C}$. Each point is a mean of 5 replicates, with no standard deviation greater than $0.3 \mathrm{~cm}$. 
colony diameter (cm)

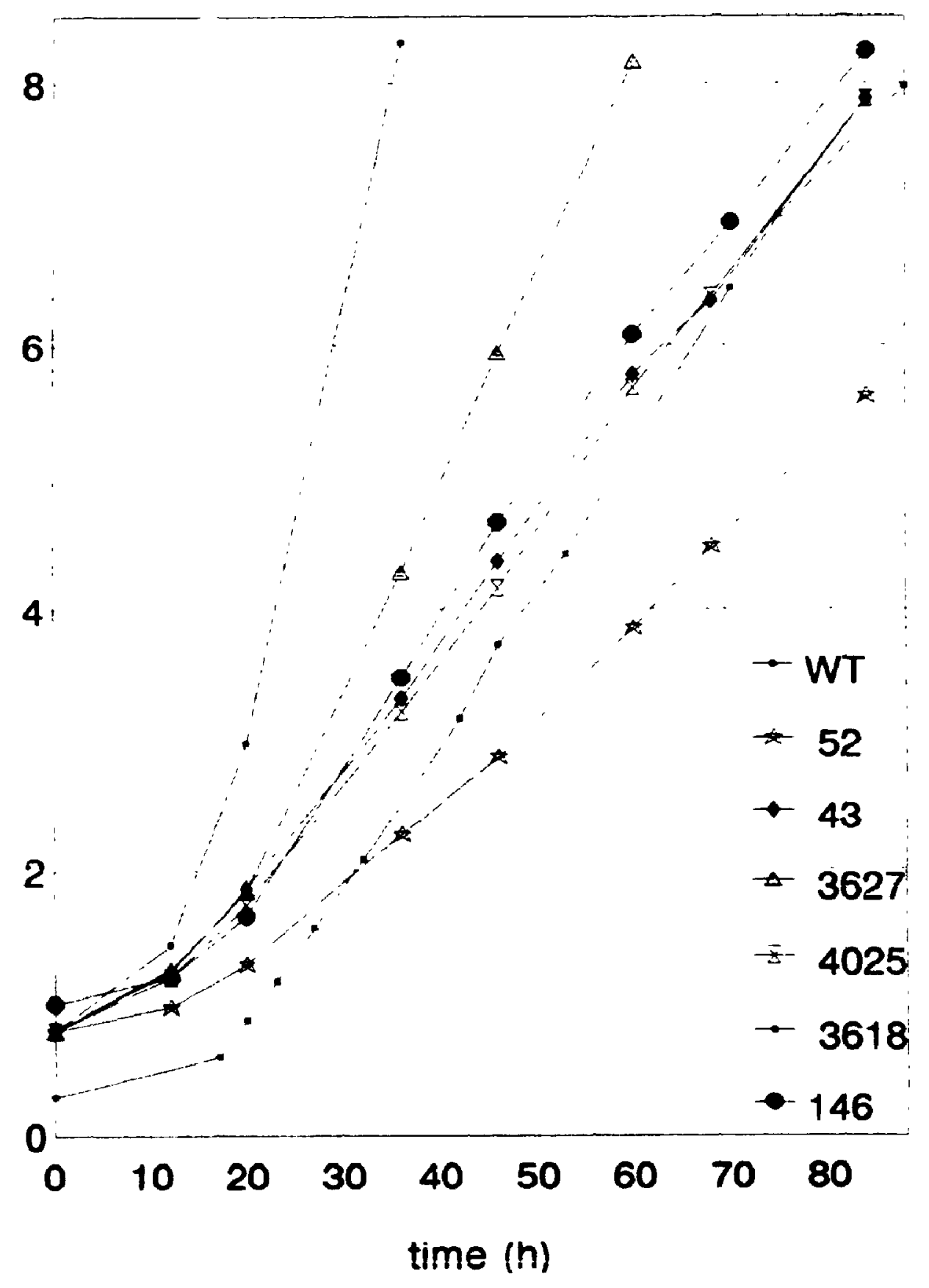


81

Figure 16b: Growth of wild-type and ro-4 mutant strains, including the ripped strains at room temperature. Cultures were grown on Vogel's Minimal Medium at between $23^{\circ}$ and $25^{\circ} \mathrm{C}$. Each point is a mean of 5 replicates, with no standard deviation greater than $0.3 \mathrm{~cm}$. 


\section{colony diameter $(\mathrm{cm})$}

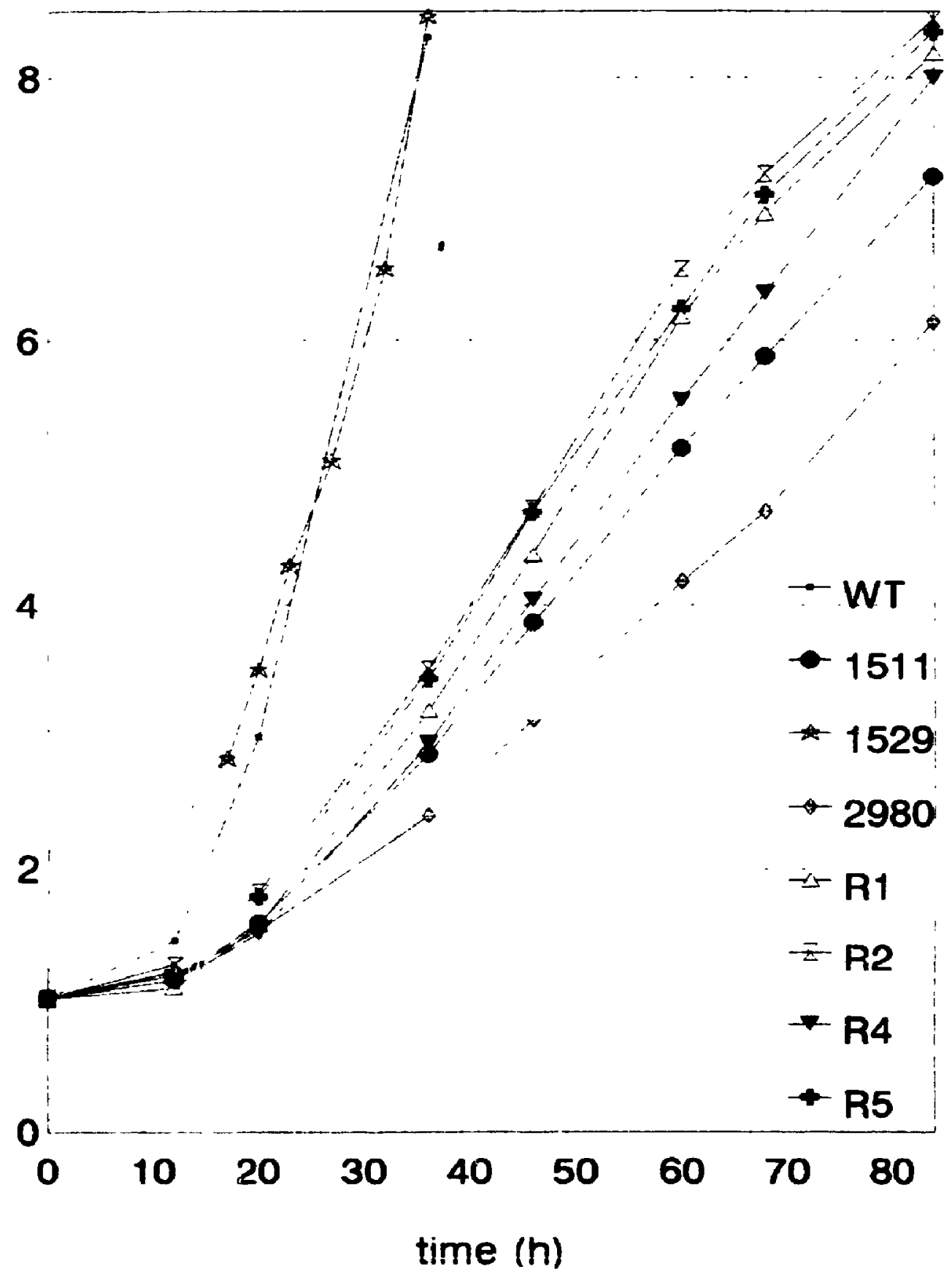


Figure 17a: Growth of wild-type and ropy mutant strains at high temperature. Cultures were grown on Vogel's Minimal medium at between $40^{\circ}$ and $43^{\circ} \mathrm{C}$. Each point is a mean of 3 replicates with standard deviations no greater than $0.6 \mathrm{~cm}$ except where indicated. 
colony diameter $(\mathrm{cm})$

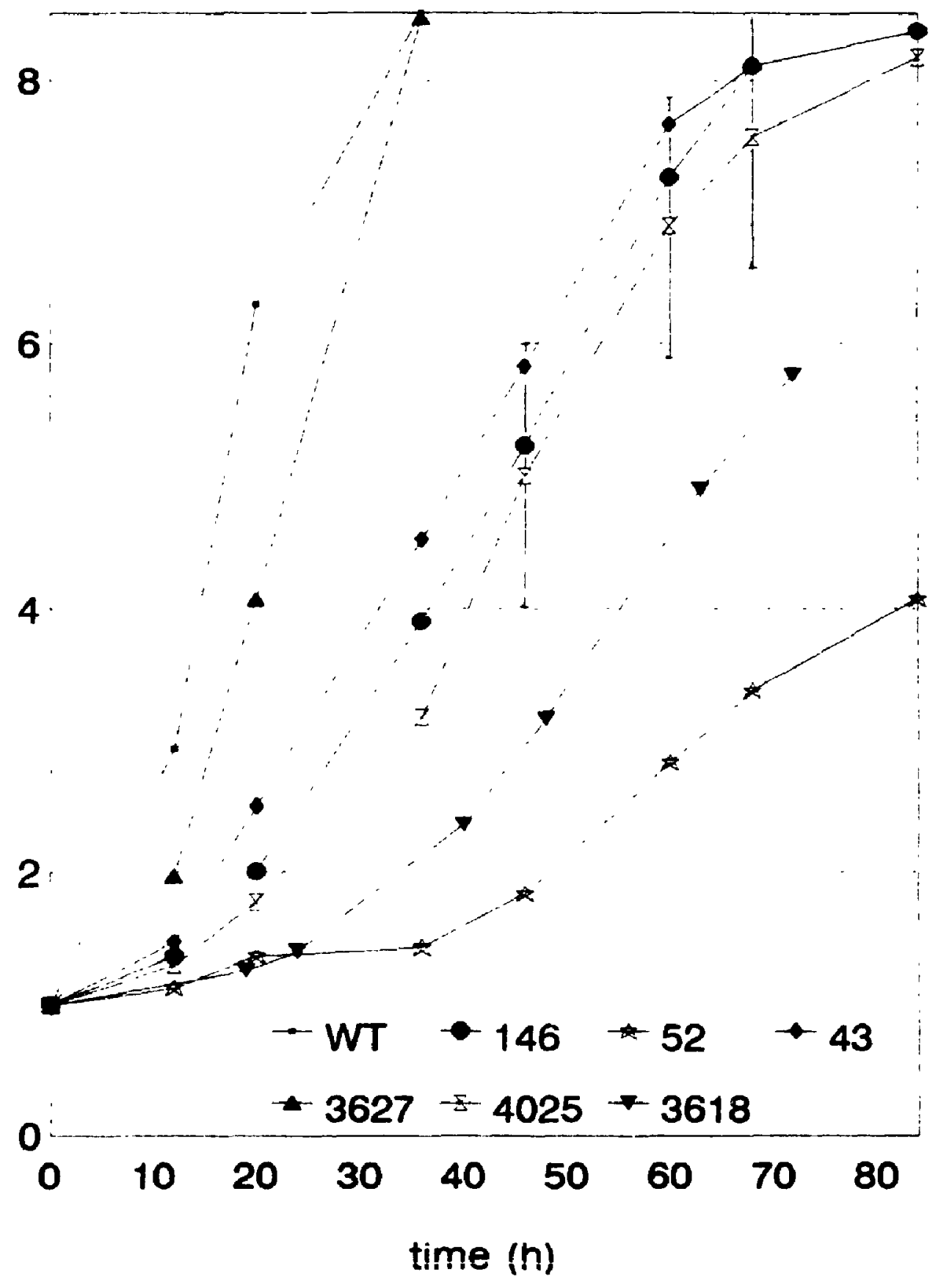


Figure 17b: Growth of wild-type and ro-4 mutant strains, including the RIP strains at high temperature. Cultures were grown on Vogel's Minimal medium at between $40^{\circ}$ and $43^{\circ} \mathrm{C}$. Each point is a mean of 3 replicates with standard deviations no greater than $0.6 \mathrm{~cm}$ except where indicated. 
colony diameter $(\mathrm{cm})$

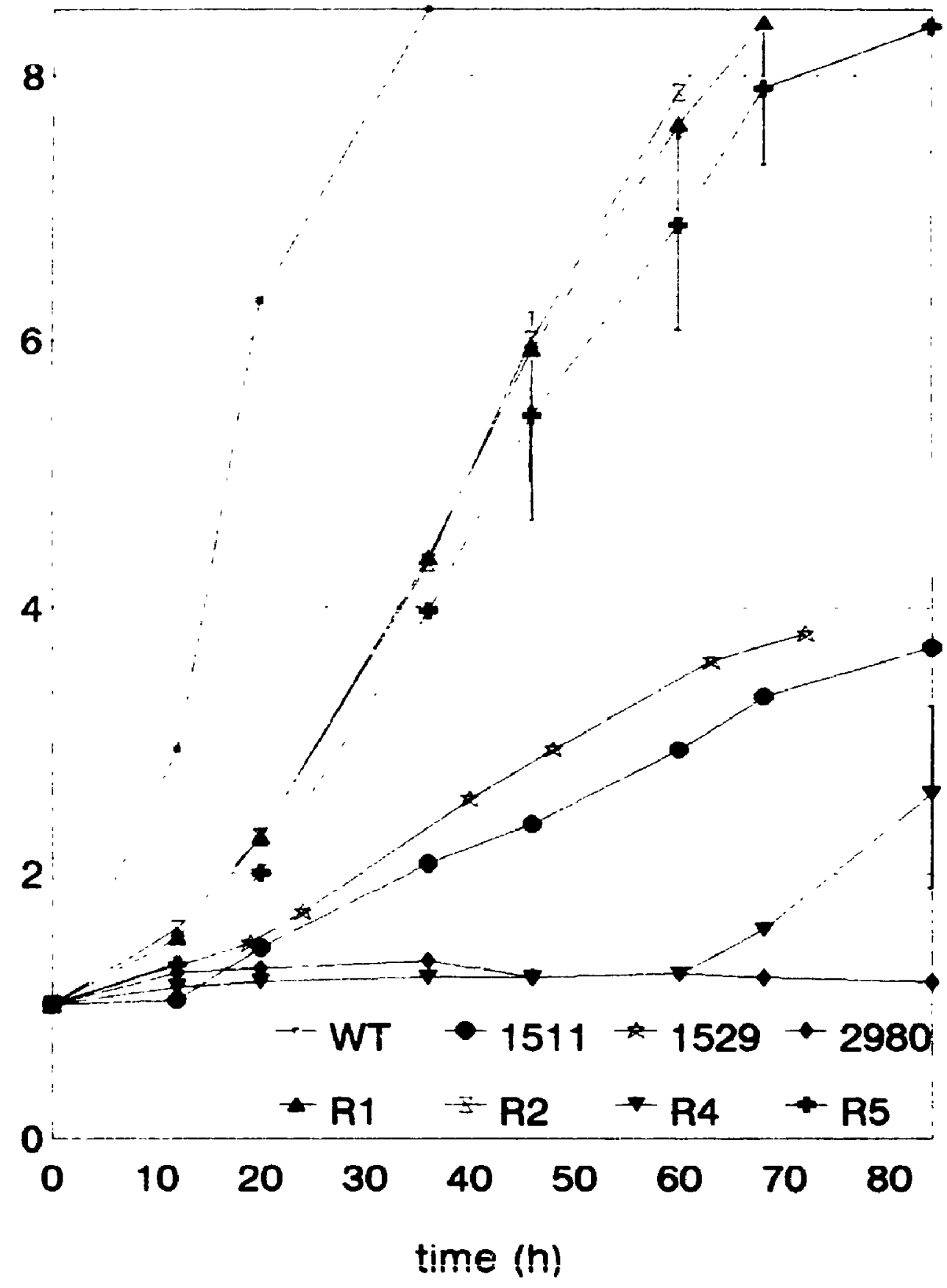




\section{d) Colony morphology of wild-type and ropy mutant strains:}

Figure 1 clearly emphasizes the advantage of the wildtype strain over the ropy mutants in terms of growth rate, since it completely covers the petri dish within 4 days. The wild-type was also photographed at ar earlier stage so a more useful comparison can be drawn between the growth habits of it and of the ropy strains. At 2 days old the wild-type has grown across most of the plate, displaying fine, sparselybranched hyphae and little if any conidiation. In contrast mutant strains of the same size have formed relatively compact colonies with profuse aerial hyphae and some conidiation. The ro-4 mutant strain 1529 has been photographed at 4 days, by which time it also has filled the plate, and $2 \frac{3}{4}$ days at which point it appears ropy. 


\section{Discussion}

\section{sequence features of the wild-type ro-4 gene in Neurospora crassa:}

The positions of the three introns in the ro-4 gene had tentatively been identified (Robb, 1993) based on sequence similarity with the mammalian actin-related procein and conser ed exon/intron junction sequences. These were confirmed by sequencing wild-type ro-4 cDNA from the strain $74 \mathrm{~A}$, and comparing this sequence to the genomic sequence. All begin after the third position of the preceding codon (phase 0). With lengths of 84,94 and 100 nucleotides, they are longer than is typical for $N$. crassa (60) and are less G/C rich; $38 \%, 42 \%$ and $45 \%$, rather than $49 \%$ (Edelmann and staben, 1994). The first two introns (positions 100 and 248) align with introns in the actin gene of Volvox, but not found in any other major actin genes known as of March, 1993 (Neber and Kabsch, 1994). Among the other members of the Arpl family, Drosophila Actr87c has five introns none of which correspond to thuse in ro-4. The introns of ro-4 do not interrupt any major structural domains (Figure 2).

All three introns contain $5^{\prime}$ and $3^{\prime}$ splice sites and internal branch points as delineated by Edelmann and staben, (1994), with some differences from the consensus sequence as shown in Figure 4. The $5^{\prime}$ end of the translation initiation site, the $5^{\prime}$ intron donor site and the internal branchpoint 
adhere more closely to the consensus sequences for the species than the $3^{\prime}$ acceptor sites.

sequence of the ro-4 mutant allele in strain 2980 :

The sequence of the strain 2980 was obtained by sequencing clones containing the $3^{\prime}$ or $5^{\prime}$ restriction fragments of the ro-4 gene ligated into the Bluescript ${ }^{\mathrm{TM}}$ plasmid. A single bp deletion was found at position +165 (relative to the translation start site). The resulting frame-shift mutation results in an altered sequence of amino acids from number 56 to number 79 at which point there is a premature stop signal (Figure 6). The resulting peptide has a putative MW of only $8.2 \mathrm{kD}$ compared to $42.8 \mathrm{kD}$ (Plamann et a1.,1994) for the wild-type protein.

A mutant protein of this nature would be missing most of the interactive sites of the functional protein. The wildtype ro-4 sequence is conserved at most of the sites responsible for nucleotide and calcium binding (Robb, 1993). In addition the wild-type ro-4 may be capable of forming heterofilaments with conventional actin, based on its similarity to centractin which has these capabilities (Melki et $a 1, \ldots 393)$.

A foreshortened coding sequence may result in a shortened lifespan for the transcribed mRNA. Muhlrad and Parker (1994) showed that in yeast, premature translational termination led to decapping of the $5^{\prime}$ end of the transcript, after which 
the transcript was degraded both in the $5^{\prime} \rightarrow 3^{\prime}$ and $3^{\prime} \rightarrow 5^{\prime}$ directions. This may mean that the putative $8.2 \mathrm{kD}$ product of the mutant allele is not translated.

Expression of ro-4 in the wild-type and ro-4 mutant strains:

Robb et al, (1995) reported that the ro-4 gene hybridizes to two bands of 1.7 and $2.1 \mathrm{~kb}$. The two lower bands labelled in the wild-type lane (Figure 8) of estimated sizes 1.65 and $2 \mathrm{~kb}$ probably correspond to the 1.7 and $2.1 \mathrm{~kb}$ species reported above. It is the $1.7 \mathrm{~kb}$ band which is affected in the mutants 2980, R5 and R2. Plamann et al. (1994) found that the cDNA for ro-4 began roughly 370 bases upstreara of the initiation codon. This would yield an mRNA molecule of roughly $1.5 \mathrm{~kb}$, not including any $3^{\prime}$ untranslated region. Harata et al. describe mRNA for act 3 in yeast as $1.7-1.8 \mathrm{~kb}$ (1994), with the encoded essential protein being in excess of $54 \mathrm{kD}$. From these results it is most plausible therefore that the $1.7 \mathrm{~kb}$ species represents the ro-4 transcript. The weak labelling of this species in 2980 is consistent with the possibility that its mRNA is quickly degraded, as proposed above.

clark and Meyer (1992) used a centractin CDNA (later identified as $\alpha$-centractin) to probe poly (A) ${ }^{+}$mRNA of human tissues and detected a single species of mRNA of about $3.1 \mathrm{~kb}$ (due to a large $3^{\prime}$ untranslated region). In 1994 clark et al. 
found that the mRNA recognized by a B-centractin probe was about $2.4 \mathrm{~kb}$ in multiple human tissues, and that the $\alpha-$ centractin probe also detected a gamma-centractin with an mRNA of about $1.4 \mathrm{~kb}$ (Clark et al., 1994). Possibly the $2.9 \mathrm{~kb}$ uppermost band in the wild-type lane represents an analogous species of IRNA to that reported by clark and Meyer (1992), and is indicative of multiple isoforms of RO4 encoded in the N.crassa genome. This theory has in its favour the western blot results in which the anti-RO4 serum recognizes a protein in the 2980 mutant strain whose sequence terminates upstream of the epitope site. However if multiple isoforms existed they could be expected to interfere with southern analyses, for example restriction fragment length analyses. The Southern analyses presented above are quite clear, even though the stringency conditions (hybridization carried out at $68^{\circ} \mathrm{C}$ ) were comparable to those used in the Northern protocol. The most likely explanation is that the stringency used in the Northern analysis was inadequate for RNA-RNA hybrids and that the $2.9 \mathrm{~kb}$ band does not represent a species of ro-4 mRNA.

clark and Meyer (1992) estimated that centractin mRNA levels must be far less abundant than those of the major actin, based on the length of exposure time required in a Northern (10x longer for centractin). Fyrberg et al.(1994) also report that mRNAs for actin-related proteins comprise far less of the mRNA pool than do mRNAs for the major actins. The calculated value for Codon Adaptation Index for ro-4 (0.489) 
is indicative of a moderately-expressed protein however. There is a possibility that the reference set did not contain enough highly-expressed genes to be a reliable standard.

\section{Protein analysis of the wild-type and ro-4 mutant strains:}

\section{a) Western analyses using a major actin antibody:}

A monoclonal anti-actin obtained from Boehringer Mannheim labelled a protein of roughly the same molecular weight as actin in the wild-type and two of the ro-4 mutant strains. However it failed to recognize any protein excracted from the strain 1529. The $r_{4} 4$ mutant strain 1529 must have a mutation in its major actin gene which disrupts the mAb epitope. It is conceivable, given its dissimilarities to the other ro-4 mutant strains in terms of growth rate and nuclear distribution that the mutation in 1529 is actually in the major actin, and not in ro-4, in other words the major actin may be located close to ro-4 in $N$.crassa.

Barja et al.(1991) reported that the major actin in $N$.crassa has a molecular weight of $43 \mathrm{kD}$ and $\mathrm{pI}$ of 6.4 . It consisted of $\alpha-, \beta-$ and gamma-isoforms with a preponderance of B-actin. only two isoforms were distinctly visible in the anti-actin Western analysis (Figure 9) which are tentatively identified as $B$-and gamma-actin, based on relative size and $\mathrm{pI}$ compared with Barja's results. Neither of these appeared in strain 1529, implying that they are both encoded by the same gene, and therefore that differences in pI are due to post- 
translational modification.

The epitope of this Boehringer Maniheim anti-actin antibody is presumably well-conserved among actins, since the antibody reacted with all six known vertebrate isoactins as well as Dictyostelium discoideum and Physarum polycephalum actins (Lessard, 1988). It was developed using chicken gizzard (rich in gamma actin) as the immunogen. The binding site on skeletal actin overlaps that of DNase I. In addition, the antibody binds an SV8 (V8 protease) proteolytic subunit comprising the amino-terminal $2 / 3$ of the molecule and overlaps the epitope of the skeletal actin antibody, but does not interfere with actin polymerization.

A polyclonal antibody against actin exists which labels all three isoforms of actin on Western blots, yet in situ recognises only specific manifestations of actin; namely myofibrils, microvilli of brush border epithelium, and "comet tails" of Listeria monocytogenes (Schrader et al.,1994). The authors hypothesize that the epitope may only be accessible in certain structures, or certain conformations. This could only explain the absence of binding in 1529 if the proteins were not already denatured as they are in SDS PAGE.

The mutations ro-4 (2980), ro-8 (1511) and ro-5 (1529) were originally mapped to separate loci at 16 (ro-4), 46 (ro5) and 70 (ro-8) mu from the centromere (Appendix I), even though tests for heterokaryon complementation were regative (Morgan et al.,1967). They were since assigned to the same 
locus (Perkins et al. 1969) on the basis of non-recombination with the paba2 locus, and inability to produce complementation in heterokaryons, a result that may indicate a dominant mutation in one of the strains. The possibility exists that the loci for the ro-4 and 1529 mutations are on opposite sides of the pabaz gene at different loci.

\section{b) nestern analyses using a RO4 antibody:}

The epitope against which the RO4-specific antibody was raised was chosen prior to the discovery of the mutation in strain 2980 . The result of this is that the purified anti-RO4 serum cannot recognize any truncated polypeptide in that ro-4 strain, since the epitope is after the point of premature termination. In one-dimensional western analyses probed with purified anti-RO4 serum two bands with roughly the same electrophoretic mobility as actin were recognizea by the antiRO4 antibody (Figure $10 \mathrm{a}$ and $\mathrm{b}$ ) migrating at between 40.3 and 43.3 kD. The lower of these two bands is the better candidate for the RO4 protein as it was absent in strain 2980 and the RIP strains in one trial, and faint in these lanes in the second. Although the predicted size of RO4 is $43.38 \mathrm{kD}$, the discrepancy is not unprecedented. Lees-Miller et al.(1992b) found that actin-rpv migrated faster than conventional actin and faster than predicted by its sequence 'whereas centractin migrated more slowly than regular actin (clark and Meyer, 1992)). The upper band may then be either another actinrelated protein, or an erroneous result. The yeast 
Saccharomyces cerevisiae has at least three Arps (Schroer et al.,1994), the slime mold Acanthamoeba castellani has 2 (Kelleher et al.,1995) and Drosophila has four (Fyrberg et al.,1994). At least two isoforms of centractin are known to exist in humans; $\alpha$ - and $\beta$-centractin are $91 \%$ identical (96\% similar) in their amino acid sequences, whereas a third isoform referred to as gamma-centractin was identified as a small mRNA species that was labelled with cDNA of $\alpha$-centractin (Clark et al.,1994).

since actin is a common allergen it would be understandable if actin-related proteins which are 35-55\% identical to it (Schroer et al.,1994) might also be recognized by pre-immune sera.

Three other protein bands, of estimated sizes 95, 50 and $37 \mathrm{kD}$ were labelled more strongly by immune than by pre-immune sera. Muhua et al.(1994) detected a $50 \mathrm{kD}$ protein in western blots probed with anti-Act5p which was due to non-specific binding and not eliminated by pre-absorption against a null strain. None of the three could be identified, however it is presumed that each contains an epitope similar to that against which the antibody was raised.

Although Kelleher et al.(1995) reported that Arp2 of Acanthamoeba castellani is degraded by repeated boiling or over time, yielding lower MW breakdown products, this was probably not a factor in the present study, as there was no obvious difference in the lanes representing separated protein 
extracts which had been allowed to degrade for various spans of time. The bands which were unique to the immune anti-serum were labelled equally across lanes (Figure 11).

In other studies of actin-related proteins the problem of scarcity interfered with recognition. Muhua et al.,(1994) estimated that the Arpl Act5p in Saccharomyces cerevisiae was present at less than $0.00022 \%$, based on their inability to detect it in a Western blot. The antibody used in the present study was applied to Western analyses of total and fractionated proteins when it was able to detect between 20 and $200 \mathrm{ng}$ of pure antigen applied in a dot blot. This represents $0.2 \%$ of a $10 \mu \mathrm{g}$ protein sample. Clark et al. (1994) estimated the abundance of $\alpha$-centractin in HeLa cells at $0.006 \%$ of total cell protein, and B-centractin was estimated to be 10 - to 20-fold less abundant. These amounts were obtained from protein immunoprecipitated with an antibody to p50. This was justified due to sucrose gradient fractionation studies that indicated that centractin cosedimented with $150^{\text {Glued }}$ and 150 but was not present in a free cytosolic pool.

Kelleher et al. (1995) report a cellular concentration in Acanthamoeba of $1.9 \mu \mathrm{M}$ for Arp2 and $5.1 \mu \mathrm{M}$ for Arp3, compared to the major actin which is present at $200 \mu \mathrm{M}$. These small concentrations are in the range of several actin-binding proteins such as $\alpha$-actinin at $4 \mu \mathrm{M}$ and capping protein at 1.3 $\mu \mathrm{M}$. The results of the Northern blotting to survey expression 
levels as well as the calculated C.A.I. to predict expression although not definitive, hint at a detectable level of RO4. c) Analyses of fractionated proteins:

The one-dimensional gels of fractionated proteins indicate that a protein exists in the wild-type and strains 1511 and 1529 which does not exist (or does not silver-stain) in 2980. This could represent the RO4 protein. The similarity between cy+osolic fraction proteins of 2980 and $R 2$ is striking, and suggests that the result of the ripping in the strain R2 may have been a premature termination such as that present in 2980. However in growth studies there is no similarity between the two strains, especially at high temperature (Figure 16b). The generally unique profile of silver-stained proteins in 2980 relative to that of wild-type belies the fact that only one locus is mutated in the strain. It is possible that the ro-4 product is designed to have a regula ury role as well. Lloyd et al.,(1993) report that expression of non-muscle actin genes can affect the expression of both other actins and tropomyosin.

The faintriess of the band bound by the anti-RO4 antibody in fractionated proteins casts doubt on either the continued activity of the antibody preparation or the efficiency of the fractionation procedure. Although between $2 \frac{3}{2}$ and 5 times as much protein was loaded per two-dimensional gel as per lane of a one-dimensional gel, the band is not as strong in the former as in the latter. A protein recognized by the RO4 antibody 
was enriched in both the cytosolic fraction and the nuclear fraction compared to the $10 \mathrm{~K}$ and $100 \mathrm{~K}$ fractions. That this protein also appeared in strain 2980 implies that it is not the putative RO4 protein identified on the basis of Western analyses of total proteins. Kelleher et al.(1995) found that anti-Arp2 from Acanthamoeba remained diffuse in the cytoplasm and failed to label any organelle including the nucleus, whereas Arp3 was localized to discrete spots within unidentified cytoplasmic lamellae. Both Arps remained in the cytoplasmic fraction even after centrifugation at 100,000 $\mathrm{g}$ for 90 minutes.

Clark and Meyer (1992) found that fluorescently-labelled anti-centractin lowalised predominantly to the microtubule organizing centre with faint cytoplasmic staining. When colcemid was used to depolymerize the bulk of the cytoplasmic microtubules the cytoplasmic staining was reduced. Later, clark et al. (1994), determined the sub-cellular localization of both $\alpha$ - and $B$-centractin to be the cytosol, as part of the 20 dynactin complex.

Phenotypic analysis of wild-type and ropy strains:

One striking conclusion arising from the fact that the strain 1529 does not have faulty nuclear distribution is that the ropy phenotype at the level of colony morphology is not obligately associated with poor nuclear distribution. The strain 1529 grows nearly as quickly as wT but exhibits a far 
greater degree of branching (which can be seen with the naked eye). This means that it actually has a greater rate of hyphal extension than WT.

In contrast the other ro-4 strains 1511 and 2980 have a much slower growth rate, distinguishing them from strain 1529 , although they too show extensive branching. This hints that the mutation in 1529 is not at the same locus as the mutations in 1511 or in 2980, and may in fact be in a closely linked major actin gene. The ro-4 RIP strains all grow more quickly than 1511 and 2980 , but not as quickly as either the wild-type or 1529, although their colony morphology is distinctly 'ropy'.

Huebschman (1952) reported that the number of nuclei in conidia of N.crassa was never zero, though it could be increased from 2.64 to 6.15 by growing the colonies on complete as opposed to minimal medium. In addition, he found that the number was inciependent of the age of the culture, suggesting that post-absission mitosis was not an important factor in determining the number.

The strain 52 which is least able to distribute nuclei among its conidia is also the slowest grower of all the ropy strains, a deficiency which is exacerbated at high temperatures. The strains 146,43 and 4025 representing the loci ro-1, ro-3 and ro-7 show similar traits in terms of growth at normal and high temperatures, and so these may all (like ro-1) be involved in the dynein heavy chain aspect of 
nuclear movement.

The high temperature effect shown by 52 and 2980 may be a result of the tendency of microtubules to polymerize at $37^{\circ} \mathrm{C}$ (in Preston et al.,1990). If nuclear movement is driven by microtubule depolymerization as suggested by Desai and Mitchison (1995), then conditions which promote this polymerization will put mutant strains at even more of a disadvantage. A $\mathrm{Ca}^{2+}$ deficiency such as that seen in frost and spray mutants would have the same effect, as $\mathrm{Ca}^{2+}$ can cause depolymerization of microtubules (in Preston et al.. 1990).

From what is known of analagous genes in Aspergillus (in particular NudF, Xiang et al., 1995) the process of nuclear migration may involve a signalling pathway incorporating G proteins. In N.crassa, the interaction of $G_{i}$ and $G_{0}$ proteins with $\mathrm{Ca}^{2+}$ channels has been implicated in the branching morphology of frost and spray mutants (Turner and Borkovitch, 1993). Thus receptor proteins, other G protein subunits, and protein kinases are all candidates for elements of the pathway which results in nuclear distribution. In addition, the other proteins involved in microtubule-based movement (for example the numerous proteins of the dynactin complex, in addition to ro-4) may eventually be identified as the faulty link in the other ropy strains. 


\section{Conclusions}

1. The introns in the wild-type ro-4 gene of Neurospora crassa were confirmed to be at the positions proposed by Robb (19.93) .

2. The mutant ro-4 allele in strain 2980 contains a premature termination signal and encodes a putative product of only $8.2 \mathrm{kD}$ which may not be translated.

3. There are three species of mRNA which hybridize to a ro-4 antisense RNA in Northern analysis. Two of these may correspond to the previously reported 1.7 and $2.1 \mathrm{~kb}$ (Robb et al.,1995) mRNAs while the third is $2.9 \mathrm{~kb}$. The $1.7 \mathrm{~kb}$ species is close to the predivted size.

4. The ro-4 mutant strain 1529 was shown by western analysis to lack the epitope recognized by a monoclonal antibody to the major actin, though polyclonal antibodies to both the major actin and to tubulin recognized protein of this strain.

5. Anti-serum raised against a synthetic peptide of RO4 recognized two bands in the range of the $43 \mathrm{kD}$ marker which were not labelled by pre-immune serum. The lower of the two was faint or absent in strain 2980 as 
predicted by the sequence of the mutant allele.

6. A single protein was recognized by the anti-RO4 antibody in cytosolic and nuclear fractions of the wild-type and of the mutant strains 1511, 1529 and 2980. This protein was enriched in the nuclear and cytosolic fractions compared to the $10 \mathrm{~K}$ and $100 \mathrm{~K}$ fractions, and migrates below the major actin.

7. The growth rate and nuclear distribution of the strain 1529 is similar to that of wild-type, although its colony morphology is ropy. In contrast, the strains 1511 and 2980 show the ropy characteristics in their colony morphology, slow growth rate, and aberrant nuclear distribution. 
Appendix I: Partial kap of Linkage Group $V$ in $N$. crassa

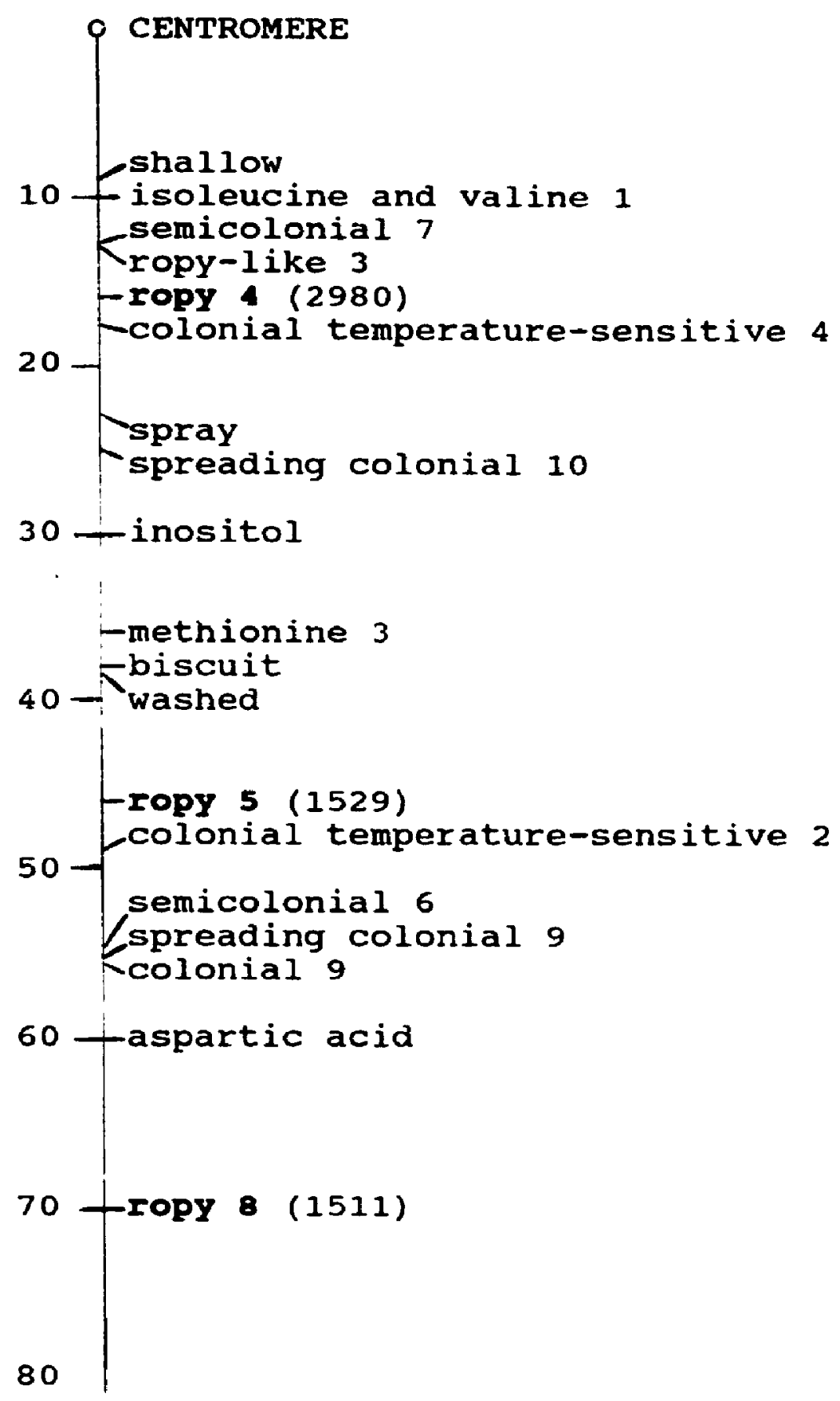

from Morgan $\in t$ al.,(1967).

Distances are in map units. 
Appendix II: Calculation of C.A.I. (Codon Adaptation Index) for ro-4:

The Codon Adaptation Index was developed by Sharp and $\mathrm{Li}$ (1987) to predict the level of expression of a gene based on the similarity of its codon usage with that of a reference set of highly-expressed genes in the same species.

The formula for the C.A.I. is

$$
\text { C.A.I. } \left.=\underset{k=1}{L} \mathbf{w}_{k}\right)^{1 / L}
$$

where $L$ is the number of amino acids in the protein which can be coded for by more than one codon, and $w$ is measure of bias for each codon.

The value for $w$ is obtained by first assigning weights to each codon in the reference set, such that each weight represents the proportion of times that codon is used in the genes of the set, and such that the sum of the weights of the codons for each amino acid is equal to the number of codons which code for that amino acid. For each codon in the protein then $w$ is the fraction of the weight for the codon divided by the maximum possible weight for any codon coding for the same amino acid.

For example, the genes used to compile the reference set in this thesis were Neucrp3, NeuTyrA and His-3 (see Appendix II). In the case of aspartic acid, on average these genes used the codon

GAU $30 \%$ of the time, for a weight of 0.6

GAC $70 \%$ of the time, for a weight of 1.4

Thus the value of $w$ for each occurence of the codon GAU in the gene ro-4, is $(0.6 / 1.4)$, whereas if the preferred codon GAC is used the value becomes 1 (that is, 1.4/1.4). The C.A.I is the product of all the $w$ values for the amino acids in the coding region (with the exception of methionine and tryptophane), raised to the reciprocal of the number of amino acids used.

In the case of ro-4, which begins

$$
\begin{aligned}
& \text { 5' ATG ACA GAC TCT TTG CAC } \\
& \text { (i.e. AUG ACA GAC UCU UUG CAC) } \\
& \text { the C.A.I calculation begins } \\
& ((0.4 / 2.3) \times(1.4 / 1.4) \times(0.8 / 2.3) \times(1 / 2.8) \times(1.5 / 1.5) \ldots]^{\prime / 368} \\
& \text { and yields the value } 0.489 \text {. }
\end{aligned}
$$


Appendix III: Average weights of Alternate codons compiled from Three Highly-expressed Genes of Neurospora crassa

\begin{tabular}{|c|c|c|c|c|c|}
\hline $\begin{array}{l}\text { Amino } \\
\text { Acid }\end{array}$ & Codon & $\begin{array}{l}\text { Average } \\
\text { Weight }\end{array}$ & $\begin{array}{l}\text { Amino } \\
\text { Acid }\end{array}$ & Codon & $\begin{array}{l}\text { Average } \\
\text { Weight }\end{array}$ \\
\hline $\begin{array}{l}\text { PHE } \\
\text { LEU }\end{array}$ & $\begin{array}{l}\text { UUU } \\
\text { UUC } \\
\text { UUA } \\
\text { UUG } \\
\text { CUU } \\
\text { CUC } \\
\text { CUA } \\
\text { CUG }\end{array}$ & $\begin{array}{l}0.4 \\
1.6 \\
0 \\
1 \\
0.8 \\
2.8 \\
0.1 \\
1.3\end{array}$ & PRO & $\begin{array}{l}\text { UCU } \\
\text { UCC } \\
\text { UCA } \\
\text { UCG } \\
\text { CCU } \\
\text { CCC } \\
\text { CCA } \\
\text { CCG }\end{array}$ & $\begin{array}{l}0.8 \\
2.3 \\
0.3 \\
0.7 \\
0.8 \\
2.3 \\
0.3 \\
0.6\end{array}$ \\
\hline $\begin{array}{l}\text { ILE } \\
\text { MET } \\
\text { VAL }\end{array}$ & $\begin{array}{l}\text { AUU } \\
\text { AUC } \\
\text { AUA } \\
\text { AUG } \\
\text { GUU } \\
\text { GUC } \\
\text { GUA } \\
\text { GUG }\end{array}$ & $\begin{array}{l}0.8 \\
2 \\
0.1 \\
1 \\
0.7 \\
2.6 \\
0.2 \\
0.5\end{array}$ & THR & $\begin{array}{l}A C U \\
A C C \\
A C A \\
A C G \\
G C U \\
G C C \\
G C A \\
G C G\end{array}$ & $\begin{array}{l}0.9 \\
2.3 \\
0.4 \\
0.5 \\
1 \\
2.4 \\
0.2 \\
0.5\end{array}$ \\
\hline TYR & $\begin{array}{l}\text { UAU } \\
\text { UAC }\end{array}$ & $\begin{array}{l}0.3 \\
1.7\end{array}$ & Cys & $\begin{array}{l}\text { UGU } \\
\text { UGC }\end{array}$ & $\begin{array}{l}0.2 \\
1.8\end{array}$ \\
\hline ter & $\begin{array}{l}\text { UAA } \\
\text { UAG }\end{array}$ & $\begin{array}{l}0.7 \\
0\end{array}$ & $\begin{array}{l}\text { ter } \\
\text { TRP }\end{array}$ & $\begin{array}{l}\text { UGA } \\
\text { UGG }\end{array}$ & $\begin{array}{l}0 \\
1\end{array}$ \\
\hline $\begin{array}{l}\text { HIS } \\
\text { GLN }\end{array}$ & $\begin{array}{l}\text { CAU } \\
\text { CAC } \\
\text { CAA } \\
\text { CAG }\end{array}$ & $\begin{array}{l}0.4 \\
1.5 \\
0.4 \\
1.6\end{array}$ & ARG & $\begin{array}{l}\text { CGU } \\
\text { CGC } \\
\text { CGA } \\
\text { CGG }\end{array}$ & $\begin{array}{l}1.5 \\
2.1 \\
0.5 \\
0.8\end{array}$ \\
\hline $\begin{array}{l}\text { ASN } \\
\text { LYS }\end{array}$ & $\begin{array}{l}\text { AAU } \\
\text { AAC } \\
\text { AAA } \\
\text { AAG }\end{array}$ & $\begin{array}{l}0.4 \\
1.6 \\
0.2 \\
1.8\end{array}$ & $\begin{array}{l}\text { SER } \\
\text { ARG }\end{array}$ & $\begin{array}{l}\text { AGU } \\
\text { AGC } \\
\text { AGA } \\
\text { AGG }\end{array}$ & $\begin{array}{l}0.3 \\
1.6 \\
0.3 \\
0.8\end{array}$ \\
\hline $\begin{array}{l}\text { ASP } \\
\text { GLU }\end{array}$ & $\begin{array}{l}\text { GAU } \\
\text { GAC } \\
\text { GAA } \\
\text { GAG }\end{array}$ & $\begin{array}{l}1.0 \\
0.6 \\
1.4 \\
0.2 \\
1.8\end{array}$ & GLY & $\begin{array}{l}\text { AGG } \\
\text { GGU } \\
\text { GGC } \\
\text { GGA } \\
\text { GGG }\end{array}$ & $\begin{array}{l}0.8 \\
1.2 \\
2 \\
0.4 \\
0.2\end{array}$ \\
\hline
\end{tabular}


Appendix IV: Distribution of nuclear number in nucleated conidia of wild-type and ropy mutant atrains.

Two hundred nucleated conidia were counted from each of the strains. The means and stzilard deviations follow:

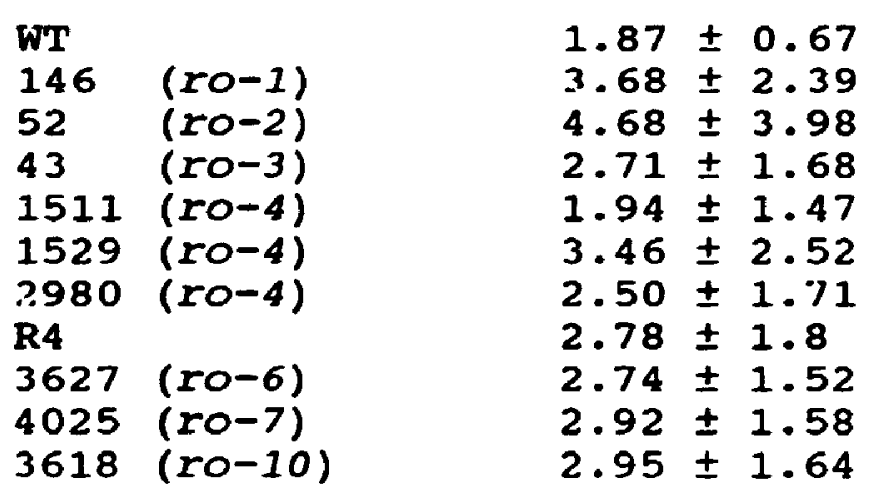




\section{Reference 3}

Amatruda,J.F. and Cooper,J.A. (1992) Purification, characterization and localization of saccharomyces cerevisiae capping protein. J Cell Biol 117 1067-1076.

Amatruda,J.F.; Gattermeir,D.J.; Karpova,T. and Cooper,J.A. (1992) Effects of null mutations and overexpression of capping proteins on morphogenesis, artin distribution and polarized secretion in yeast. J Cell Biol 119 1151-1162.

Barja,F.; Thi,B-N,N. and Turian,G. (1991) Localization of actin and characterization of its isoforms in the hyphae of Neurospora crassa. FEMS Microbiology Letters 77 19-24.

Barnes,G.; Drubin,D.G. and Stearns,T. (1990) The cytoskeleton of Saccharomyces cerevisiae. Current opinion in cell Biology 2 109-115.

Bruchez,J.J.P.; Eberle,J. and Russo,V.E.F. (1993) Reculatory sequences involved in the translation of Neurospora crassa mRNA: Kozak sequences and stop codons. Fungal Genetics Newsletter 40 85-88.

Bruchez,J.J.P.; Eberle,J. and Russo,V.E.A. (1993) Regulatory sequences in the transcription of Neurospora crassa genes: CAAT box, TATA box, introns, poly(A) tail formation sequences. Fungal Genetics Newsletter 10 89-96.

Caesar,C.T.; Rossier,C.; Barja,F.; Turian,G. and Roos, U-P. (1988) Induction of multiple germ tubes in Neurospora crassa by antitubulin agents. European Journal of Cell Biology 46 68-79.

Clark,S.W. and Meyer,D.I. (1992) centractin is an actin homologue associated with the centrosome. Nature 359 246-250.

Clark,S.W. and Meyer,D.I. (1994) ACT3: a putative centractin homologue in $s$. cerevisiae is required for proper orientation of the mitotic spindle. J cell Biol 127 129-138.

Clark,S.W.; Staub,O.; Clark,I.B.; Holzbaur,E.L.F.; Paschal,B.M.; Vallee,R.B. and Meyer,D.I. (1901) B-Centractin: characterization and distribution of a new member of the centractin family of actin-related proteins. Molecular Biology of the cell 5 1301-131.

Collin=...A. (1994). Dynein-based organelle Movement in "Microtubules", Hyams,J.S. and Lloyd,C.W. (eds.), Wiley-Liss, Inc. PP 367-380. 
Desai,A. and Mitchison, T. (1995) A new role for motor proteins as couplers to depolymerizing microtubules. Journal of Cell Biology $128 \quad 1-4$.

Dicker,J.W. and Turian,G. (1990) Calsium deficiencies and apical hyperbranching in wild-type and the "frost" and "spray" morphological mutants of Neurospora crassa. J Gen Microbiol $1361413-1420$.

Drubin,D.G. (1991) Development of polarity in budding yeast. Cel1 65 1093-1096.

Edelmann,S.E. and Staben,C. (1994) A statistical analysis of sequence features within genes from Neurospora crassa. Experimental Mycology 18 70-81.

Echevirri,C.J.; Paschal,B.M; Vaughn,K.T. and Vallee,R.B. (1996) Molecular characterization of the 50-kD subunit of dynactin reveals function for the complex in chromosome alignment and spindle organization during mitosis. $J$ Cell Biol 132 617-633.

Eshel,D.; Urrestarazu,A.; Vissers,S.; Jauniaux,J-C.; van Vliet-Reedijk,J.C.; Planta,R.J. and Gibbons,I.R. (1993) Cytoplasmic dynein is required for normal nuclear segregation in yeast. Proc Natl Acad Sci USA 90 11172-11176.

Fidel,S.; Doonan,J.H. and Morris,N.R. (1988) Aspergillus nidulans contains a single gene which has unique intron locations and encorss a gamma-actin. Gene 70 283-293.

Fischer,R. and Timberlake,W.E. (1995) Aspergillus nidulans aspil (anucleate primary sterigmata) encodes a coiled-coil protein required for nuclear positioning and completion of asexual development. J Cell Biol 128 485-498.

Frohman,M.A. (1990) RACE: Rapid Amplification of CDNA Ends in "PCR Protocols A Guide to Methods and Applications", Innis,M.A.: Gelfand,D.H. and Sninsky,J.J. (eds.) Academic Press, pp 28-38.

Fyrberg,C.; Ryan, L.; Kenton,M. and Fyrberg, E. (1994) Genes encoding actin-related oroteins of Drosophila melanogaster. J Mol Biol 241 498-50:.

Garnjobst,L. and Tatum,E.L. (1967) A survey of new morphological mutants in Neurospora crassa. Genetics 57 579604 .

Gill,S.R.; Shroer,T.; Szllak,I; Sceuer,E.R.; Sheetz,M.P. and Cleveland,D.W. (:991) Dynactin, a conserved, ubiquitously expressed component of an activator of vesicle motility 
mediated by cytoplasmic dynein. J Cell Biol 115 1639-1650.

Goldman,G.H and Morris,N.R. (1995) Extragenic suppressors of a dynein mutation that blocks nuclear migration in Aspergillus nidulans. Genetics 139 1233-1232.

Harata,M.; Karwan, A. and Wintersberger,U. (1994) An essential gene of Saccharomyces cerevisiae coding for an actin-related protein. Proc Natl Acad Sci USA 91 8258-8262.

Hennessey,E.S.; Drummond,D.R. and Sparrow,J.C. (1993) Molecular genetics of actin function. Biochem J. 282 657-671.

Hoch,H.C. and Staples,R.C. (1985) The microtubule cytoskeleton in hyphae of Uromyces phaseoli ge $\mathrm{mlings:}$ its relationship to the region of nucleation and to the F-actin cytoskeleton. Protoplasma 124 112-122.

Huebschman, C. (1952) A method for varying the average number of conidia of Neurospora crassa. Mycologia 44 599-604.

Inoué, S. and Salmon,E.D. (1995) Force generation by microtubule assembly/disassembly in mitosis and related movements. Molecular Biology of the Cell 6 1619-1640.

Kelleher,J.F.; Atkinson,S.J. and Pollard,T.D. (1995) Sequences, structural models, and cellular location of the actin-related proteins Arp2 and Arp3 form Acanthamoeba. J Cell Biol 131 385-397.

Kormanec,J.; Schaaff-Gerstenschäger,I.; Zimmermann,F.K. ; Perecko,D. and Küntzel,H. (1991) Nuclear migration in saccharomyces cerevisiae is controlled by the highly repetitive $313 \mathrm{kDa}$ NUM1 protein. Mol Gen Genet 230 277-287.

Lees-Miller,J.P.: Henry,G. and Helfman,D.M. (1992a) Identification of act2, an essential gene in the fission yeast schizosaccharomyces pombe that encodes a protein related to actin. Proc. NatL. Acad. Sci. USA. 89 80-83.

Lees-Miller,J.P.; Helfman,D.M. and Schroer,T.A. (1992b) A vertebrate actin-related protein is a component of a multisubunit complex invovled in microtubule-based motility. Nature 359 244-246.

Lessard,J.L. (1988) Two monoclonal antibodies to actin: one muscle selective and one generally reactive. Cell motility and the cytoskeleton $10 \quad 349-362$

Li,Y.Y.: Yeh,E.; Hays,T. and Bloom,K. (1993) Disruption of mitotic spindle orientation in a yeast dynein mutant. Proc Natl Acad Sci USA 90 10096-10100. 
Lloyd,C.; Schevsov,G. and Gunning,P. (1992) Transfection of nonmuscle $\beta-$ and $\alpha$-actin genes into myoblasts elicits different feedback regulatory resonses from endogenous actin genes. The Journal of Cell Biology 117 787-797.

McGrail,M.; Gepner,J.; Silvanovich,A.; Ludman,S.; Serr,M. and Hays, T.S. (1995) Regulation of cytoplasmic dynein function in vivo by the Drosophila Glued complex. J Cell Bio 131 411-425.

Melki,R.; Vainberg,I.E.; Chow,R.L. and Cowan,N.J. (1993) Chaperonin-mediated folding of vertebrate actin-related protein and gamma-tubulin. J Cell Biol 122 1301-1310.

Morgan,M.P.; Garnjobst,L. and Tatum,E.L. (1967) Linkage relations of new morphological mutants in linkage group $V$ of Neurospora crassa. Genetics 57 605-612.

Morris,N.R. and Enos,A.P. (1992) Mitotic gold in a mold: Aspergillus genetics and the biology of mitosis. TIG 8 32-37.

Morris,N.R.; Xiang,X. and Beckwith,S.M. (1995) Nuclear migration advances in fungi. Trends in Cell Biology 5 278282 .

Muhlrad,D. and Parker,R. (1994) Pr :mature translational. termination triggers mRNA decapping. Nature 370 578-581.

Muhua,L.; Karpova,T. and Cooper,J.A. (1994) A yeast actinrelated protein homologous to that in vertebrate dynactin complex is important for spindle orientation and nuclear migration. Cell 78 669-679.

Oakley, B.R.; Oakley,C.E.; Yoon, Y. and Jung,M.K. (1990) gammaTubulin is a component of the spindle pole body that is essential for microtubule function in Aspergillus nidulans. Cell 61 1289-1301.

Osmani,A.H.; Osmani,S.A. and Morris,N.R. (1990) The molecular cloning and identification of a gene product specifically required for nuclear movement in Aspergilius nidulans. J cell Biol $111543-551$.

Palmer,R.E.; Sullivan,D.S.; Huffaker. 1' and Koshland,D. (1992) Role of astral microtubules and actin in spindle orientation and migration in the budding yeast, saccharomyces cerevisiae. $\mathrm{J}$ Cell Biol 119 583-593.

Paschal,B.M.; Shpetner,H.S. and Villee,R.B. (1987) MAP1C is a microtubule-activated ATPase which trans. ,cates mictrotubules in vitro and has dynein-like properties. J Cell Biol 105 1273-1282. 
Paschal,B.M.; Shpetner,H.S. and Vallee,R.B. (1991) Purification of brain cytoplasmic dynein and characterization of its in vitro properties. Methods in Enzymology 196 181191.

Paschal,B.M.; Holzbaur,E.L.F.; Pfister,K.K.; Clark, .; Meyer,D.I. and vallee,R.B. (1993) Characterization of a 50-kDa polypeptide in cytoplasmic dynein preparations reveals a complex with p150GLED and a novel actin. J Biol chem 268 15318-15323.

Plamann,M.; Minke,P.F.; Tinsley,J.H. and Bruno,K.S. (1994) Cytoplasmic dynein and actin-related protein Arpl are required for normal nuclear distribution in filamentous fungi. $J$ Cell Biol 127 139-149.

Preston, T.M.: King,C.A. and Hyams,J.S. (1990) The cytoskeleton and cell motility Blackie, London.

Read,E.B.; Okamura,H.H. and Drubin,D.G. (1992) Actin- and tubulin-dependent functions during Saccharomyces cerevisiae mating projection formation. Molecular Biology of the Cell 3 429-444.

Reissig,J.L. and Kinney,S,G. (1983) Calcium as a branching signal in Neurospora crassa. J Bacteriol 154 1397-1402.

Roberson, R.W. and Vargas,M.M. (1994) The tubulin cytoskeleton and its sites of nucleation in hyphal tips of Allomyces macrogynus. Protoplasma 182 19-31.

Robb,M.J. (1993) Isolation adn characterization of the ro-4 gene responsible for a morphological mutation in Neurospora crassa. Master's Thesis, Carleton University Press.

Robb,M.J.; Wilson,M.A. and Vierula,P.J. (1995) A fungal actirirelated protein involved in nuclear migration. Mol Gen Genet $247583-590$.

Sailbrook,J.; Fritsch,E.F. and Maniatis,T. (1989) Molecular Cloning: A Laboratory Manual, Second Edition. Cold Springs Harbour Laboratory Press, U.S.A.

Schafer,D.A.; Gill,S.R.; Cooper,J.A.; Heuser,J.E. and Schroer,T.A. (1994) Ultrastructural analysis of the dynactin complex: an actin-related protein is a component of a filament that resembles F-actin. J Cell Biol 126 403-412.

Schmid,J. and Harold,F.M (1988) Dual roles for calcium ions in apical growth of Neurospora crassa. J Gen Microbiol $1342633-$ 2631.

Schrader,M.; Temm-Grove,C.J.; Lessard,J.L. and Jocł.usch, B.M. 
(1994) Chicken antibodies to rabbit muscle actin with a restricted repertoire of $F$-actin recognition. European Journal of cell Biology 63 326-335.

Schroer,T.A. and sheetz,M.P. (1991) Two activators of microtubule-based vesicle transport. J Cell Biol 115 13091318 .

Schroer,T.A. (1994) New insights into the interaction of cytoplasmic dynein with the actin-related protein, Arpl. J cell Biol 127 1-4.

Schroer,T.A.; Fyrberg, E.; Cooper,J.A.; Waterston,R.H.; Helfman,D.; Pollard,T.D. and Meyer,D.I. (1994) Actin-related protein nomenclature and classification. $J$ Cell Biol 127 $1777-1778$.

Schwob,E. and Martin,R.P. (1992) New Yeast actin-like gene required late in the cell cycle. Nature 355 179-182.

Selker,E.; Cambareri,P.; Garrett,P.; Jensen,B.; Haack,K.; Foss, E.; Turpen, C.; Singer,M, and Kinsey,J. (1989) Use of RIP to inactivate genes in Neurospora crassa. Fungal Genetics Newsletter 36 76-77.

Selker,E.U.: Fritz,D.Y. and Singer,M.J. (1993) Dense nonsymmetrical DNA methylation resulting from repeat-induced point mutation in Neurospora. Science 262 1724-1728.

Sharp,P.M. and Li,W-H. (1987) The codon adaptation index - a measure of directional synonomus cruon usage bias, and its potential applications. Nucleic Acids Research 15 1281-1295.

Springer,M.L. (1993) Genetic Control of Fungal Differentiation: The Three Sporulation Pathways of Neurospora crassa. BioEssays $15 \quad 365-374$

Springer,M.L. and Yanofsky,C. (1989) A morphological and genetic analysis of conidiophore development in Neurospora crassa. Genes and Development 3 559-571.

Steinberg,G. and Schliwa,M. (1993) organelle movements in the wild type and wall-less fz;sg;os-1 mutants of Neurospora crassa are mediated by cytoplasmic microtubules. J Cell sci 106 555-564.

Thompson-Coffe,C. and Zickler,D. (1993) Cytoskeletal interactions in the ascus development and sporulation of sordaria macrospora. J Cell Sci 104 883-898.

Turner,G.E. and Borkovich,K.A. (1993) Identification of a G protein $\alpha$ subunit from Neurospora crassa that is a member of 
the $G_{i}$ family. Journal of Biological Chemistry 268 1480514811 .

Vaughn,K.T. and Vi;lee,R.B. (1995) Cytoplasmic dynein binds dynactin through a direct interaction between the intermediate chains and pa50 $0_{\text {Glued. }} \mathrm{J}$ Cell Bio 131 1507-1516.

Weber,K. and Kabsch,W. (1994) Intron positions in actin genes seem unrelated to the secondary structure of the protein. The EMBO Journal 13 1280-1286.

Webster,J. (1986) Introduction to Fungi Cambridge University Press, Cambridge.

Willins, D.A.; Xiang, X. and Morris, N.R. (1995) An alpha tubul in mutation supresses nuclear migration mutations in Aspergillus nidulans. Genetics 141 1287-1298.

Xiang,X.; Beckwith,S.M. and Morris,N.R. (1994) Cytoplasmic dynein is involved in nuclear migration in Aspergillus nidulans. Proc Natl Acad Sci USA $912100-2104$.

Xiang,X.; Osmani,A.H.; Osmani,S.A.; Xin,M and Morris,N.R. (1995) NudF, a nuclear migration gene in Aspergillus nidulans, is similar to the human LIS-1 gene required for neuronal migration. Molecular Biology of the cell 6 297-310. 

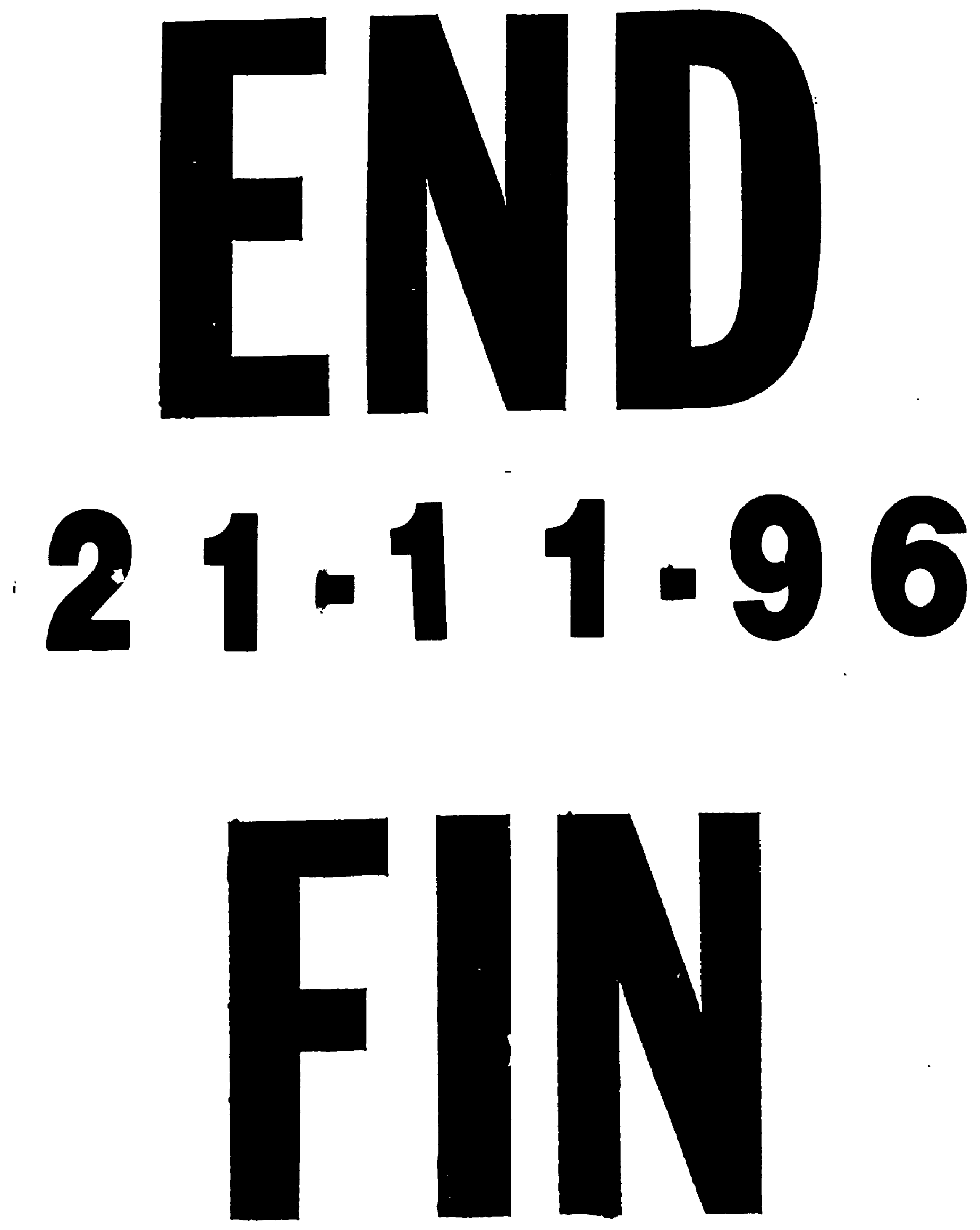